\title{
XXI.
}

\section{Ueber Venentuberkel und ihre Beziehungen zur tuberculösen Blutinfection.}

\author{
Von Prof. Carl Weigert in Leipzig.
}

Vorbemerkungen.

Der folgende Aufsatz soll eine Reibe anderer einleiten, die sich ebenfalls auf die Lehre von der Tuberculose beziehen und gewissermaassen die Fortsetzung meiner Mittheilung im 77. Bande dieses Archivs darstellen. Was man in diesen Veröffentlichungen zu suchen hat und was nicht, mögen die folgenden Vorbemerkungen erläutern.

Wenn man für die Tuberculose die Infectionstheorie als erwiesen annimmt, so kann man bei Betrachtung der Producte dieser Krankheit, selbst vom rein anatomischen Standpunkte aus sebr verschiedene Gesichtspunkte haben. Man kann

1) das Gift selbst in den durch die Wirkung desselben entstandenen Affectionen nach zuweisen suchen, also wohl organisirte Wesen, welche dasselbe repräsentiren. In dieser Beziehung bin ich durchaus unglücklich gewesen. Ich habe niemals mit irgend welcher Sicherheit Mikrokokken etc. bei Tuberculose gefunden, sofern es sich nicht um Complicationen mit fauligen oder andern Prozessen handelte. Dass man aus solchem negativen Befunde absolut picht den Schluss ziehen darf, dass das Gift nicht organisirt wäre, habe ich anderweitig entwickelt ${ }^{1}$ ).

1) Nach Absendung dieses Aufsatzes ist die wichtige Eutdeckung Koch's über die Natur des Tuberkelgiftes gemacht worden. Derselbe hat auf das Ueberzeugendste den Nachweis geliefert, dass dieses Gift von einer specifiscben Bacillenform repräsentirt wird, deren Nachweis mit den von mir benutzten Färbemitteln nicht möglich war. Für die Mittheilungen in diesem Aufsatze ist diese Entdeckung sehr erwünscht gekommen, zu ändern ist in denselben nichts, höchstens kann man statt der uobestimmten Worte „Gift" oder „Se- 
2) Man kann dasjenige zu erforschen suchen, was jeh an einem anderen . Orte ${ }^{1}$ ) als Primärwirkung eines Giftes bezeichnet habe, d. h. (wo es sich nicht, wie bei bösartigen Geschwülsten etc., um Depositionen vermehrungsfahhiger Zellen an einen andern Ort handelt) um die primäre Schädigung der Gewebe, durch welche meiner Ansicht nach erst locale Zellvermehrungen angeregt werden können. Das Suchen nach solchen primären Gewebsschädigungen wird ja denjenigen Forschern durchaus unnülz erscheinen, welche es einfach als selbstverständlich ansehen, dass durch ein schädliches Agens die Zellen wie das Ovulum durch das Sperma ganz direct zur Wucherung angeregt werden können. Gehen doch Viele namentlich aus der französischen und aus der Stricker'schen Schule so weit, zu meinen, dass durch ein Gift oder gar durch einen mechanischen "Reiz" direct die Zellen in den "état embryonnaire" übergeführt und so zur Vermehrung veranlasst würden! Diese Anschauung über Verjüngung lebender Wesen (und solche sind ja die Zellen) durch chemische Stoffe etc. ist nicht neu. Uralt ist vielmehr der Glaube, dass ein lebendes Wesen verjüngt werden könne durch die „bekannten Säfte" von Hexen

per quos renovata senectus

In florem redeat primosque recolligat annos.

Freilich gingen die Hexengläubigen insofern weiter, wie jene Forscher, als sie den ganzen Zellencomplex des Menschen sich verjüngen liessen, während diese sich mit einem mehr oder weniger kleinem Theile desselben begnügen. Andererseits wird dies dadnrch wett gemacht, dass die modernen Anhänger jener Verjüngungstheorie die Verjüngung bis zum embryonalen Zustande gehen lassen, während jene sich mit dem Jünglingsalter als Grenze begnügten und dass sie diese Verjüngungskraft nicht specifischen Zaubermitteln, sondern allen möglichen Agentien zuschreiben, die aber sonderbarer Weise sämmtlich "schädliche" sirıd und nichts mit jenen "natürlichen" Mitteln zu thun haben, die Mephisto dem Faust empfieblt. Ich hoffe

minium “ pun den Ausdruck „Tuberkelbacillen“ setzen. Ich hoffe aber auch, dass diese Mittheilungen nicht für äberflïssig gehalten werden - für die Theorie der verschiedenen Tuberkelformen beim Menschen sind derartige Arbeiten entschieden immer noch nöthig.

1) Artikel „Entzündung “ der Realencyclopädie der mediciniscben Wissenschaften, redigirt von Eulenburg. Wien, Urban und Schwarzenberg. 
die moderne Verjüngungstheorie wird ebenso in das Bereich der Fabel verwiesen werden, wie die alte.

Wegen der Gründe für meine Auffassung, dass Zellen überhaupt nicht durch einen „Reiz“, wie durch ein Lycopodiumkörnchen oder ein Cantharidenstückchen direct zur Wucherung gebracht werden können, verweise ich auf meine oben citirte Arbeit über „Entzündung“. Hier kann ich auf diese Dinge um so weniger eingehen, als ich für das Tuberkelgift keine dahingehenden factischen Angaben machen kann. Um dieselben zu eruiren, muss eine eingehende Untersuchung angestellt werden, deren Beendigung noch weit im Felde steht.

3) Man kann ferner den Versuch machen mit Hülfe feinster histologischer Forschung die Entstehung der ja zweifellos vorhandenen neugebildeten Zellelemente zu erforschen, also den activen Vorgängen auf den Grund zu gehen. Auch darüber wird man im Folgenden nichts Besonderes finden und zwar schon deshalb, weil mir zum Verständniss derselben die noch nicht festgestellten, sub 2 erwähnten Veränderungen nöthig erscheinen, dann aber weil unsere heutigen Methoden für die Entscheidung solcher histogenetjscher Fragen noch gar zu viel zu wünschen übrig lassen.

4) Endlich kann man die gröberen Unterschiede der tuberculösen Prozesse, soweit dieselben die Form und Grösse, die Localisation und Verbreitung derselben betreffen, vom Standpunkte der Infectionslebre einer erneuten Untersuchung für werth halten und solche Fragen sollen dann im Folgenden erörtert und durch Casuistik illustrirt werden.

Für die anatomisch-pathogenetische Untersuchung zerfällt dabei die Infectionslehre in zwei verschiedene Theile. Einmal kommt es darauf an zu zeigen wie sich die Verbreitungswege der Tuberculose im Körper darstellen, sobald dieselbe an einer Stelle „primär ${ }^{\natural f}$ zur Entwicklung gekommen ist. Eine solche Infection von einem im Körper bereits vorhandenen primären Heerde aus brauchte noch nicht die Anwesenheit eines dem Organismus fremden Giftes zu beweisen, sie findet sich ja auch z. B. bei bösartigen Geschwülsten. Soll nun die anatomische Forschung auch gleichzeitig die Lehre vom Tuberkelgifte unterstützen, so muss sie zu zeigen versuchen, dass der primäre Heerd in directer oder indirecter Beziehung zur A ussenwelt, zur Luft, zur Nahrung etc. steht, eine Beziehung, die den Zutritt des Giftes zu dieser Stelle erklärlich macbt. Gerade in 
letzterer Beziehung wird der Versuch die Infectionslehre wie durch das Experiment, so auch durch die anatomische Forschung zu stützen noch lückenhaft sein. Für einige Prozesse (z. B. die tuberculösen Gelenkleiden) scheint mir die Sache noch sehr dunkel, für andere werde ich wenigstens auf "Möglichkeiten " hinweisen. Dies dürfte immerhin doch nöthig sein, um an recht vielen Orten die Forschung in der anzugebenden Richtung anzuregen, und so mit vereinten Kräften das $z \mathfrak{u}$ erzielen, was dem Einzelnen unmöglich ist.

Solche Unvollkommenheiten wird man wohl bei der Neuheit dieser Betrachtungen, die erst seit wenigen Jahren möglich sind, entschuldigen, zumal da denn doch eine Reihe von Erscheinungsformen der Tuberculose übrig bleibt, die recht gut mit Hülfe der Infectionstheorie einem erneuten Studium und einem besseren Verständniss zugänglich sind. Dass dies letztere nach den alten Anschauungen recht mangelhaft war, wird wohl jeder zugeben. Man erklärte alle die Verschiedenheiten immer nur mit dem Schlagworte der Prädisposition, oder was dasselbe ist mit dem der specifisch en Schwäche.

Diese Worte haben, wenn wir von einem Gifte sprechen, auf welches sich die "Disposition" etc. bezieht, wenigstens in sofern einen Sinn, als sie uns auf Analogien mit andern Infectionsstoffen hinweisen, bei welchen ähnliche Verhältnisse vorliegen, und auf solche mit allen pflanzlichen Seminien, die auf verschiedenem Boden verschieden gedeihen. Viel ist damit ja auch nicht gesagt, aber man kann sich doch wenigstens etwas dabei denken. Man wird auch diese Hülfsworte erst dann entbehren können, wenn das Gift in allen seinen biologischen Beziehungen, von denen wir jetzt noch garnichts wissen, ganz genau studirt ist. Früher bezogen sich nun aber jene Ausdrücke nicht einmal darauf, dass man darunter eine Verschiedenheit des Nährbodens verstand, durch welche das an und für sich specifische Gift nur in der Wucherung unterstützt, in ihr gehindert oder beschränkt wurde etc. Man snchte vielmehr die Specificität der Art und des Ortes der Erkrankung allein in der specifischen Prädisposition der Körper und der Organe und glaubte, dass zum Hervorrufen derselben gar keine oder sonst ganz indifferente, nicht besonders geartete "Reize“ ausreichten, wie Traumen, Erkältungen etc. In diesem Sinne waren jene Worte nur Umschreibungen der Thatsache, dass dje Körper specifisch erkrankten, 
und sie erinnern ejgentlich sehr an jene berühmte Erklärung der schlafmachenden Wirkung des Opiums: Quia est in eo virtus dormitiva, cujus est natura sensus assoupire.

\section{Abschnitt.}

Allgemeines über tuberculöse Blutinfection.

Das Thema das uns zunächst beschäftigen wird ist die Frage nach den Gründen gewisser Formen der "generalisirten Tuberculose“ und speciell nach den Beziehungen derselben zur Venentuberculose.

Nicht jede Tuberculose (im ätiologischen Sinne) braucht „generalisirt“ zu sein, trotzdem jeder die Fähigkeit zur Infection von Körperorganen innewohnt. So giebt es viele Fälle von tuberculöser Lungenphthise, die zwar ihre Infectiosität deutlich, selbst mit Bildung exquisiter Miliarknötchen ${ }^{1}$ ) zu erkennen geben, ohne dass man aber bei ihnen von einer "Generalisation" sprechen kann, wenn man darunter nehmlich die Tuberkeleruption an Stellen versteht, die für das Seminium derselben nur auf dem Wege des Blutstroms und zwar des allgemeinen Blutstroms zu erreichen sind.

Für eine Generalisation in diesem Sinne ist daher vor allem eine Tuberkeleruption an jenen Stellen nöthig. Das Fieber der Schwindsüchtigen gebört nicht hierher, denn ein solches ist nicht nothwendig mit dem Uebertritt von Gift in's Blut za identificiren, ebensowenig wie es bei einem Erysipel, einer localen Eiterung etc. damit zusammeuzubängen braucht. Es kann ja von der Resorption chemischer Stoffe, vielleicht von Producten des Tuberkelprozesses, abhängen, ohne dass das Gift selbst im Blute vorbanden zu sein braucht. Auch die Amyloiddegeneration ist selbstverständlich in dieser Auffassung keine "generalisirte Tuberculose“. Endlich sind von den eigentlich tuberculösen Erkrankungen diejenigen nicht als generalisirte Tuberkel aufzufassen, welche durch Weiterschreiten per contiguitatem, Fortkriechen in den Lymphwegen, durch Ueberimpfung oder durch Eintritt in das Pfortadergebiet entsteben. Gerade diese aber machen das Bild der gemeinen

1) Sehr treffend spricht sich über die Beziehungen von Kăseheerden zur Bildung infectiöser Miliarknötchen bereits 1872 Lépine aus, citirt bei Grancher, Arch. de plyss. 1878. p. $521 \mathrm{f}$. 
tuberculösen Phthise aus ${ }^{1}$ ) und genügen, ihre Gefäbrlichkeit im Gegensatz zu andern tubereulösen Localerkrankungen zu erklären. Namentlich ist es die Ueberimpfung durch die Sputa, durch welche Kehlkopfs- und Darmerkrankungen, ja (durch Wiederaspiriren derselben) neue Lungenaffectionen entstehen können. Auch das Weiterschreiten in die Ungebung kann grosse Theile des zum Leben so wichtigen Organes zerstören etc.

Der Eintritt des Tuberkelagens in das Pfortadergebiet ist deshalb in das Kapitel der generalisirten Tuberculose nicht ohne Weiteres mit zu rechnen, weil trotz desselben die Organe des Gesa mm tkreislaufs, a uf die es hier a nk o m m t, verschont bleiben, wenn nicht besondere Complicationen da sind. Wir sprechen unten noch ausführlicher uber dieses sonderbare Verhalten.

Man muss aber von einer generalisirten Tuberculose im obigen Sinne sprechen, wenn, zu einer tuberculösen Lungenerkrankung z. B., sich noch eine solche von Milz, Nieren und anderen Organen hinzugesellt, welche nur auf dem Wege des allgemeinen Blutstroms für ein Gift zugänglich erscheinen. Stellt man sich aber auf den Standpunkt, für die Tuberculose ein solches Gift als Vorbedingung anzunehmen, so heisst Generalisation der Tuberculose nichts anderes als: Infection des allgemeinen Blutstroms mit Tuberkel$\mathrm{g}$ ift und Ablagerung des letzteren in verschiedene Organe. Diese Ablagerung kann unter verschiedenen klinischen und anatomischen Formen erfolgen, für welche ich mir erlaube drei Typen aufzustellen, welche allerdings durch Uebergänge mit einander in Verbindung stehen, so dass man über die Bezeichnung eines Falles hier und da zweifelhaft sein kann. Es kann vorkommen:

1) Die acute allgemeine Miliartuberculose, d. b. eine acute Ueberschüttung des Körpers mit einer grossen Menge miliarer und submiliarer Knötchen, die in auffallender Regelmăssigkeit bestimmte Organe befallen, von denen nur gan a usnah ms weise eines oder das andere ohne Tuberkel ist: In erster Linie Milz, Lunge, Leber, dann Niere, Chorioidea, Schilddrüse, Knochenmark, Herz. Bei einer echten acuten Miliartuberculose darf man selbst bei makroskopischer Betrachtung (ausser der Leber, in welcher

1) Wenn daher für den Begriff der Tuberculose auf dem letzten Chirurgencongress eine "Generalisation" für nöthig gehalten wurde, so ist das entschieden zu weit gegangen. 
die Tuberkel sebr oft nur mikroskopisch zu erkennen sind) böchstens einmal in der Schilddrüse oder der Chorioidea die Knötchen vermissen, - aber das ist nur ganz selten der Fall. Namentlich habe ich sie seit Jahren im Herzen nie vergeblich gesucht.

Neben diesen regelmässig befallenen können noch andere Organe miliare Tuberkel enthalten, Venen, seröse Häute etc.

2) Eine zweite Form ist charakterisirt durch eine geringe Zahl von Tuberkeln in einigen oder mebreren Organen, welche nur durch den Blutstrom von der nebenherbestehenden localisirten Tuberculose der Lunge etc. erreicht werden können. Die Knötchen können miliar oder verschieden gross sein. In ihren höheren Graden nähert sich diese Form der ersten oder (hãufiger) der dritten Gruppe. Ich möchte diese zweite Art der generalisirten Tuberculose Uebergangsform nennen. Sie findet sich oft bei Phthisen, sehr häufig aber namentlich bei kleinen Kindern.

3) Es kann eine sehr reichliche Bildung von tuberculösen Heerden in mehr chronischer Form erfolgen. Charakteristisch ist dann die ungleiche, zum Theil aber beảeutende Grösse der Heerde und die starke Verkäsung vieler derselben. Auch sie kommt öfter bei kleinen Kindern, namentlich aber auch bei Thieren vor: Chronische Allgemeintuberculose.

Diese Formen können sich insofern combiniren, als z. B. zur dritten Form eine acute allgemeine Miliartuberculose oder vereinzelte frisch zerstreute Miliarknötchen der Organe hinzutreten können.

Unter welchen Umständen tritt nun das Tuberkelgift bei diesen Krankbeiten in's Blut über?

Diese Frage wäre allerdings nicht gerechtfertigt, wenn man mit Martin ${ }^{1}$ ) annähme, dass das Tuberkelgift schon von vornherein beim Menschen im Blate verbreitet wäre und erst von diesem aus in den Lungen etc. nur dann deponirt würde, wenn in demselben eine „Entzündung" entstünde. Es wäre dann erst recht nicht erklärt, warum das Tuberkelgift manchmal Organe befällt, in denen sich eine solche Entzündung etc. garnicht nachweisen lässt. Diese ganze Annahme Martin's beruht aber auf einer falschen Voraussetzung und es scheint mir, dass er selbst in seinen spätern Arbeiten nicht mehr recht daran glaubt. Das Tuberkelgift tritt in den Lungen

1) Arch, de phys. 1880, p. 171. 
nur deshalb so häufig in Wirksamkeit weil es so häufig durch die Athmungsorgane dem Körper zugeführt, also direct in diese "geimpft ${ }^{\text {" }}$ wird. Die Münchener Versuche lehren diese Möglichkeit direct, ebenso indirect alle anderen künstlichen Uebertragungen, welche zeigen, dass das Tuberkelgift zunächst an der Impfstelle oder den zu dieser gehörigen Lymphdrüsen seine Wirkungen äussert und, wenn überhaupt, erst später in's Blut übergeht.

Wenn wir nun etwas näher auf die Fälle von generalisirter Tuberculose eingehen wollen, so wird es am besten sein, wieder die acute allgemeine Miliartuber'culose zunächst als Paradigma zu wählen. Hier liegen die Verhältuisse für die inductive Forschung am klarsten. Ich habe zwar schon in meiner vorigen Mittheilung einige Bemerkungen über dieselbe gemacht, doch glaube ich jetzt die Sache ausfübrlicher stüızen zu müssen, da meine damaligen kurzen Auseinandersetzungen nicht recht überzeugt zu haben scheinen. Wiederholungen werde ich möglicht vermeiden. - Die beiden andern Formen können nur mehr anhangsweise berücksichtigt werden.

Unter den tuberculösen Erkrankungen ist die acute allgemeine Tuberculose verhältnissmässig selten und namentlich ist sie selten im Vergleich mit der tuberculösen, gewöhnlichen Lungenschwindsucht, zu der sie nicht so vielfache Beziehungen hat wie man glauben sollte.

Auf diese Beziehungen bin ich in meiner ersten Mittheilung nur mit ganz kurzen Bemerkungen eingegangen. Ich muss mich aber diesmal etwas weiter darüber auslassen, namentlich da auch Orth kürzlich ${ }^{2}$ ) Einiges darüber veröffentlicht hat und frühere Angaben von mir erwähnt. Derselbe betont mit vollem Rechte, dass ein principieller, ätiologischer Unterschied zwischen tuberculöser Phthise und acuter allgemeiner Miliartuberculose nicht besteht, so sehr dieselben auch anatomisch und klinisch different erscheinen. Auf die Bedingungen für die Dissemination des Tuberkelgiftes geht er nicht weiter ein; doch macht er ebenfalls mit vollkommener Berechtigung auf die grosse Verschiedenheit aufmerksam, welche in Bezug auf die Angaben bezüglich des Zusammenvorkommens jener beiden Affectionen existirt. Die von ihm erwähnte Differenz in

1) Berl. klin. Wochenschrift. 1881. No. 42 . 
diesen Angaben ist in der That eine so auffallende, dass sie einer Erklärung bedarf. So hatte ich in einer Discussion bei Gelegenheit eines Vortrages uber Tuberculose (Sehles. Gesellsch. für vaterländische Cultur 1877, 13. Juli) bemerkt, dass ich selbst unter 20 Fällen nur einmal diese Combination gefunden hätte. Das wäre für m eine Fälle 5 pCt., Rühle giebt an, dass die Lungenschwindsucht ,eine der gewöhnlicbsten Veranlassungen" zur Erzeugung der acuten Miliartuberculose sei, 0 rth hat über $50 \mathrm{pCt}$. Phthisen bei letzterer Krankheit, Litten 25 pCt. gefunden. Wie soll man sich solche auffallend verschiedene Angaben erklären? Einmal aus $\mathrm{Zu}-$ fälligkeiten, die bei so kleinen Zahlen eine grosse Rolle spielen. Ebenso wie man oft (bei einem mittleren Materiale) viele Monate keinen Fall von acuter allgemeiner Miliartuberculose zu sehen bekommt, dann aber eine ganze Reihe hintereinander, ohne dass an einen endemischen oder epidemischen Zusammenhang der Fälle zu denken wäre, ebenso findet man oft ganze Reihen von acuter allgemeiner Miliartuberculose ohne eigentliche Phthise und dann wieder eine ganze Anzahl Combinationen beider.

Ferner aber sind die Meinungen darüber, was man Phthise und was man acute allgemeine Miliartuberculose nennt, vielleicht doch nicht so ganz identisch. Ich hatte damals ausdrücklich geringe schiefrige Induration etc. nicht zur Phthise gerechnet und $R$ ühle muss entschieden manche Dinge, die man, wenn man will, als Uebergangsformen bezeichnen kann und auf die wir oben schon kurz hinwiesen, der acuten allgemeinen Miliartuberculose mit angereibt haben.

Ich habe nun das Leipziger Material auf diese Frage hin durchgesehen und da ergiebt sich Folgendes:

Seit April 1878 sind hier p. p. 600 Phthisen secirt worden, acute Miliartuberculosen aber 28. Wenn man dieselben chronologisch mit No. 1-28 bezeichnet, so stellt sich das Verhältniss zur Phthise folgendermaassen:

A) Gar keine phthisischen Lungenheerde wiesen auf: $\left.4,5^{1}\right), 7,10,11,12,14,20,21,26=10$.

B) Geringfügige von mir fruber nicht als "Phthisen “ bezeichnete Prozesse: $1,2,3,6,8,13,15,16=8$.

1) Siehe dieses Archiv Bd. 77. S. 282 u. 284. 
Ich gebe, um Missverständaisse zu vermeiden, ganz kurz die Beschreibung dieser älteren Heerde:

1) Beide Lungenspitzen schiefrig indurirt, im linken Oberlappen eine kleine mit schwärzlichen Massen umgebene Höhle.

2) In der rechten Lungenspitze einige kleine käsige Heerde, links aur miliare Knötchen.

3) Siehe dieses Archiv Bd. 77. S. 277.

6) Das Lungengewebe überall mit ziemlich schmalen, schwieligen, pigmentirten Strängen durchzogen.

8) Siehe unten den mit No. XII bezeichneten Fall.

13) "Schwielige Prozesse in beiden Lungen“ (ausführliches Protocoll fehlt).

15) In der Spitze beider Lungen schiefrig indurirte Partien von Wallnussgrösse mit derben käsigen Einsprengungen.

16) Im linken Oberlappen ein etwa baselnussgrosser aus einem Conglomerat kleinerer bäsiger Stellea gebildeter Heerd, dessen Centrum von einem Bronchus gebildet wird, der ebenfalls von käsigen Massen erfüllt ist; im rechten eine schiefrig indurirte Partie von Haselnussgrösse mit vereinzelten käsigen Heerden um einen ebenfalls käsig infiltrirten Bronchus.

C) Mit sicherer, wenn auch nicht ausgedehnter Phthise: 9, 17, 18 (ausführliches Protocoll fehlt), 19, 22, 23, 24, 25, 27, $28=10$.

Auch hier siebt man, wie trügerisch kleine Zahlen sind. Hätte ich hier nach den ersten 16 Fällen meine Berechnung in alter Weise angestellt, so kam auf diese nur 1 Phthise $(6,25 \mathrm{pCt}$.), jetzt aber kommen auf 28 schon $10=$ ca. 36 pCt. Rechnet man die zweifelhaften Fälle als wirkliche "Phthisen", so ergeben sich über 64 pCt. Ich bemerke übrigens, dass die ,sicheren Phthisen“ vielfach nur wenig prägnantere Veränderungen zeigten, als die der zweiten Gruppe, ich habe aber lieber möglichst viele als solche bezeichnet.

Rechnet man wieder alle die Fälle subB als „Phthisen“, so sind immerbin unter den secirten "Phthisen" nur ca 3 pCt. mit acuter allgemeiner Miliartuberculose combinirt. Während nun woh] sämmtliche sonst als solche in den Protocollen ausdrücklich bezeichnete irgend welche Spuren der specifischen Infectiosität (im Körper selbsi) an sich trugen, so ist das Blut also nur in einer sehr geringen relativen Zahl so vergiftet gewesen, dass man von einer Ueberschwemmung desselben mit dem Gifte sprechen kann. Daraus würde folgen, dass jedenfalls die Phthise als solche nur unter ganz bestimmten seltenen Bedingungen die in Rede stehende 
Krankheit erzeugt und dass diese Bedingungen sich verbältnissmässig oft auch ohne Lungenschwindsucht vorfinden müssen.

Diese Seltenheit der acuten allgemeinen Miliartuberculose bei Phthise macht es auch erkiärlich, warum die alte Buhl'sche Theorie sich keinen rechten Anklang verschaffen konnte. Nach dieser war nur auf das Vorhandensein ejnes (erweichten) käsigen Heerdes überhaupt Werth gelegt und solche finden sich doch bei tuberculösen Phthisen immer genug. Da nun aber bei dieser nur selten die schwere acute Allgemeininfection mit Tuberkelgift entsteht, so muss man annehmen, dass eben doch noch etwas anderes hinzukommen muss. Durch dieses andere muss eine acute Ueberschwemmung des Körperblutes mit Tuberkelgift ermöglicht werden. Diese Bedingung muss deshalb erfüllt sein, weil 1) die ungeheure Menge der Tuberkel, von denen doch jeder durch ein Giftpartikel erzeugt ist, nur durch eine grosse Menge von Tuberkelgift erklärlich ist und weil 2) die Gleichartigkeit derselben und der klinisch $2 u$ constatirende schnelle Krabkheitsverlauf auf eine rasch eintretende Absetzung der sämmtlichen Giftheilchen schliessen lässt. Da nun die befallenen Organe nur durch den Blutweg so schneil mit jenem Virus versorgt werden können, so muss das Blut in kurzer Zeit eine grosse Menge davon empfangen $d$. h. es muss mit Tuberkelgift acut ubers $\mathrm{ch}$ wemm $\mathrm{t}$ werden.

Es genügt demnach nicht, wie Orth z. B. annimmt, eine „,böhere Potenzirung des Giftes", wen n durch diese nicht erst indirect jene Bedingung erfüllt wird. Sonst wären durch eine solche wohl starke Localwirkungen, leichteres Fortschreiten in die Umgebung, leichte Ueberimpfbarkeit erklärlich, vielleicht auch eine allmähliche chronische Durchseuchung des ganzen Körperblutes, aber eben nicht jenes schnelle Auftreten unzäbliger Tuberkel.

Freilich wäre es sehr schwer, für diese gewissermaassen deductive Ableitung einen inductiven Unterstützungsbeweis zu liefern, wenn das Tuberkelgift sich in ähnlicher Weise im Blut rasch anhäufen könnte, wie einige andere Infectionsstoffe, z. B. das Recurrensgift. Dieses tritt ohne sichtbare locale Heerderkrankung in's Blut ein und vermehrt sich rapide in ibm oder in innern Körperorganen. Aehnlich erklärte in der That Buhl die Pathogenie mancher Fälle von acuter allgemeiner Miliartuberculose, deren Giftstoff er einfach in 
grosser Menge von den Lungenalveolen her resorbirt dachte, ohne dass hier eine Localerkrankung stattgefunden hätte. Aber so rein auf Deduction ist man doch nicht angewiesen.

Es sind bereits zwei Wege ${ }^{1}$ ) bekannt, durch welche Gift in's Blut gelangen kann, ja es handelt sich dabei um sehr grobe Veränderungen, die jene acute Ueberschwemmungen des Blutes mit Tuberkelgift sehr wobl erklären.

Eine dieser Veränderungen ist die ausgedehnte Tuberculose des Ductus thoracicus, die Ponfick entdeckt hat. Hierbei wird, wenn die Communication mit der Vena subclavia offen ist, eine grosse Menge Gift in diese und so überhaupt in's Blut übergeführt. Mit diesem Befunde würde man aber nur einen Bruchtheil der Fälle genügend anatomisch erklären können, und es ist daher nothwendig, dass noch andere Wege vorhanden sind, durch welche, bei Freisein des grossen Lymphganges, grosse Massen des Virus schnell in den Kreislauf treten können. Die Constatirung dieser Wege ist erst möglich gewesen, seitdem durch mich gezeigt worden ist, dass nicht blos, wie man bis dahin glaubte, Lymphgefässe, zu denen ja auch der Ductus thoracicus gehört, sondern auch grössere Venen an ihrer Innenfläche tuberculöse Producte entwickeln können.

Ehe wir den Einfluss der Venentuberculose auf die tuberculöse Blutinfiltration eingehender besprechen, wird es nöthig sein, an das bisher vorhandene casuistische Material zu erinnern und eine Anzahl neuer Fälle eingehend zu beschreiben.

Ich kann dabei meine Verwunderung darüber nicht zurückhalten, dass solch grobe, makroskopische Rrankheitsproducte nicht nur früher von mir, sondern von allen andern pathologischen Anatomen hatten übersehen werden können. Es ist mir auch auffallend, dass trotz meiner Veröffentlichungen von andern Seiten keine Mittheilung über ähnliche Beobachtungen erfolgt sind (ausser von $M \ddot{g} g \mathrm{ge}$ ), zumal dieselben nicht gar so selten sind und für die ganze Infectionslehre wichtig genug erscheinen. Die bisher beschriebenen Fälle sind fast an dea Fingern herzuzählen, wenn man selbstverständlich von denjenigen absieht, welche die längst bekannten vielfach geschilderten Veränderungen der äussern

1) Oder wenn man den in der früher erwähnten Sitzung der Schles. Ges. f. vaterl. Cultur mitrechnet, drei: als dritte Eintrittsstelle wäre das Herz selbat anzusehen. 
Häute betreffen, oder tuberculöse Prozesse in obliterirten Gefässen, die eben aufgehört haben $G$ efässe zu sein, oder endlich die nicht tuberculösen obliterirenden Endarteritiden.

Der erste Fall, welcher überhaupt veröffentlicht worden ist, ist von mir selbst kurz erwähnt worden in der schon oben citirten Sitzung der schlesischen Gesellschaft für vaterländische Cultur am 13. Juli 1877. Ich batte damals schon vach solchen Dingen gesucht, welche den Uebertritt von Tuberkelgift in's Blut verständlich machten, dachte aber, da die Tuberculose des Ductus thoracicus erst im September desselben Jahres bekannt wurde (in München), nur an die Venen. Leider war ich erst später auf die Lungenvenen aufmerksam geworden. Die nächsten, nun schon letztere Venen betreffenden Fälle sind von mir 1878 bei der Kassler Naturforscherversammlung mitgetheilt, dann erschienen die Fälle von Mügge und endlich noch ein neuer von mir. Das ist Alles, wenn man nicht die von Cornil neuerdings beschriebenen Fälle, kleine Hirngefässe betreffend, mitrechnen will. Cornil waren übrigens meine Mittheilungen entgangen. (Journal de l’an. et de la phys. 1880.)

\section{Abschnitt.}

Neue Fälle von Venentuberculose.

Es folgen jetzt eine Anzahl neuer Fälle. Dieselben sind (zur Erleichterung des Citirens im darauf folgenden Texte) so numerirt, dass die in den vorigen Beiträgen veröffentlichten Fälle mitgezählt werden. No. 1 steht in diesem Archiv Bd. 77, S. 277, No. 2 S. 282, No. 3 S. 284, No. 4 S. 288 , No. 5 S. 290 . Die mikroskopischen Beschreibungen beschränken sich auf das Nothwendigste, namentlich unterlasse ich es, auf irgend welche uns hier nicht interessirende Controversen einzugehen. Um aber Missverständnisse zu vermeiden bemerke ich, dass eine grosse Anzahl Knötchen zur Sicherstellung der Diagnose stets auf ibre Natur mikroskopisch untersucht wurden. Wenn daher über dieselben nichts weiter bemerkt ist, so sind sie als typische Miliartuberkel zu betrachten.

Für die mikroskopische Untersuchung gerade der Tuberkel empfehle ich sehr eine Doppel- (oder eigentlich dreifache) Färbung mit essigsaurem Picrocarmin und Gentianaviolett. Die Schnitte bleiben 3-5 Minuten in ersterem, dann werden sie in angesăuertem 
Wasser ausgewaschen, nachber kommen sie einige Momente in Alkohol, hierauf in eine concentrirte Lösung von Gentianaviolett a uf nur wenige Augenblicke, endlich werden sie mit Alkohol, Nelkenöl, Balsam behandelt. Da man in der concentrirten Lösung von Gentianaviolett die Schnitte schwer findet, so ist es gut, wenn man dieselben nach dem Auswaschen in angesäuertem Wasser einige Momente in Alkohol bringt; sie schwimmen dann auf der wässrigen Lösung des Gentianavioletts und sind leicht zu finden. Diese Färbung ist viel besser wie z. B. die so sehr gerühmte Eosin-Hämatoxylinfärbung, weil noch eine dritte Farbe vorhanden ist und auch die Uebergangsfarben sehr schöne Differenzen bieten. Das Protoplasma der Riesenzellen, die körnigen Käsemassen etc. etc. erscheinen gelb, Bindegewehe roth, die scholligen kernlosen Massen gelbroth, Kerne blau etc. Die Farbenangaben in dem folgenden Texte beziehen sich stets auf eine solche Tinction.

\section{G r u p p e.}

Fälle von acuter Miliartuberculose bedingt durch grosse Venentuberkel.

Fall vi. Acate allgemeine Miliartuberculose ausgehend von grossen Lungenvenentuberkeln. Miliartuberkel in Lungenvenen.

Franz K, 36 Jahre alt, obducirt am 27. Juli 1879.

Diagnose: Acute allgemeine Miliartuberculose. Verkäste Bronchlaldrüsen. Grössere Tuberkelheerde in Lungenvenen. Miliartaberkel in solchen. Tuberculoseder Lungen ohne Phthise. Tuberculose der Niere, Milz, Schllddrüse, Herz, Chorioidea und Kochenrark. Tuberculöse Peritonitis. Tuberculöse Darmgeschwäre. Tuberculöse Magengeschwüre. Gegchwellte, verkäste Mesenteriallymphdrüsen. Solitärtuberkel in der linken, vorderen Centralwindung. Operirte Mastdarmfistel. Alter Selbstmordversuch. Depression des Schädels. Rostfarbene Narbe im Gehirn. Meckel'sches Divertikel.

Kräftig gebauter Leichnam.

Das Koochenmark des rechten Oberschenkelbeines geröthet, von zahireichen miliaren knötchen durchsetzt.

$\mathrm{Z}$ werchfell beiderseits im 3. Intercostalraum.

Bei Eröffaung des Bauches zeigt sich in demselben eine reichliche Menge leicht getrübter, röthlicher Flüssigkeit. In der linken Pleuraböhle ebenfalls reichliche Mengen hämorrhagischer Flüssigkeit.

Linke Pleura selbst mit wenigen dünnen Fibrinbeschlägen versehen, mit einer Anzahl piliarer Koötcben besetzt. Die rechte Pleura zeigt ebenfalls, wenn auch etwas weniger reichliche Knötchenbildung und leichte Fibrinbeschläge, doch ist die Pleurahöhle frel vọ Flüssigkeit. 
Es ist noch ein geringer Thymusrest vorhanden.

Herz entsprechend gross. Durchmesser des linken Ventrikels 1,3; Höhe 9; Umfang der Aorta 6,5; der Pulmonalis 7; Durchmesser des Conus art. 0,3. Im Conus art. sieht man sehr deatlich mehrere miliare Knötchen über die Invenfläche des Endocards hervorragen. Klappen zart hellgraubraun. In der Aorta ganz wenig gelbliche Verdickungen.

Die' linke Lunge in Unterlappen dunkelroth, zäh, luftleer, durchsetzt mit einer reichlichen Anzabl miliarer kleiner Knötchen, nur im vorderen Theil des 0berlappens ein kirschkerngrosser schiefriger Heerd mit käsigen Einsprengungen, ohne Zerfall, sonst nirgends ältere Heerde. Spitze ganz frei.

Verfolgt man die Lungenvenen vom Hauptstamm aus, so sieht man in einem Aste 2. Ordnung, der vom mittleren Theil des Oberlappens herkommt, aus einer Oeffoung einer Nebenvene (also 3. Ordnung) eine zerfallene grössere thrombusăhnliche Masse herausschauen. Scbneidet man diesen Ast, aus welchem die Masse heraussieht, auf, so zeigt sich in demselben eine $2 \mathrm{Cm}$. lange, 0,4 breite und 0,2 hobe weissliche Auflagerung, deren Oberfläche sonst glatt erscheint und unmittelbar in die ebenfalls glatte Oberfläche der übrigen Venenwand sich fortsetzt. Auf dem Durchschnitt zeigt diese Auflagernng eine trüb weissliche bis auf die vorbin erwăhnte Spitze derbe Beschaffenheit. Diese Auflagerung endet an einer weiteren Verästelungsstelle der Vene und scheint aus einem verschlossenen kleinen Venenlumen herauszukommen. In einem anderen Ast der Lungenvene und zwar im unteren Theil des Oberlappens (auch in einem Ast 3. Ordnung) sitzt ein miliares, weissliches Knötchen der Innenfläche der Vene auf. Bronchien und Arteriea ohne Besonderheiten.

Bronchialdrüsen gross, verkäst.

Rechte Lunge überall lufthaltig, durchsetzt von einer ziemlich grossen Zahl miliarer Knötchen. Spitze vollkommen frei. In einem Ast der Lungenvene, die von der Spitze der Lunge berkommt, sitzt eine sehr lange Auflagerung auf einer Selte der Venenwand bei vollkommen freiem Lumen. Diese Auflagerung geht bis an eine stark geschwellte Bronchialdrüse beran, wo sie endet. An dieser Stelle sind bereits die Venen 2. Ordnung im Begriff zum Hauptstamm sich zu vereinigen. Diese Auflagerung ist an ihrer ganzen Oberfläche glatt, besitzt eine Länge von $3 \mathrm{Cm}$, eine Breite von 0,4 and eine Dicke von 0,1-0,2. Die 0berfläche dieser Auflagerung erscheint jedoch in ihrem oberen (peripherischen Theil) ganz höckrig, wie aus lauter etwas mehr als miliarer Koötchen zusammengesetzt.

Auch hier Bronchialdrü sen stark vergrössert, verkäst.

In der Schilddrüse einzelne ganz kleine graue Knötchen.

Kehlkopf und Trachea frei.

Drüsen an der Bifurcation der Trachea stark geschwellt, verkäst, zum Theil erweicht.

Die grossen Venen frei.

An der rechten Seite des Stirubeins findet sich eine eingesunkene, mit höckrigem Grund versehene rundliche Stelle von ca. $3 \mathrm{Cm}$. Höhe und 5,5 $\mathrm{Cm}$. Breite.

Der unterste Theil dieser etwas vertieften Fläche setzt sich in eine schmale 
Spalte im Koochen fort, die das Stirnbein durchdringt und bis an die Innenfläche desselben fortgeht. Hier ist die Lamina vitrea etwas abgehoben, in dem grössten Theil des Umfanges aber und in ihrer Umgebung vollkommen intact. (Der erhabene Theil der Vitrea ist rundlich und hat einen Durchmesser von 1,5 Gm.) Der untere Theil dieser erhabenen Stelle ist jedoch frei und überragt als schmaler, znngenförmiger Rand den von aussen kommenden Spalt, der demnach vollkommen frei auf der Innenfläche des Schädels ausmündet. In dieser Spalte steckt ein Stückchen geschwärztes Blei. An derselben Stelle, wo diese Depression nod Fractur des Knochens statt hat, ist die Dura mater mit den unterliegenden Häuten fest verwachsen und die Hirnrinde mit dem obersten Theil der Marksubstanz in eine rostfarbene, weiche Masse umgewandelt. Die Stelle, um die es sich hier handelt, sitzt im vordersten Theil der 3. (untersten) Stirnwindung, hat die Grösse eines Zweimarkstückes und reicht bis an die Grenze der Pars orbitalis des Stirnlappens herap. In der Mitte der vorderen Centralwindung sitzt ein rundlicher erbsengrosser, derber, weisslich-käsiger Heerd mit rother Umgebung.

Im übrigen Hirn nichts Besonderes. In der linken Chorioidea ein graues Knötchen.

Das ganze Peritoneum ist besetzt mit einer Unzahl miliarer Knötchen. Das grosse Netz in Form eines 2-3 Finger breiten, dicken Wulstes nach oben geschoben. Das Peritoneum ausserdem noch mit zarten feinen Fibrinbeschlägen versehen.

Milz mit ihrer Umgebung durch derbe Fibrinmassen verklebt $(15 \mathrm{Cm}$. hoch, $7,5 \mathrm{Cm}$. breit, $4 \mathrm{Cm}$. dick). Milzsubstanz weicb. Man bemerkt in derselben a usserordentlich zahlreiche Knötchen.

Beide Nieren entsprechend gross $(11 \mathrm{Cm}$. hoch, $5,5 \mathrm{~cm}$. breit, 3,5 $\mathrm{Cm}$. dick). Kapsel leicht abtrennbar. Anf der Oberfläche sieht man vereinzelte weissliche Stellen von Stecknadelkopfgrösse, die in der rechteo Niere mehrfach zu Gruppen vereinigt sind und die sich zum Theil in keilförmige, grauweissliche Heerde fortsetzen, die sich sehr wenig scharf begrenzt gegen die übrige graurothe Nierensubstanz abbeben (in dieser ist die Zeichnung vollkommen deutlich). Manche der Stellen sind jedoch nur rundliche Einlagerungen obne keilförmige Fortsätze.

Nebennieren, Nierenbecken und-Kelche obne Besonderheiten.

Nierenkapsel zlemlich fettreich.

Gallenwege frei.

Im Magen 3 linsengrosse, rundliche Geschwüre in der Schleimbaut, die von einem etwas erbabenen Rande umgeben sind und in welchen man einige andeutliche, weissliche Pünktchen sieht. Die Geschwüre sitzen sämmtlich an der Hiaterwand des Magens im Fundus.

Duodenum ohne Besonderheiten.

Leber zeigt eine ungleichmässige, fleckige Zeichnung. Peripherische Theile grauröthlich; Centra graoroth. Zwischen den einzelnen Läppchen sieht man hie und da feine graue durchscheinende Streifen und Punkte. Lebergefässe frei.

Im Darm bemerkt man schon von aussen eine ganze Anzahl hämorrhagischer Partien, die quergestellt zur Axe des Darmes sind. Auf der Schleimhant zeigen sich dann eine sehr reicbliche Anzahl Geschwüre, theils rundlich, theils queroval. 
Auch im Dickdarm findet man namentlich in Anfangstheil verschiedene Geschwüre, aber nicht so reichlich, wie im Dünudarm. Der Rand der Geschwüre ist erhaben und zeigt einige weissliche Knötchen.

Die Rectalschleimhaut bis auf den untersten Theil frei. Dicht über dem Anns beginnt jedoch ein Substanzdefect, der sicb nach binten in ein halbapfelgrosses Loch fortsetzt, welches hinter dem Anus in die Hant und das Unterhautfettgewebe hineingeht. Diese Höhle zeigt einen schwarzrothen Grund, der geglättet und leicht böckrig erscheint. Schneidet man auf demselben ein, so trifft man in der Umgebung eine Anzahl käsiger Knoten von Halberbsengrösse bis Erbsengrösse mitten in Fettgewehe eingesprengt und zum Theil bis dicht an die Fläche des Geschwüres heranreichend.

Mesenteriallymphdrüsen stark geschwelt, verkäst, zum Theil erweicht.

Das grosse Netz lässt sich durch Auseinanderfalten aus dem wolstartigen Zustande in seine schürzenartige, normale Form zurückführen.

Geschlechtsorgane und Harnblase ohne Besonderheiten.

Mikrosk opische Untersuchung.

Es konnte nur die Auflagerung in der rechten Lunge, die also nicht erweicht war, zur mikroskopischen Untersuehung verwendet werden. Die der linken Lunge wurde, bis anf die (abgefallene) erweichte Spitze, die mikroskopisch angesehen wurde, zur makroskopischen Demonstration aufbewahrt.

Die Schnitte wurden theils in der Längsichtung, theils in der Querrichtung der Venen durch verschiedene Stellen der Auflagerung angefertigt, senkrecht zur Fläche der Vene. Wir wollen auch hier wie in den Fällen 1, 2 und 3 der leichteren Uebersicht wegen, von dem Boden, der Decke, den Seitentheilen und dem Centrum der Auflagerung sprechen. Bei Schnitten parallel mit der Venenaxe sind natürlich „Seitentheile“ nur da vorhanden, wo die Auflagerung aus der Venenwand emporsteigt, also am peripherischen und am centralen Ende ihrer Verbindung mit der Vene.

Die Hauptmasse der Auflagerung wird vou dem, makroskopisch läsig erscheinenden Centrum gebildet. Es bestehi im innersten Theile aus einer feinkörnigen in Pikrinsäure gelblich gefärbten Masse mit (durch Gentianaviolett) blau gefärbtem Kerndetritus hier und da versehen. Am Rande schliessen sich an dieses amorphe Centrum als Uebergånge zu den anliegenden zelligen Massen öfters gelbroth gefärbte Schollen an, welche kernlos sind und theils die Gestalt und Grösse der benachbarten kernbaltigen Rundzellen haben, theils aber zu bizarren Balken verschmolzen sind.

Die Seitentheile steigen ziemlich scharf abgesetzt von der freien Fläche der benachbarten normalen, nur etwas verdickten Venenwand auf. Die letztere hört an ihrer Grenze auf und löst sich in ein stark verdicktes, an Rundzellen reiches, im peripherischen Theile gefässhaltiges Bindegewebe auf. In diesen liegen dann epithelioide Zellen und Langhans'sche Riesenzellen theils ohne bestimmte Groppirung, theils zu kleinen, exquisit knötchenartigen Haufen zasammengestellt. Diese umschliessen öfters ein käsiges Centrum, welches aber den centralen Theil der Knötchen durchbricht und stch wie ein Stiel in die grosse centrale Käsemasse einsetzt.

Der B od en besteht ebenfalls aus einer mit Rundzellen, Langhans'schen Riesenzellen etc. reich versehenen Masse, die ebenfalls mit der centralen Käsemasse zusammenhängende Buckel von amorphem kernlosem Material einschliessen. Vielfach 
scheint es auf den ersten Blick, dass dieser „Boden“ gar nicht der Venenwand selbst angehört, sondern ausserhalb derselben liegt und dass die eigentliche Fortsetzung der Venenwand vielmehr die Decke der ganzen Auflagerung darstellt. Doch kann man sich sehr leicht darüber orientiren, dass in der That die Grenze der Venenwand unterhalb des bäsigen Centrums liegt. Die Membrana elastica interna ist nehmlich zwar meistens, namentlich auch stets unterhalb der Seitentheile, unterbrocben, aber doch noch bier und da zu erkennen, so dass man die Lage der Venenwand als unter dem kăsigen Centrum befindlich constatiren kann. Ihre Kenntlichkeit wird noch dadurch erleichtert, dass sie auffallend dick, wie die Elastica einer Arterie erscheint. Die erwähnten Zellen des „Bodens“ liegen daher in der ganz zerstörten Media der Venen, nach aussen sich allmählich in die Adventitia verlierend.

Die Decke der Auflagerung besteht aus einer dünneren oder dickeren Schicht rötblich gefärbten Bindegewebes mit spindligen Kernen, aber auch mit reichlichen Rundzellen und einzeln eingestreuten Langhans'schen Riesenzellen namentlich in der Näbe des käsigen Centrums. Dieses springt unregelmässig höckrig bald hier, bald dort in die Decke vor und năhert sich so mehr oder weniger der freien Fläche derselben, sie hier und da fast erreichend. Die letztere zeigt dann stellenweise Auflagerungen einer blăttrigen röthlichen Substanz mit eingestrenten Kernen, die der Oberfläche lockerer ansitzt.

So ist das Verhalten im grössten Theile der Auflagerung. (Die höckrige Beschaffenheit des peripherischen Endes machte sich mikroskopisch nicht geltend.) Am centralen Ende jedoch, da wo eine kleinere Vene sich der grossen anschliesst, ändert sich das Verhältniss. Der Boden der ganzen Masse behălt zwar seine Construction im Ganzen bei, aber rückt mehr und mehr aus der Venenwand heraus. Die Elastica interna ist verschwunden, die Käsemassen des Centrums liegen in der Flucht der Umgeb ung der Vene, die riesenzellenreichen Rundzellenanhäufungen des „Bodens“ lassen nirgends mehr etwas von der Venenwand erkennen, sie ragen mitten in das hier reichlich vorhandene lockere Bindegewebe, die Decke nähert sich dem Niveau der angrenzenden Innenfläche der Vene. Năhert man sich in Längsschnitten der seitichen Grenze der Auflagerung immer mehr, so liegt die Fortsetzung jener Auflagerung endlich ganz ausserhalb der Vene selbst als ein allseitig von reichlichen, oft von einem Netzwerk durchzogenen Rundzellen, Langhans'schen Riesenzellen und typischen Knötchen von epitbelioiden Zellen umgebener käsiger Knoten, der von der Vene durch ein von solchen Zellen ganz freies breites Spatium abgetrennt ist und so aussieht wie die in der Nähe befindlichen verkästen Theile der grossen Lymphdrüsen.

Diese $L y m p h d r$ ü sen siad stark verkăst, besteben vielfach aus einem amorphen Centrum nod einer schmalen, sích in der Umgebung allmählich verlierenden Peripherie von Rundzellen und Langhans'schen Riesenzellen ohne typische Knötchenanordaung, während an anderen Stellen noch normales mit Pigment versehenes Lymphdrüsengewebe vorhanden ist. Von der Vene sind sie überall durch einen deutlichen Spalt und durch rundzellenfreies Bindegewebe getrennt.

Von der Auflagerung der linken Lunge wurde nur die erweichte äusserste Spitze untersucht, die aus einem Gemisch von kernbaltigen Rundzellen, kernlosen gleichgestalteten Schollen und amorphem Material bestand. - 
Die millaren Knötehen der Organe und der Vene zeigen nichts Besonderes.

Der käsige Knoten im Hirn besteht aus einem amorphen Centrum mit einer Umgebung von reichllchen Rundzellen, an welcher dann wieder kleine Käseheerde, mit ähnlicber Umgebung daransitzen, deren Centrum mit der Hauptkäsemasse oft durch einen Fortsatz verbunden ist. Riesenzellen sah ich hler nicht.

Die grösseren knoten im Beckengewebe waren wieder aus einem grossen käsigen Centrum mit schmaler kernhaltiger Peripherie zusammengesetzt, die auch Riesenzellea enthielt, aber keine Mlliarknötchenbildung aufwies. Hingegen fanden sich ausser jenen Solitärtuberkeln isolirt etwas grössere Miliarknötchen vor, welche epithelioide Zellen, Biesenzellen, kernarmes oder kernloses Centrum hatten. Diese bleinen Knötchen fanden sich erst bei der mikroskopischen Untersuchung, doch konnte man da alle möglichen Grössenübergänge von lhnen zu den grossen Heerden finden. Deutliche Verschmelzungen ans mehreren kleineren Knoten warev nicht nachzuweisen, alle hatten vielmehr eine mehr rundliche Gestalt.

\section{Epikritische Bemerkung.}

Es handelt sich hier also um einen Fall von aciter allgemeiner Miliartuberculose, der zu einer schon bestehenden Tuberculose des Dünn- und Dickdarms (n. b. obne Lungenphthise, also nieht durch verscbluckte Sputa, sondern wohl durch tuberkelgifthaltige Nahrung bedingt), des Mastdarm- und Beckenzellgewebes, sowie zu einer älteren tuberculösen Peritonitis hinzugetreten ist. Es fanden sich vielfach verkäste Lymphdrüsen und von ihnen aus sind, wie wir noch sehen werden, die grösseren Lungenvenenheerde angeregt. Von dem der linken Seite, der an seiner Spitze ulcerirt ist, hat dann die tuberculöse Blutvergiftung ihren Ausgang genommen, die die acute allgemeine Miliartuberculose bedingte.

Ich möchte noch auf die isolirt im Beckenzellgewebe sitzenden Knoten und die wohl echt tuberculöse Mastdarmfistel hinweisen.

Tuberculöse Magengeschwüre sind zwar noch nicht viel beschrieben, aber sie sind doch nicht so gar selten. Ein besonderes Interesse haben sie sonst nieht.

Chirurgen dürfte die geheilte mit Hirnverletzung verbunden gewesene Schädelschusswunde bemerkenswerth erscheinen.

Fall VII. Acute allgemeine Miliartuberculose ausgehend von einem grossen Lungenvenen tuberkel.

Charlotte A., 16 Jahre alt, Handarbeiterin, obducirt am 21. November 1881.

Acute allgemeine Miliartuberculose obne. Phthise. Geschwellte Bronchialdrüsen. Tuberculöse Pblebitis pulm. sin. Miliartuberkel in Lunge, Milz, Niere, Leber, Herz, Chorioidea, rechter Pleura, Perltoneam, Gl.thyreoidea. Meningitis tuberculosa. Kleine tuberculöse Darmgeschwüre. Cystitis. Pyelitis (Catheterismus).

Archiv f. pathol, Anat. Bd. LXXXVIII. Hft. 2. 
Graciles, aber wohlgebildetes Mädchen. Fettpolster gut entwickelt. Knochen durften nicht nachgesehen werden.

D u ra prall gespannt.

Gyri stark abgelpattet.

An der Convexität der Pia vereinzelte gelbe Knötchen, die anscheinend in die obersten Schichten des Gehirns hereinragen. An der Oberfläche des Stirnhirns ist die Arachnoidea mit gelbem sulzigem Exsudat durchsetzt.

An der Basis in der Umgebung der Optici und des Trichters eine gelbe sulzige Masse, ehenso längs der Arteriae fossae Sylvii und der Arteriae profundae cerebri. Innerhall dieser Masse unterscheidet man längs der genannten Arterien deutlich dicht gedrängte gelbe Knötchen. Solche sitzen auch in reichlicher Anzahl auf den Gyris rectis, wo aber dle Pia nur weisslich getrübt erscheint, in geringer Anzabl zerstreut auch an verschiedenen anderen Stellen der Basis.

Ventrikel sehr weit, mit trübgrauer Flüssigkeit erfüllt, Im Ependym die Gefässe ziemlich weit.

In der linken $\mathrm{C}$ borio idea ungemein reichliche grane Knötchen.

$Z$ werchfell rechts im 3 . Intercostalraum, links an der 4. Rippe.

Von der Thymus sind noch Reste vorhanden.

Rechte Lunge mit der Brustwand verwachsen, linke Lunge bis auf eine geringe Adhäsion an der Spitze frei.

Pleurahöhle leer.

Herz klein, ca. 190 Grm., in thm Speckhaut und Cruormassen. Linker Ventrikel 0,9 dick, 7,3 hock. Aorta 5,0. Pulm. 5,3. Con. dext. 0,5 dick.

Im Conus dexter und zwar am oberen Rande dicht neben dem einen Zipfel der Tricuspidalis eine Gruppe von 5 miliaren, über das Endocard deutlich bervorragenden grauen Knötchen; ein noch grösseres ähnliches findet sich im linken Ventrikel an der linken Wand $1 \mathrm{Cm}$. unter der Mitte des Ansatzes des linken (hinteren) Mitralzipfels.

L i n k e L u ge durchsäet mit unzähligen miliaren granen Koötchen; im hlnteren Theil blutreich, vorn blass; nirgends findet sich ein älterer kăsiger oder schiefriger Heerd. Arterien und Bronchíen frei; hingegen sitzt in dem grossen Venenaste, der von der Mitte des Oberlappens herkommt, eine ganz umschriebene Verdickung der Wand, die rasch eine Breite von $0,5 \mathrm{~cm}$. annimmt und eine Höhe von ca. $2 \mathrm{Mm}$. hat; dieselbe setzt sich in den Venenhauptstamm fort und gewinnt hier eine Breite von $7 \mathrm{Mm}$. und eine Höhe von $3 \mathrm{Mm}$. Bei näherer Besichtigung ergiebt sich aber, dass dlese eigenthümliche Auflagerung sich peripherisch noch in einen kleinen Venenast fortsetzt und von da wieder in einen kleineren, so dass die ganze Länge derselben $2,2 \mathrm{Cm}$. betrăgt. Sie beginnt schmal und liegt der einen Wand der Vene bandartig auf, doch so, dass die Venenlumina durch dasselbe nur wenig verengt werden. Im centralsten Theil ist die Oberfläche dieser Auflagerung erweicht, sonst erscheint dieselbe überall ganz glatt, in der Mitte gelb, käsig, am Rande grau durchscheinend, wie festes Bindegewebe. Auf elnem Durchschnitt ist die Masse in der äussersten Schicht durchscheineod, in der nächsten Zone gelblich, trocken, in der Mitte erweicht. Die in der Nähe liegenden Bronchialdrüsen geschwellt, zum Theil verkäst. 
Nach Ablösung der rechten Lunge ergiebt sich, dass hier zahlreiche miliare Koötchen mit geringer Fỉbrinauflagerung auch auf der freien Fläche der Pleura liegen.

Gefässe und Bronchien rechts frei. 'Rechte Lunge selbst -wie die linke.

Trachea, Kehlk opf und Halsgefässe frei.

In der Schilddrüse eine Anzahl deutllcher, grauer, miliarer Knötchen.

Am unteren Theil des Zwerchfells an der rechten Seite sebr reicbliche millare Knötchen.

Das grosse Netz mit deutlichen aber spärlichen Knötchen durchsetzt.

Auf der linken Selte des Zwerchfells ebenfalls, aber spärliche Knötchen.

Milz mit der Umgebung etwas verklebt. Gewloht $200 \mathrm{Grm}$. An der Oberfläche sitzen einige gelbe Knötchen mit einem grau durchscheinenden ziemlich grossen Hof. Milz selbst dunkelroth, durchsäet von einer Unzahl miliarer grauer Knötchen. Nebennierea ohne Besonderheiten.

Nieren. $10,5,4,75,4 \mathrm{Cm}$. Kapsel leicht abtrennbar. An der Ober@äche bemerkt man eine grosse Anzahl überstecknadelkopfgrosser grauer und gelblicher Knötchen, die zum Theil das Niveau der Oberfläche ein wenig überragen. Auf dem Durchschnitt zeigt sich das Gewebe ziemlich blutreich. Zeichnung deutlich. Riade $9 \mathrm{Mm}$. breit; das ganze Gewebe, sowohl die Marksabstanz, sowle namentlich die Rinde durchsetzt mit grossen Mengen überstecknadelkopfgrosser grauer und gelblicher Knötchen oder ähnlicher radiărer Streifen. Viele dieser Knötchen und Streifen enthalten im Innern eine trübe gelbe käsige, theils trocken aussehende, theils erweichte Masse, die dann von den übrigen Theilen des Knötchens resp. des Streifens wie von einem breiten Hof umgeben ist.

Ni er enbecken stark geröthet, mit undeutlichen Knötchen versehen. Nierenvenen frei.

Die Leber (Gewicht ca. $1100 \mathrm{Grm}$ ) zeigt an der Oberfläche verejnzelte Knötchen, die aber sehr reichlich an 2 Stellen des rechten Lappens sitzen, wo derselbe mit schmalen bindegewebigen Strängen an das Zwerchfell angeheftet ist. Sie zeigt eine undeutiliche Läppchenzelehnung und für das blosse Auge wenige aber deutliche graue miliare Knötchen.

Gallenwege frei.

Magen uad Daodenum ohne Besonderheiten, ebenso das Pancreas.

Im Düngdarm und Dickdarm eine ziemliche Anzahl nicht über linsengrosser Geschwüre, mit aufgeworfenem Rande, in welchem, sowie im Grunde vielfach deutllche Knötchen enthalten sind.

Auch an der Serosaseite sitzen bier mehrfach Knötchen, zum Theil in Form von kurzen rosenkranzähnlichen Zügen anf dem Dünndarm auf.

Ausser den Geschwüren noch mässig reichliche über stecknadelkopfgrosse Knötchen in der Darmschleimhaut. Sonst auf der Darmserosa nur zerstreute graue miliare Knötchen.

Mesenterialdrüsen ganz wenig geschwellt, grauroth mit weissen undeutlichen Knötchen.

Der Brusttheil des Ductus thoracicus eng, mit wasserheller Flässigkeit gefüllt. Cysterna chyli ziemlich weit, ebenso die zuführenden grossen Lymphgefasse. Nirgends Tuberkel zu bemerken. 
Uterus etwas anteflectirt, Scheide eng, gerunzelt. Ovarienoberfäche glatt, Im rechten Ovarium ein dunkles kleines Corpus luteum.

Im Douglas's chea Raum zlemlich reichllche Knötchenablagerung.

Blasenschleimhaut dunkelroth mit einem träben. Belage versehen, der sicb lelcht abspülen lässt.

Drüsen an der A orta etwas geschwellt, graurotb mit undeutlichen Knötchen.

Aortenintima ohne deutliche Knötchen, ebenso Vena cara, azygos, ju gularis etc.

Mikroskopische Untersucbung.

Die mikroskopische Untersuchung wurde in der Weise vorgenommen, dass die ganze Lănge der Venenauflagerung in ca. Millimeter hohe Querschnitte zerlegt wurden, diese wurden mit Bergamottöl und Paraffin bebandelt ond in 0,02 Mm. dicke Schnitte zerlegt. (Dünnere Schnitte, die sich aber bekanntlich ganz gut mit dem Mikrotom anfertigen lassen, schienen nicht wünschenswerth, dickere sind von eingeschmolzenen Präparaten nicht gut brauchbar.) Sie wurden erst nachträglich in der oben angegebenen Weise gefärbt und aus jeder Serie eine Anzahl Schnitte untersucht.

Im centralsten Theile fält die obere erweichte Masse (die Venenwand als unten betrachtet) sehr leicht aus den Schnitten heraus. Nur hier und da hleiben Fetzen der Decke mit haften, die aus einem Gemisch von röthlichen streifigen Massen mit Rundzellen nud eingestreuten Langhans'schen Riesenzellen bestehen. Die noch auf dem „Boden“ sitzen gebliebene centrale Masse bestebt aus körniger gelbgefürbter Substanz. Der Boden der Auflagernng selbst besteht aus Rundzellen von der Grösse uad Gestalt der Lymphkörperchen mit Gefässen dazwischen. In diese eingesprengt sitzen zierliche umschriebene kleine Knötchen aus epithelioiden öfters zu einem Netzwerk vereinigten Zellen bestehend, die manchmal ein käsiges Centrum einschliessen und nor hier und $d a$, an der Grenze der käsigen Hauptmasse Riesenzellen enthalten. Gefãsse sind in diesen Knötchen nicht zu erkennen. Die Membrana elastica fehlt in den centralsten Theilen der Auflagerung ganz, so dass dje Käsemasse und ihre umgebenden Zellen sich im umgebenden Gewebe verlieren.

Die Seitentheile bestehen in der Nähe der Venenwand, die an ihrer Grenze sich in jene zu verlieren scheint, aus einem streifigen, mächtigen, rötblich gefärbten Gewebe mit deutlichen Gefässen, theils mit spindligen Zellen, theils mit Haufen von Ruodzellen, namentlich in der Nähe des Bodeus. Die oberen Theile der Seitenstücke verlieren sich allmäblich in die Decke mit threa spärlichen röthlichen Gewebsmassen und reichllichen Ruadzellen.

Etwa $5 \mathrm{Mm}$. nach der Peripherie zu bleibt wenigstens die Decke an den Schnitten haften und thre höheren Theile bestehen hier aus einer gelb gefärbten Masse (ähnlich dem Centrum) mit spärlichen Pundzellen, aber verhältnissmässig reichlichen, oft ganz isolirt liegenden Biesenzellen. In der Nähe der centralen Partien verläuft eín Bronchialast mit anliegenden Lymphdrüsen.

Weiter nach der Peripherie zo bleibt auch die centrale Inbaltsmasse in den Sehnitten liegen, die dann ebenso aussiebt wie die oben gescbilderten Reste in der Näbe des Bodens. Die in der Nähe der Seitentheile liegenden Partien der Decke sind roth gefärbt und ziemlich breit, mit Spindelzellen versehen; nach oben zu aber 
verschmälert sích die Decke beträcbtlich. Die zellenreichen Stellen der Basis finden sich nur in der Nähe der Seitentheile, in der Mitte geht die käsige Masse bis an die hier schon vielfach deutlich durch ihre elastische Haut abgesetzte Venenwand, die nur spärliche Rundzellen aufweist. Die Seitentheile enthalten aussen derbe rothgefärbte mit Spindelzellen und Gefässen versehene Massen, innen reichliche Rundzellen und deutlich abgesetzte Knötchen von epithelioiden, netzförmig zusammenhängenden Zellen mit sehr spärlichen Langhans'schen Riesenzellen. Die Decke besteht bls an ihre Kuppe aus rothen Massen.

Noch weiter nach der Peripherie zu stellt die Decke jetzt überall eine dicke rothgefärbte Masse mit spindligen Elementen dar, der an der Grenze der centralen Käsemasse isolirte oder von klelnen Haufen zerstreuter Rundzellen umgebene Riesenzellen anliegen. Die Gefässe der Seitentheile gehen bis weit in die Decke hlnein. Am Boden ist die Membrana elastica als dicke, geschlängelte Haut deutlich zu erkennen, nur auf kürzere Strecken ist sie (namentlich stets in der Nähe der Seitentheile) verschwunden. Unterhalb der Elastica ist die Venenwand nur von spärlichen Rundzellen durcusetzt. In den Seitentheilen deutliche Knötchen von der früher angegebenen Structur. Das Centrum besteht jetzt in der Nähe des Bodens aus rolbgelb gefärbten kernlosen Schollen von der Grösse und Gestalt der weissen Blutkörperchen, welche sicb in die körnige amorphe gelb gefärbte Masse allmählich verlieren.

Wieder peripherwärts treten in der Venenwand selbst Riesenzellen neben ganz zerstreuten vereinzelten Rundzellen auf, ohne Knötchenanordnung. Sonst wie früher.

Entfernt man sich lmmer mehr vom Centrum, so kommt man jet2t in denjenigen Theil der Auflagerung, der schon makroskopisch als ganz glatte, bandartige leichte Verdickung der Venenwand erschien. Hier ist die Decke so dick, dass sie der normalen benachbarten Venenwand an Durchmesser mindestens gleichkommt und bei dem ganz ähnlichen Aussebn beider, sowie bei der geringen Abweichung von der Fluchtlinie der Vene, kann es scheinen, als ob jetzt die Käsemasse ganz ausserbalb der Vene läge und die Decke die eigentliche Fortsetzung der letzteren darstellte. Dass dem aber nicht so ist, kann man an der Lage der Eiastica erkennen, die hier stark verdickt äberall am Boden vorhanden 1st und nur an den Seitentheilen fehlt. Auch hier treten mehrfach sehr typische Miliarkaötchen mit Langhans'schen Riesenzellen etc. in der eigentlichen Venenwand im Boden auf. Aucb in den Seitentheilen sind immer stellenweise Rundzellenanhäufungen mit Riesenzellen vorhanden.

Die Decke nimmt in ihrem Durchmesser nach der Peripherie hin noch zu nod erreicht etwa den dreifachen der Venenwand selbst.

Die Fortsetzung nach der Peripherie zu lässt die Auflagerung in immer bedeutenderer Grösse im Verhāltniss zum Venenlumen erscheinen, während ihre absolute Grösse entsprechend dem immer kleiner werdenden Gefässkaliber abnimmt. Endlich wird die Vene ganı von der Käsemasse ausgefüllt, die Elastica bleibt jetzt an einem grossen Theile des Umfangs erhalten, wie immer verdickt. Endlich ist nur etwa ein Viertel des Venenumfangs ohne solche und hier sitzi eine im peripherischen Thetle des Umfangs mit grossen dünnwandigen Gefässen versehene lymphkörperchenreiche Masse, die sich allmählich in das käsıge Centrum verliert, aber 
nach aussen nicht die Grenze der Venenwand mit ihren immer spărlicher werdenden Zellen überschreitet.

Die peripherische Spitze dieser bis dahin mit käsiger Masse erfüllten Vene besteht aus einer das Innere (an der Elastica kenntlicb) ausfüllenden Bindegewebsmasse ohne Käse und Rundzellen.

Die Leber enthlelt zahlreiche Miliarknötchen, die aber nur bel mikroskopischer Untersuchung deutlich waren.

Fall Vill. Acute Millartuberculose ausgehend von efnem grossen Lungenvenentuberkel.

Paul Sch., Eisendreher aus Leipzig, 25 Jahre alt, obducirt am 4. Februar 1882.

Diagnose. Lungenphthise. Polypöser grosserTuberkel in einer Vena pulmonalis. Acute allgemeine Miliartuberculose. Tuberkel in Lunge, Milz, Nieren, Leber, Schilddrüse, Chorioidea, Herz. Tuberculöse Meningitis. Tuberkel in der Dura.

Mittelmässig genährter Leichnam.

Dura gespannt.

Pia an der Basis und dem Chiasma nervorum opticorum mit sulzigen gelben Massen durchtränkt, die namentlich auch in der Gegend des linken Oculomotorius stark angehäuft sind; diese Massen setzen sich in die Fossae Sylvii fort sowle auf den vorderen Theil des Oberwurms.

An den Fossae Sylv. sieht man sehr deutlich reichliche miliare Knötchen in den sulzigen Massen liegen.

In beiden Chorioideae je eln sebr deutlicher graver miliarer Knoten.

An der Basis der mittleren Schädelgrube an der Dura deutliche miliare Knötchen.

$\mathrm{Z}$ werchfell rechts im 4 ., links 5 . Intercostalraum.

Herz 260 Grm. Linker Ventrikel 1,2 dick, 9,5 hoch. Aorta 5,8. Pulm. 5,2. Con. dext. 0,5. Musculatur auffallend grau, wässerig, feucht. Klappen vollkommen zart. An dem Endocard des linken Ventrikels an der Vorderwand vereinzelte, aber sehr deutliche, scharf hervorspringende miliare Knötchen, dem Endocard aufsitzend. Am Eingang des Con. dext. ein ebenfalls sehr deutliches Knötchen von Stecknadelkopfgrösse.

Beide L ungenspitzen fest mit der Brastwand verwachsen.

In der linken Lunge ist ein grosser Theil der hinteren Hälfte des Oberlappens in eine scbwielige schiefrige Masse umgewandelt, in welcher verkäste Knoten und bis kirschkerngrosse Cavernen sitzen. Das äbrige Lungenparenchym von einer grossen Anzabl gleichartiger miliarer grauer und weisslicher Knötchen durchsetzt, meist ohne schwärzliche Höfe, hier und da gruppenweise sitzend.

In einem Ast der Vena pulmon. 3. Ordnung des Oherlappens (mitten in lufthaltigem Gewebe), der eiven Umfang von 1,2 Cm. hat, sitzt auf der einen Wand auf einer linsengrossen Fläche ein polypöses gelbliches Gebilde fest, dessen Oberfläche höckrig, bier und da wie zerfressen erscheint. Dieses Gebilde ist $1,2 \mathrm{~cm}$. lang, $0,3 \mathrm{Cm}$. breit und dick. Nach dem frelen Theile zu ist es ein wenig kolbig; auf seiner Oberfläche sitzen dann noch röthliche zähe Blutgerinnsel locker auf. Wo 
dieses Gebilde der Wand des Venenstammes aufsitzt, setzt sich an dieselbe eine kleine Vene an, deren Lumen vollkommen durch eine derbe gelbliche kăsige Masse verstopft scheint. Diese Verstopfung der kleinen Vene lässt sich etwa $0,5 \mathrm{Cm}$. weit verfolgen. Arterien und Bronchien frei. Im Uebrigen ist der Hauptstamm der mit der Auflagerung versehenen Vene vollkommen glatt, bläulich.

Rechte Lunge von ganz ähnlicher Beschaffenheit der Schnittfläche; nur sind hier die schwieligen Massen im Oberlappen von etwas geringerem Umfang (kleinapfelgross).

Arterien und Venen dieser Lunge frei, ebenso die Venae anonymae, jugulares, cava superlor, azygos ete.

Ductus thoracicus rollkommen frei.

Kehlkopf, Trachea, Oesophagus, Zunge, Rachen frel.

In der Schilddrüs e dentliche miliare grane Knötchen, aber sehr spärlich.

B ronchialdrü sen mässig geschwellt, schwärzlich.

Aortenintima zart, mit ganz vereinzelten verwaschenen, flachen gelben Stellen.

Milz 160 Grm., zähe, von einer grossen Menge miliarer grauer Knötchen durchsetzt, die sich von dem gleichmässig hellgraurothen, nicht sehr dunklen Parenchym nur wenig abheben. Malpighi'sche Körperchen undeutlich.

Nebennieren ohne Besonderheiten.

Nieren $(13,0,6,0,4,0 \mathrm{Cm}$.). Kapsel leicht abtrennbar, Rinde dunkelbraunroth mit ziemlich reichlichen millaren grauen Knötchen, Rindenzeichnung deutlich $(0,8)$. Marksubstanz dunkelbraunrotb.

Magen, Duodenum, Darmkanal obne Besonderheiten.

L eber $1400 \mathrm{Grm}$. Schnittfäche auffallend gleichmässig dunkelbraunroth, ohne deutliche Läppchenzeichnung, auf derselben vereinzelte grave Knötchen schon mit blossem Ange sichtbar.

Gallenblase mässig mit dunkelbrauner Galle gefüllt.

Grössere Lebervenen frei, ebenso die Pfortaderäste.

Harnblase und Hoden frei, ebenso Mastdarm.

Mikroskopische Untersuchung.

Die polypöse Auflagerung der Hauptrene wird mit dem angrenzenden Venentheil in eine Schnittserie zerlegt. Schnittrichtung parallel mit der Venenaxe. Auf diesen zeigt sich Folgendes: Da wo die Auflagerung von der sonst intacten nur mit geringer Verdickung der Intima versehenen Venenwand aufsteigt (entsprechend den "Seitentheilea" der zur Venenwand queren Schnitte), ist zunächst an der Vene ein mit deren Media direct zusammenhängendes röthlich gefärbtes Bindegewebe mit Gefässen vorhanden. Es entbält spärliche Spindel- and Rundzellen. Nach dem Centrum der Auflagerung zu sind aber reichliche Rundzellen vorhanden, in denen eingestreut zierliche Miliarknötchen mit epithelioiden Zellen, Netzwerk und Riesenzellen liegen. Sie enthalten theils ein separates käsiges Inneres, theils bängt dies unmittelhar mit der verkästen centralen Hauptmasse der Auflagerung zusammen.

Der Boden ist mit nicht sehr reichlichen Rundzellen versehen; die Vene nimmt hler noch einen kleinen offenen Seitenast auf, der die Basis der Auflagerung durchsetzt. 
Das was der Decke entsprechen würde, ist hier nur in der Năhe der Seitentheile auf den meisten Schnitten erbalten, das Centrum fällt zum grössten Theile heraus. Da wo dieses dem Boden aufsitzt, findet sich zunächst an den „Seitentheilen" ein rothgefärbtes Bindegewebe als Fortsetzung der letzteren zur Decke. Je mehr sie sich aber von der Vene entfernen, desto mehr Rundzellen treten in der Decke auf, desto spărlicher wird die roth gefärbte Zwischenmasse, bis endlich die Decke nur aus einem groben Maschenwerk von blassröthlichen kernlosen Balken besteht, in deren Maschen theils körnige gelblich gefärbte Substanz, theils kernhaltige Leucocythen, theils auch rothe Blutkörperchen liegen. Diese Substanz der Decke reisst ungemein leicht ab.

Das käsige Centrum besteht in der Nähe des Bodens aus kernlosen gelbroth tingirten Schollen yon der Grösse und Gestalt weisser Blutkörperchen, die sich nach innen balkig verbinden und ausziehen und ganz allmählich in die centrale körnige gelbliche Masse übergehen. In letzterer treten dann je mehr sich die Auflagerung von der Vene entfernt immer reichlicher Rundzellen auf, die tingirbare Kerne enthalten und zwischen sich eine mehr röthlich gefärbte feinkörnige Substanz haben. -

Die Seitenvene wird an Querschnitten untersucht. Sle war nur scheinbar ganz thrombosirt, bei mikroskopischer Untersuchung nimmt die bald zu schildernde Auflagerung nur etwa $\frac{2}{3}$ des Venenumfangs für sich in Anspruch, wäbrend das letate Drittel normal erscheint. Beim Aufschneiden mit der Scheere hatte ich gar nicht das eigentliche Venenlumen eröffnet, sondern war in die Käsemasse der Auflagerung hereingerathen.

In den der Hauptvene nahe liegenden Schnitten besteht die Auflagerung in ihrem Centrum aus der gewöbnlichen Käsemasse, die Decke in ibren äusseren Theilen aus streifigen Bindegewebe, innen aus dichten Rundzellen mit sebr zahlreichen Riesenzellen, ebenso die Seitentheile. Am Boden ist die Elastica bis auf die Gegend der Seitentheile erbalten, dick, die Venenwand selbst mit nur wenig Rundzellen versehen, aber dicht an ihr verschiedene exquisite Miliarknötchen mit Riesenzellen etc.

Entfernt man sich von der Hauptvene, so bleibt zwar im Uebrigen Alles unverändert, aber jenseits der Venenwand, dicht an ihr beginnend, tritt ein Haufen von lymphoiden Rundzellen auf, der sich nach aussen in das umgebende Bindegewebe ohne feste Grenze verliert und in diesen äusseren Theilen reichliches Langenpigment enthält.

Auf noch weiteren (mehr peripherisch gelegenen) Schnitten ist aber die lntima durchbrochen und die Käsemasse der Auflagerung hängt ganz unmittelbar mit einer die Venenwand selbst durchsetzenden, z. Th. aber augenscheinlich schon ausserhalb liegenden ähnlichen kernlosen Substanz zusammen. An diese schliesst sich noch mehr nach aussen eine Auhäufung kernhaltiger Rundzellen mit Riesenzellen an, die ganz allmählich in's umgebende Bindegewebe sich verliert und in ihren peripherischen Theilen mit Lungenpigment durchsetzt ist.

Endlich erscheint die Vene an einer Stelle, wo eine zweite kleinere, offene, einmündet, ganz gescblossen, die Rundzellen, die der Decke entsprechen würden, schliessen sich erst an die äussere Wand der Vene an (deren Häule ganz intact 
erscheinen), und diese setzen sich unmittelbar fort in eine Kăsemasse von ungefähr derselben Grösse, wle die der Auflagerung in der Nähe, allseitig umgeben von Rundzellen. In den Rundzellen sind reichliche Riesenzellen eingestreut. Nach aussen rejcht die Käsemasse bis unmittelbar an das schwarze Lungenpigment mit seinen Rundzellen und Riesenzellen und es zeigen sich schwarze Körnchen nicht nur frel in der Käsemasse, sondern auch in den Riesenzellen eingescblossen. Die einmündende offene kleine Vene hat eine verdickte Intima.

Fall IX. Acute allgemeine Miliartuberculose ausgehend von einem grossen Tuberkel der Nebennierenvene.

August F., 56 Jahre alt, Handelsmann.

Mässig ausgedehnte Lungenphthise, abernurlinks. Bronchioctatische Caverne im linken Unterlappen. Geringe tuberculöse Darmgeschwürsbildung. Verkäste Stellen in der Prostata. Tuberculöse Geschwäre in der Harnblase. Grösserer tuberculöser Heerd in einer Papille der linken Niere. Verkäsug beider Nebennieren, ohne Bronzebaut. Tuberculöse Phlebitis in der linken Vena superrenalis. Acute allgemeine Miliartuberculose. Tuberkel in Lunge, besonders rechts, in Milz, Niere, Herz, Schilddrüse, Chorioidea, Knochenmark, Leber, Vena anonyma sin. - Amputationsstumpf des linken Arms. Gallensteine.

Mässig kräftig gebauter Mann. An der $\mathrm{Haut}$ ist eine auffallende Bronzefärbung nicht zu bemerken; sie ist nur etwas hellbräunlich gefärbt, wie es bei Leuten mit mangelhafter Hautpflege oft der Fall ist. Der linke Unterarm fehlt; an den unteren Extremitäten kleine Hautblutungen. Im Knochenmark des rechten Oberschenkelbeins eine Anzahl sebr deutlicher, stecknadelkopfgrosser, weisser oder gelblicher, scharf umschriebeoer Koötchen, in deren Umgebung das Mark geröthet ist, während es sonst gelb und fettglänzend erscheint.

Die linke Lunge mit der Brustwand fest verwacbsen, namentlich im unteren Lappen. Der Oberlappen zeigt ziemlich verbreitete, etwas grössere käsige Heerde, die gruppenweise stehen, vielfach in ihrer Mitte erweicht und zugleich in Höhlen umgewandelt sind. Zwischen innen, hie und da schiefrige Bindegewebsmassen, in der Spitze 2 haselnussgrosse Cavernen. Im Unterlappen nur ganz vereinzelte Miliarknötchen; hingegen ist ein grosser Theil des seitlichen Unterlappens in eine ausgebuchtete, mit glatten Wänden versehene, faustgrosse Caverne verwandelt, in deren Umgebung sich nichts von käsigen Substanzen vorfindet. Diese Caverne steht mit mehreren Bronchien in Verbindung; doch fehlt hier eine Schleimhautauskleidang. Hingegen ist die Höhle glattwandig, theils von rother, theils von gelber Farbe.

Bronchialschleimbaut geröthet. Bronchialdräsen melanotisch, geschwelt, hie und da mit grauen Stellen und erweichten schwärzlichen Partien. Dabei sind die Drüsen vielfach mit den Arterien verwachsen, deren Wände mehrfach buchtig ausgezogen sind und hie und da auf der Innenfläche und auf dem Durchschnitt grau verfärbt erscheinen. Die Venen sind frei.

Die rechte Lunge ist voluminös und ganz frei von älteren Verănderungen, hingegen durchsetzt von einer sehr grossen Zahl miliarer grauer und weisser Knöt- 
chen. Im Uebrigen sind die Verhältnisse der Arterien und Bronchien wie auf der anderen Seite. Venen frei.

Herz. Linker Ventrikel 1,2 dick, 10,0 hoch. Aorta 7,2 Cm. Pulmon. 8,0. Conus dexter 0,8. Klappen vollkommen zart. Musculatur gelbroth. Im rechten Ventrikel eine gelblich gestrichelte Zeichnung unter den Endocard; keine makroskopisch sichtbaren Koötchen. Hingegen im linken Ventrikel auf einem Papillarmuskel der Mitralis ein miliares graues, über dem Endocard scharf vorspringendes, kaum stecknadelkopfgrosses Knötehen.

o e s ophagus frei.

Kehlkopfknorpel verknöchert. Kehlkopfschleimhant frel. Ebenso Rachen, $Z$ unge etc.

In der Schilddrüse einige undeutliche miliare Knötchen, anch ein dentliches im linken Lappen. In der Vena a nonyma sin. an der Hinterwand ein kleines, kaum stecknadelkopfgrosses granes Knötchen.

Hirn ohne Besonderheiten.

In der linken Chorioide a einige ganz kleine graue Knötehen, in deren Ümgebung das Pigment etwas stärker angehäuft erscbeint, als an anderen Stellen.

Milz $250 \mathrm{Grm}$, derb, dunkelroth, durchsetzt von einer ungeheuren Zahl ganz feiner weisser Knötchen.

Nebennieren auffallend gross. In der linken ist im inneren Theil noch ein Abschnitt von gewöbnlichem Nebennierengewebe, dessen Länge 2,5, dessen grösste Dicke 0,8 beträgt. In diesem Theil ist die Rinde kaum verfettet. Intermediärsubstanz schwärzlich. Marksubstanz grauroth. Lateralwärts treten in der Nebenniere vereinzelte stecknadelkopfgrosse, verkäste gelbe Heerde auf, dann aber grosse käsige Knoten von 1,6 Cm. Dicke, an deren Rande nach oben hin noch eine schmale graurothe Rindenschicht erhalten ist. Präparirt man die Vena superrenalis, so findet sich eine polypöse, gelbe, käseähnliche Masse, die frei in das Lumen der Vene hineinschaut. Sie hat eine Länge von mindestens $1 \mathrm{~cm}$. (die Spitze war beim Herausschneiden der Nebenoiere abgeschnitten). Diese polypöse Masse sitzt peripherisch in der Nähe der käsigen Heerde fest and besitzt einen Durchmesser von ca. $3 \mathrm{Mm}$., der sich peripherwärts ein wenig vermindert. Die Oberfläche des polypösen Gebildes, das nur mit einer kaum linsengrossen Fläche an der Wand festsitzt und sonst ganz frei centralwärts in die Vene hineinragt, ohne mit der Wand irgend welche Verbindung einzugehen, ist etwas höckrig, aber doch im Allgemeinen glatt, nur in der Năhe der Spitze erweicht und wie ulcerirt. Die übrige Oberfläche der Vene vollkommen glatt; die Schnittfăche der Wand zeigt die gewöhnliche Dicke einer solchen Vene; doch an der Stelle, wo das polypöse Gebilde festsitzt, ist sle auf das Doppelte verdickt, derb, von käsigen Massen durchsetzt. Die rechte Nebennle re ( $6 \mathrm{Cm}$. breit, 3,2 hoch, 1,6 dick) zeigt auch noch Stellen mit ganz normalem Nebennierengewebe; sonst besteht dieselbe aus käsigen Knoten von unregelmässiger Begrenzung und trockener Schnittfläche, zwischen denen graurothe, glatte, zähe Züge von Bindegewebe vorhanden sind und an deren Rande noch hier und da Reste des normalen Parenchyms zu sehen sind. Die Vena superrenalis dextra verliert sich in die Käsemassen. An der äussersten Stelle, wo ihr Lumen der Präparation zugãngig ist, erscheint dasselbe höckrig, hie und da mit gelben Knötchen in der Wand. 
Im Magea einige schwärzlich erweichte Stellen.

Duodenum ohne Besonderheiten.

Leber, ca. $2000 \mathrm{Grm}$, hellgelblich; auf der Schnittfläche die Peripherien breit, gelblich; die Centra schmal, gelblichroth. Knötchen mit blossem Auge nicht zu seben. In der Gallenblase eine grosse Anzahl polyedrischer Steine, die das Lumen vollkommen ausfüllen und nur eine geringe Schleimmasse zwischen sich haben. Die peripherischen Steine sind an manchen Stellen mit der Gallenblasenwand sehr fest verbunden. Die Wand selbst zeigt an der Innenfläche ein weisses, glattes Aussehen, ohne Spur der eigentlichen Schleimhautbeschaffenheit.

Im unteren Theil des Dünodarmes und im Coecum ganz vereinzelte, ca. 20 Pfennigstück-grosse Geschwüre mit etwas erhabenem Rande, in welchem kleine Knötchen sichthar sind.

Prostata etwas gross, namentlich der linke Lappen; auf dem Durchschnitt des linken Lappens (undeutlich auch im rechten Lappen) deutliche käsige Heerde, theils von millarer Grösse, theils zu erbsengrossen unregelmässigen Knoten zusammengestellt.

Hoden und Nebenboden frei. Ebenso die Samenblasen anscheinend frei, während das linke \as deferens eine ganz leichte, gelbliche Zone um das Lumen herum zeigt, die rechts nicht zu sehen ist. In dem Recessus recto-vesicalis des Bauchfells ganz vereinzelte Knötchen.

In der Harnblase auf der vorderen Wand ein unregelmässiges dreieckiges Geschwür von 1,5 $\mathrm{cm}$. Durchmesser, $1 \mathrm{Mm}$. Höhe, mit ausgezackten, etwas aufgeworfenen, gelblichen Rändern, deren Umgebung geröthet erscheint. Der Grnad gelblicb, glatt.

Nieren 11, 4,5, 3,5. Oberläche glatt, mit vereinzelten dunkelrotben Punkten, die sich nicht wegwischen lassen, ond vereinzelten weissen verschwommenen Knötchen. Rindenzeichnung deutlich. Rinde gelblichroth, $7 \mathrm{Mm}$. breit Marksubstanz von derselben Farbe; die Glomeruli treten auffallend deutlich hervor. Nierenbecken frei, aber in einer Papille der linken Niere ein kirschkerngrosser Heerde mit gelblichem, käsigem Rande und graurotbem, etwas wejehem Centrum. Sonst in den Nieren noch zerstreute miliare gelbliche Knötchen.

\section{Mikroskopische Untersuchung.}

Die grossen Knoten der Nebennleren stellen unregelmässige Massen dar, welche mikroskopisch aus einer kernlosen, granulösen, gelbgefärbten Hauptmasse besteht, in deren Umgebung theils kernarme bindegewebige Zïge, theils reichliche Rundzellenanhäufungen sich fonden. Letztere sind an manthen Stellen in ganz auffallead geringer Zahl vorhanden, meist aber reichlich. Riesenzellen sind sebr selten zu sehen, danı entweder mit Häufchen von Rundzellen umgeben oder fast ganz frei von solchen im angrenzenden Bindegewebe. Die kleineren Knoten sind mit reichlicheren Rund- und zahlreicheren Riesenzellen in der Peripherie versehen.

Die durch die Knoten verlaufenden kleinsten Venenstämmchen sind häufig durch Anbäufung von Rundzellen und aworphen Massen in ihrem Innern ganz vollgestopft und manchmal nur schwer noch kentlich. In anderen sitzen solche Zellanbäufungen nur in Form von kleinen Wărzchen auf einem Theile der Wand auf, während die übrige Vene frei ist. Die Wand derselben ist sebr dünn, mit den umgebenden Gewebe verschmolzen. 
Der grosse Knoten in der Vene wurde in Längsschnitte zerlegt. Da wo derselbe der Vene ansitzt, steigen von der Wand derselben rothgefärbte, gefässhaltige, Im Allgemeinen kernarme Bindegewebsmassen auf (Seitentheile), in welchen aber an der inneren Seite reichliche Rundzellen aufsitzen und auch sonst Heerde von solchen sich vorfinden. Ausserdem sieht man in ihnen spärliche, aber sehr typische kleinste Knötchen mit epithelioiden Zellen und Langhans'schen Riesenzellen.

Der Boden der Auflagerung ist nur von sehr spärlichen Rundzellen durchsetzt, und zwar da, wo er an die centrale Kăsemasse anstösst. Die letztere gebt aber iiber die eigentliche Venenwand herans in das umgebende Bindegewebe hinein. Eine Elastica feblt hier ganz. Die Käsemasse selbst besteht in ibren der Vene benachbarten Theilen aus jener schon oft erwähnten feinkörnigen, gelbgefärbten keralosen Masse. Die dem freien Ende der Auflagerung entsprechenden Theile derselben enthalten jedoch reichliche Rundzellen.

Die Decke iśt nur in der Nähe der Seitentheile dentich bindegewebig, weiter nach oben (von der. Vene entfernt) löst sle sich in ein grobes Maschenwerk röthlicb gefärbter Balken auf, welche Haufen von Rundzellen enthalten. Noch mehr nach oben verschwindet die eigentliche Decke ganz und die centrale Masse liegt frei da, uur von röthlichen balkigen Fibrinmassen und Haufen von kernbaltigen Rundzellen bedeckt.

In Betreff der übrigen Tuberkel sei nur bemerkt, dass der einzelne Herztuberkel ein typisches Miliarknötchen war, dass aber der "Tuberkel“ der Vena anonyma sinistra bei der Demonstration im Kurs verloren ging.

\section{Epikritische Bemerkung.}

Wir haben hier neben einer mässig ausgedehnten nur auf die linke Lunge beschränkten Phthise mit einer grossen ulcerirten Bronchiectasie links unten, noch eine Urogenitaltuberculose und Verkäsung in beiden Nebennieren. Bronzehaut bestebt nicht, es ist auch noch ein grosser Theil des Nebennierenparenchyms erhalten. In den Nebennieren ist ausser mehrfacher Tuberculose kleiner Venenästchen auch ein grösserer erweichter Heerd in dem Hauptstamm der rechten $V$. suprarenalis vorhanden, von welchem dann die acute allgemeine Miliartuberculose ausging.

Es folgen nun noch $\mathrm{z}$ wei weitere Fälle von acuter allgemeiner Miliartuberculose, bei denen die Venenheerde der Sammlung einverleibt wurden und daher nicht mikroskopisch untersucht werden konnten. Die Venenbefunde sind makroskopisch schon charakteristisch yenug, doch bitte ich Fall XI nur als einen Anhang zu den früheren zu betrachten, da mir bei diesem die Pathogenese noch etwas zweifelhaft zu sein scheint. 
Fall X. Acute allgemeine Miliartuberculose ausebend von einem grossen Lungenvenenbeerde.

Alma P., 17 Jahre alt, Dienstmädchen, obducirt am 5. Januar 1880.

Diagnose: Acute allgemeine miliare Tuberculose. Alte tuberculöse adbäsive Pleuritis links. Grosser Tuberkelheerd in der rechten Lugenvene. MiliareTuberkel in Lange, Lungenvenen, Herz, Peritoneum, linker Pleura, Milz, Nieren, Nierenbecken, Chorioidea, Thyreoidea, Knochen, Leber, Ductus thoracicas. Netzhatblutungen. Grosses, frisches Corpus lateum rechts.

Gut gebautes Mädchen. Todtenstarre noch nicht gelöst.

Zwerchfell beiderseits im 4. Intercostalranm. Die linke Lunge mit der Brustwand durch lockere bindegewebige Adbäsionen verwachsen. Im rechten Pleuraraum mässige Mengen klarer hellgelber Flüssigkeit.

Im Herzbeutel ebenfalls etwas klare Flüssigkeit.

Auf der Aussenfläche des Herzens ganz vereinzelte miliare Knötchen.

Im Herzen selbst findet man, im Conus arteriosus eine grössere Anzahl miliarer Knötchen, vereinzelte sitzen auch an anderen Stellen des rechten Ventrikels. Sie überragen das Endocard als feine Knötchen nach innen zu. Im linken Ventrikel sitzen vereinzelle derartige Knötchen; eins derselben findet sich in der Năhe des Ansatzpunktes des vorderen Zipfels der Mitralis.

In den Adhäsionen, welche die linke Lunge mit der Brustwand verbinden, bemerkt man reichliche miliare Knötchen.

Die linke Lunge füblt sich derb an, ist sebr schwach lufthaitig, grauroth, durchsetzt von einer Unzabl miliarer, grauer und weisslicher Knötchen. Das dazwlschenliegende Gewebe hat eine graurothe Färbung; nirgends findeo sich ältere phthisische Heerde. Die Lungenvene ist frei von grösseren Thrombosen; hingegen finden sich an einzelnen Stellen miliare Knötchen auf der Intima vor. Die Arterien sind frei. In den Bronchien reichliche röthliche, schaumige Flüssigkeit.

Auch die rechte Lunge ist frei von jedem älteren phthisischen Prozess. Die Lungenarterien und Bronchien normal. Hingegen findet sich in einem Aste der Lungenvene, da wo sich 2 Aeste 3. Ranges zu einem 2. Ranges vereinigen, ein polypöser gelblicher Vorsprung, der eine Länge von $1,2 \mathrm{Cm}$. und eine Dicke von ca. 3-4 Mm. besitzt. Der nach dem Herzen zugekehrte Theil ragt frei in das Lumen der offenen Vene hinein und bat eine kolbig angeschwollene Form. Er ist von grosser Brüchigkeit, so dass ibn die geringste Berührung zerreissen kann. Der vom Herzen abgekehrte Theil sitzt sebr fest an der Vene an, setzt sich aber sehr scharf überall gegen den Intimaüberzug ab, welch letzterer glatt und glänzend ist.

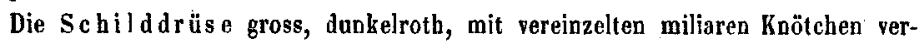
sehen.

Der Ductus thoracicus grösstentheils vollkommen frei; nur an einer ganz kleinen Stelle im Brusttheil findet sich das Lumen verschlossen durch gelbe käsige weiche Masse. 
Die Trachea, der 0esophagus ohne Besonderbelten.

Lymphdrïsen amHalse und die Bronchialdrüsen geschwellt, geröthet, von reichlichen miliaren Knötchen durchsetzt.

Stirna ah t erhalten.

Hirn ohne Besonderheiten.

In der rechten Netzhaut mebrere grössere Blatungen, in der linken mehrere kleine.

In der Chorloidea reichliche Tuberkel.

$\mathrm{MiJz}(300 \mathrm{Grm}$.$) ist durchsetzt von miliaren Knötchen, die dicht gedrängt$ stehen.

Beide Nieren gross $(12,0,6,0,3,5 \mathrm{Cm}$.$) . Kapsel leicht abtrennbar, Rinde$ $7 \mathrm{Mm}$. breit. Auf der Oberfläche sehr reichliche verschieden grosse graue Punkte, die häufig von einem kleinen deutlichen Hof umgeben sind. Diese Punkte setzen sich in Form von Streifen zum Theil auch durch die Marksubstanz fort. Diese Streifen in der Marksubstanz sind zum Theil mehrere Millimeter breit und laufen den Harnkanälchen parallel.

In der Schleimhaut des einen Nierenbeckens ein miliarer Knoten.

Nebentieren ohne Besonderheiten.

Im grossen Netz vereinzelte ganz feine miliare Knötchen. Auch auf dem Peritonealüberzug der Leber und der Nleren vereinzelte Knötchen, etwas reichlicher im Douglas'schen Raum.

Gallenwege frei.

Magen, Duodenum, Gallenblase ohne Besonderheiten.

In der Leber siebt man vereinzelte grössere weissliche oder gelbliche Knötchen. Die Centra der Leberläppchen sind dunkelgrauroth, scharf abgesetzt gegen die hellgrauen Peripherien.

Pancreas dunkelgrauroth, ohne deutlich erkennbare Knötchen.

Im Dickdarm dickbreiige gelbliche Kothmassen; Scbleimhaut vollkommen intact; ebenso Dünndarm.

Im rech te n 0 varium eine baselnussgrosse mit dunkelgelbrother; dickbreiiger Masse erfüllte Cyste mit intacter Oberfläche.

Uterusschleimhaut leicht geröthet.

S cheide stark gerunzelt.

H y m en ringförmig.

Fall XI. Acute allgemeine Miliartuberculose, möglicherweise ausgehend von einem Heerde der Vena thyreoidea.

Walther N., stud, jur., 25 Jahre alt, obducirt am 8. Februar 1880.

Diagnose: Acute allgemeine Miliartuberculase. Tuberkel in Herz, Lungen (keine Phthise), Milz, Leber, spärlich in den Nieren. Hochgradige Tuberculosedes linken Schild drüsenlappens. Grösserer Tuberkelheerd in dem Verbindungstheil der Vena thyreoidea superior und inferior.

Sehr kräftig gebauter Mann. Todtenstarre noch nicht gelöst. Kn ochen durften nicht untersucht werden. 
Hirn und A gen durften nicht nutersucht werden.

Bei Eröffnung des Thorax sinken die Lungen nur wenig zurück.

In Herzbeutel wenig klare Flüssigkeit.

Herz. Linker Ventrikel 1,0, 11,0. Aorta 6,0. Con. dext. 0,3. Pulm. 6,0.

Musculatur des Herzens grauroth. Im Conus arteriosus einige millare Knötchen, die zum Theil das Endocard deutlich überragen. Klappen vollkommen zart.

Beide Lungen auffallend schwer.

Rechte Lunge $1200 \mathrm{Grm}$., linke $1050 \mathrm{Grm}$.

Auf der Pleura beiderseits reichliche miliare Knötchen durcbschimmernd, doch ist die Pleura überall glatt.

L ungengewebe schwach lufthaltig, durchsetzt von einer sehr grossen Zahl miliarer Knötchen, die dicht gedrängt an einander stehen, virgends von schwărzlicben Heerden umgeben sind. Gefässe vollkommen frei, soweit sie sich makroskopisch verfolgen lassen. Auch miliare Eruptionen sind nicht zu erkennen. Nirgends in den Lungen ein älterer phthisischer Heerd.

In den Bronchien zäher Schleim.

Ductus thoracicus frei.

Aortenintima vollkommen zart, ebenso die grösseren Halsvenen.

Auf der linken Seite geschwellte Bronchialdrüsen.

Im recbten Schilddrüsenlappen keine deutlichen miliaren Knötchen, bingegen die ganze äussere Partie des linken Schilddrüsenlappens von sebr reichlichen miliaren Knötchen durchsetzt, die an vielen Stellen sehr dicht stehen and zu grösseren käsigen Heerden zusammengeflossen scheinen. An dlesem Lappen vorbei zieht eine $8 \mathrm{Mm}$. im Umfang haltende Vene, die zur Vena thyreoidea inferior führt und diese mit der Vena thyreoidea superior verbindet. In dieser Vene, da wo sie an den reichlich mit Knötchen durcbsetzten Schilddrüsenthellen vorüberzleht, sitzen zwei Knoten, die von rechts nach links $3 \mathrm{Mm}$., in der Dicke $1 \mathrm{Mm}$. und in der Höhe 1,5 Mm. zusammen messen. Das Venenlumen ist vollkommen frei.

Milz $400 \mathrm{Grm}$. weich. Durch die Oberfläche schimmern blasse Stellen durch. Palpa ziemlich blass, mit reichlichen feinen Pünktchen durchsetzt, die sich jedoch nicht gerade sehr scharf markiren.

Beide Nebennleren ohne Besonderheiten.

In belden Nieren die Kapsel leicht abtrennbar; spärliche makroskopisch sichtbare Knötchen.

Nierenbecken frei.

Am Ausgang der Blase einzelne feine Knötchen.

Auf der Aussenfläche der Albuginea testis kleine ganz durchscheinende derbe Knötchen beiderseits.

Prostata ohne Besonderheiten.

Gallenwege frei.

Leb er 2200 Grm., hat eine Schnittfäche mit nicht sebr deutlicher Läppchen. zeichnung und sehr zahlreichen, makroskopisch aber nicht deutlich sichtbaren grauen und weisslicben Knötchen.

In der Gallen b lase wenig Galle.

Magen und Darm ohne Besonderheiten. 
Epikritische Bemerkung.

In diesem Falle fand sich nur an einer Stelle des Körpers ein grösserer Käseheerd, der auch mit etwas grösseren Venenknoten in Verbindung stand. Dieser sass sonderbarer Weise in der Schilddriise, wo ich noch nie einen solchen grossen Heerd gesehen habe. Die bedentende Grösse des Heerdes spricht für ein längeres Besteben, als dje sonst vorhandenen miliaren Tuberkel haben können, und auch der Zusammenhang mit den immerhin elwas grösseren Venenknötchen für eine ältere Beschaffenbeit beider. Doch sind mir letzlere etwas zu klein erschienen für die Blutïberschüttung und ich gebe anheim, ob man diesen Fall als sicher in der Pathogenese der letzteren aufgeklärt ansehen will.

$$
\text { II. } G r \sim p p e .
$$

Zwei Fälle von acuter Miliartuberenlose von Tuherculose des Ductus thoracicus ausgehend, bei denen Miliartuberkel in Venen gefunden wurden.

$$
\text { Fall XII. }
$$

Johann G., Zimmermann, 53 Jahre alt, obducirt am 5. September 1879.

Diagnose: Scrophulose und Tuberculoseder mesenterialen und retroperitonealen Lymphdrüsen. Miliartuberculose und tuberculöse Entzündang des Ductus thoracicus. Acute allgemeine Miliartuberculose. Tuberkeln i. Lunge, Milz, Niere, Scbilddräse, Herz, Pfort ader, V. pulmonalis, V. azygos. - Atherose and Erweiterung der Aorti und anderer grosser Arterien.

Bei Erôtfonung der Brust zeigt sich im vorderen Mediastinum die Aorta in reichlicher Ausdehnung vorliegend.

Das Herz ist gross, zeigt an seiner vorderen Fläche ejnige Sehnenflecken. Linker Ventrikel $1,2 \mathrm{Cm}$. dick. Höhe $9,5 \mathrm{~cm}$. Papillarmuskeln etwas platt. Klappen vollkommen zart. Musculatur graugelbroth.

Umfang der Aorta oberbalb der Klappen $10 \mathrm{Cm}$.

Rechter Ventrikel im Conus arteriosus $4 \mathbf{M m}$. dick. Umfang der Aorta pulmonalis $7 \mathrm{Cm}$. Im Conus arteriosus nach der Hinterwand zu eine Gruppe von ca. 20 feinen weisslichen Knötchen. Ein etwas grösserer derartiger Knoten sitzt an der Vorderwand des Con. art. als grauweisslicher, scharf umschriebener Höcker das Endocard überrågend. In dem linken Ventrikel auf einem hinteren Papillarmuskel ein ähnliches nur kleineres Knötchen.

Coronararterien mit zarter Intima.

Aorta sehr weit. Ihre Innenfläche im aufsteigenden Theile uneben, von grauer, weisslicher und gelhlicher Färbung. Die gelblichen Stellen fühlen sich kalkig an. Hier und da Substanzdefecte an der Innenfläche, aber ohne thrombotischen Belag. Im weiteren Verlauf ist die Aorta thoraclca ebenfalls sehr weit und von ganz äbnlicher Beschaffenheit. Auch die grösseren vom Aortenbogen abgehenden 
Blutgefässstămme zeigen eine ähnlicbe Beschaffenheit der Intima. Im unteren Theil der Aorta thoracica findet man graurothe Gerinnselmassen anfliegen. In der Höhe des Tripus Halleri hat die Aorta einen Umfang von $8 \mathrm{~cm}$. Unterhalb des Abgangs der Mesenterialis superior verengert sich die Aorta wiedernm und zwar ziemlich rasch, so dass sie unmittelbar darunter einen Umfang von $5 \mathrm{Cm}$. und dicht über der Theilungsstelle einen von $4,5 \mathrm{~cm}$. hat. Dieser schmälere Theil zeigt eine viel glättere Intima, in der nur inselförmige theils weissliche, theils gran durchscheinepde Verdickungen von uaregelmåssiger Gestalt sitzen.

Arterla e crur a les beiderseits sind starr, weit, mit ringförmigen Verkalkungen versehen und mit leistenförmigen Vorsprüngen, die quer zur Axe stehen, ausgestattet, zwischen denen dann entsprechende Buchten vorhanden sind.

Intima der Pulmonalarterie vollkommen zart.

Beide Lungen von sebr zahlreichen miliaren, grauen und weissen Knötchen durchsetzt und auch mit reichlichen miliaren schwärzlichen Knötchen versehen. In der Spitze der linken Lunge ein walloussgrosser, schiefriger Heerd mit käsigen, derben Einsprengungen. Dabei sind die Lungen sehr blutreich, ödematös. Bronchìalschleimbaut geröthet, mit etwas Schleim belegt. An der Oberfläche sitzen die Knötchen nur subpleural. Am rechten Bronchus in der Nähe einer melanotischen Bronchialdrüse schwarz verfärbte Stellen der Intima.

In den Langenvenen der linken Lunge nichts Besonderes. In der rechten Lunge sitzt in der Nähe des Hauptstammes der Lungenvene in einem Aste, der von der unteren Lungenpartie herkommt, eln scharf umschriebenes gelbliches Knötchen mit ganz glatter Oberfläche. Knötchen.

Schilddrüse klein, dunkelgrauroth, mit vereinzelten grauen und weissen

In der Vena azygos 4 sehr deutliche weissliche Knötchen auf der Intima.

Hirn ohne Besonderheiten.

Chorioi dea nicht nachgesehen.

Ebenso K n och e nmark nicht nachgesehen.

Im B a u che klare, hellgelbe Flüssigkeit.

Milz 17; 9; 5,5 Cm.; ziemlich weich, durchsetzt von sehr grossen Mengen feiner weisser Pünktchen.

Beide Nieren gross $(13 ; 5 ; 3,5 \mathrm{Cm}$.) mit einigen accessorischen unregelmässigen Gefässverbindungen. Kapsel leicht abtrennbar; schon auf der Oberfläche sieht man zahlreiche kleine miliare Knötchen, die sich auch auf dem Durchschnitt präsentiren. Rinde trüb, grau. Marksubstanz bläulichroth. Nierenarterien mit glatter Intima.

Magen eng. Schleimhaut gefaltet ohne deutliche Knötchenbildung.

Im Darmbanal nirgends ein Geschwür zu bemerken. Schleimhaut vollkommen intact. Am Ausgang der Blase einige weissliche Knötchen. An der Hinterwand ein vereinzeltes, weissgelbliches Knötchen mit stark injicirter Umgebung.

Gallenwege frei.

Leber ziemlich gross. In der Gallenblase dunkelbraune Galle. Leberarterien nur mässig verdickt. In der Pfortader sitzt an einer Stelle ein stecknadelkopfgrosses, weissliches Knötchen mit glatter Oberfläche. Es sitzt in der Nähe des 
nach dem linken Leberlappen abgehenden Hauptastes. In der Leber selbst undeutliche graue und weissliche miliare Knötchen.

In dem Hauptstamm der Vena cava inf. und in den Lebervenen wurden keine knötchen bemerkt.

Pancreas ohne Besonderheiten.

Ebenso Mesenterial- und Milzvenen ohne Besonderheiten.

Mesenterialarterien mit verdickter Intima versehen, erweitert, äberall gat durchgängig.

Mesenterial- und retroperitoneale Lymphdrüsen ausserordentlich stark vergrössert, letztere die Aorta eng umschliessend.

Mesenterialdrüsen verkäst, doch derb. Der Peritonealüberzug an ihrer Oberfläche mit kleinen Knötchen versehen, sonst ist das Peritoneum frei, nur im Douglas'schen Raum finden sich vereinzelte kleine Knötchen. In einigen der erwähnten Drüsen grauroth thrombosirte Venen. Ebenso sind die Venen um die Prostata herum thrombosirt.

Die Retroperitonealdrüsen sind mehr dunkelroth und von ungemein zahlrelchen, grauen und weisslichen wiliaren Knötchen und verkästen Stellen durchsetzt. Einzelne dieser Drüsen haben ein gradezu hämorrbagisches Ausseben.

Der Hauptstamm des D uctus thoracicus nun zeigt in der Gegend der Cysterna chyli eine sehr beträchtliche Erweiterung. Die Innenwand nicht verdickt, mit einer ungeheuren ZahI miliarer Knötchen besät. Weiter nach oben $3 \mathrm{Cm}$. oberhalb der Erweiterung wird die Wand des Ductus thoracicus sehr verdickt, mit röthlichen Fibringerinnselo verklebt, so dass die Sonde nur mit Mahe einen Durchgang findet. Der Durchschnitt der Wand ist theils ein röthliches Gewebe mit grauen Steller, theils aber auch exquisit käsig. Die Verdickung und Verklebung des Duct. thorac. setzt sich bis oberhalb des Zwerchfells fort, wird jedoch im Brusttheil geringer und von einzelnen glatten Stellen unterbrochen. An den glatten Stellen ist auch die Wand nicht verdickt. Weiter oben in der Höhe des Lungenhilas tritt wiederum eine sebr starke Verdickung und bäsige Durchsetzung der Wand auf und das Lumen ist hier wiederum verklebt. Dann wird die Verklebung wieder gelöst, das Lumen frei und die ganze Innenfläche des Ductus thoracicus erscbeint von nun ab von grauen, graurötblichen und weissen unregelmässigen Höckerchen besetzt. Die glatten Stellen hören jetzt ganz auf. Die Wandung selbst nicht so starr und dick, wie im unteren Theil. Mikroskopische Untersuchung.

Die Venenknötchen zeigen eine etwas verschiedene Structur, wenn sie auch im Priccip unter einander übereinstimmen. Einer sass in der eigentichen Venenwand und boben die Intima nur empor, die anderen überragen die letztere als ein knopfförmiger hauptsächlich aus Rundzellen bestehender Hügel, der in den seitlichen Theilen auf der Intima einfach aufzuliegen scheint, bei hinter einander folgenden Schnitten aber jedesmal mit einem Heerde in der Venenwand selbst zusammenhängt, der im Centrum liegt. An dieser Stelle hängen die über die Intima hervorragenden und die in der Venenwand liegenden Massen unmittelbar zusammen.

Manche der Knoten enthalten Riesenzellen, andere nicht, bei manchen ist das Centrum ganz kernlos, bei einigen nur kernarm.

Die Oberläche der Knötchen nach dem Lamen der Vene hin war hier glatt. 


\section{Fall XIII.}

Carl Wilhelm L., 60 Jahre alt, Landschaftsmaler aus Leipzig, obducirt am 25. Jannar 1881.

Acute allgemeine Miliartuberculose. Hochgradige Tuberculose der retroperitonealen und retroplearalen Lymphdrüsen. Tuberculöse Kehlkopfgeschwĩre. Tuberkel in Lunge, Herz, Chorioidea, Milz, Leber, Nieren, Lungenvenen, Knochenmark. Starke Tuberculose des Dact. thoracicus. - Geringe Endocarditis aortica. Erweiterung des Aortenbogens mit umschriebenem Thrombus. Atrophe beider Optici. Gallensteine.

Kräftig gebauter, ziemlich fettreicher Mañ.

Beide Lungen mit der Brustwand durch bindegewebige Stränge verbunden. Beide sind blutreich, schwach lufthaltig, doch nirgends ganz luftleer. An einigen Stellen sieht man ein ganz undeutlich graurothes Infiltrat, das sich allmählich in der Umgebung verliert. In der rechten Lunge ist an einer Stelle im unteren Theil des Oberlappens eine hasejnussgrosse scharf umsehriebene, halb käsige, halb verkalkte runde Einlagerung (Drüse). Dagegen sind beide Lungen durchsetzt von einer grossen Zahl miliarer grauer und weisser Knötchen ohne schiefrige Umgebung. Nirgends aber finden sonst sich in den Lungen phthisische käsige oder fndurative Heerde. Die Arterien und Bronchien sind frei. Die Lungenvenen ebenfalls zum grössten Theil frei; nur an einer Stelle in einem grossen Venenast der rechten Lunge sitzt an der Intima ein graues hirsekorngrosses Knötchen fest an, das mit überhängenden Rändern versehen ist.

Herz schlaff, mit einem ziemlich reichlichen Fettansatz an der Aussenfläche. Linker Ventrikel $0,9 \mathrm{Cm}$. dick, 10,5 hoch. Aortenumfang 8. Die Klappen zart, aber an den Schliessungsrändern der Aortenklappen ganz kleine nicht sehr zahlreiche graurothe Knötchen.

Herzmuskel graugelb. Die Art. cor. sin. entspringt 0,5 cm. über der oberen Grenze des betreffenden Sinus Valsalvae; Con. dext. 6,2, Pulm. 9,5 Cm. Die Hlappen rechts zart. Im Endocard des Conus arteriosus dexter sitzen ganz vereinzelte, gerade noch sichtbare miliare graue Knötchen, die nach innen vorragen, auf.

Im Kehlk opf befindet sich am hinteren Rande beider wahrer Stimmbänder, nach oben zu auf die Schleimhant der beiden Aryknorpel sich erstreckend je ein oben ziemlich tiefes Geschwür, das mit einem grauen hier und da gelblich fetzig belegtem Grunde versehen ist und in welehes im oberen Theile entblösste Knorpelstäckchen hineinragen. Sonst ist die Kehlkopf- und Trachealschleimhaut leicht geröthet und mit kleinen Blatungen versehen.

Die Trachealhöhle ist seitlich comprimirt, die Schilddrüse vergrössert, zum grössten Theil mit gallertigen, gelblichen und bräunlichen Massen durchsetzt. Nur an einigen Stellen ist das Gewebe von der gewöhnlichen Beschaffenheit der Schilddrüse, namientlich im oberen und hinteren peripherischen Theil und an diesen Stellen sieht man hier und da eingesprengte miliare weisse Knötchen.

Die Jugularvenen und die Carotiden frei, letztere bis auf ganz leichte Verdickangen und gelbliche Verfärbungen der Intima. 
Die Aorta erscheint von Anfang an ziemlich weit, mit gelblich verfärbten Stellen der Intima, namentlich weit ist sie im Bogen. Am Uebergang des Aortenbogens in die Aorta descendens sitzt an der binteren rechten Wand eine umschriebene derbe Gerinnselmasse fest auf, die eine Höhe von $6 \mathrm{~cm}$., eine Breite von 3,5 Cm. nnd eine grösste Dicke von $1 \mathrm{Cm}$. hat. Diese Gerinnselmasse ist auf die Oberfläche wie ein Tannenzapfen gerunzelt, aus weissen und grauröthlichen Partien zusammengesetzt. Unmittelbar unter dieser Stelle hat die Aorta noch einen Umfang von $7 \mathrm{Cm}$. und bleibt so weit bis an den Abgang der A. coeliaca. Unterhalb dieser Stelle verengert sie sich und ist etwas über $5,5 \mathrm{Cm}$. weit, um sich nur noch wenig bis zur Theilung zu verschmälern. Während in dem weiten Theile der Aorta reicbliche aber flache, grau durchscheinende, weissliche und gelbliche Verdickungen der Intima vorhanden sind, die hier und da mit einem dünnen gallertigen gelblichen Schleier überdeckt erscheinen, zeigt die Aorta abdom. eine sonst ganz glatte Intima mit verschiedenen gelblich verfärbten Einlagerungen.

Die Drüsen in der Umgebung der Aorta bis zar Bifurcation der Trachea hinauf sind sehr stark geschwellt, besonders stark die im abdominalen Theile. Sie bestehen aus einer grauröthlichen Grundsubstanz, in welche viele trüb weisse oder gelbe Knötchen eingesprengt sind, die versehiedentlich confluiren, aber doch so, dass diese confluirten Stellen noch deutlich eine Zusammensetzung aus einzelnen Knötchen erkennen lassen.

Ausserdem finden sich in den Lymphdrüsen noch reichliche dankelrothe Pünktchen eingesprengt.

Dicht angeschmiegt an diese Drüsen, zum Theil sehr fest mit ihnen zusammenhängend, verläuft der Ductus thoracicus, der auffallend weit erscheint. Im untersten Theile desselben beträgt der Umfang 1,1 Cm. Die Wandung ist glatt, doch sitzen derselben zahlreiche weisse Knötchen auf. In der Gegend des Zwerchfells verschmälert er sich und misst nor $7 \mathrm{Mm}$. im Umfang, um sich nach oben noch mehr zu verschmälern und in der Gegend der Bifurcationsstelle der Trachea einen Umfang ron kaum $4 \mathrm{Mm}$. zu haben. Noch weiter aufwärts erweitert er sich aber wieder etwas und sein Endstäck hat wieder einen Umfang von $7 \mathrm{Mm}$. Auf der ganzen Strecke sitzen auf der Innenfläche des Ductus thoracicus theils vereinzelte theils in Gruppen beisammen stehende miliare weisse Knötchen auf, die besonders reichlich im untersten nnd obersten Theile sind. An letzterem hat die Innenfläche eine röthliche Färbung, während sie sonst blassgrau erscheint.

Auch in den in die Gysterna chyli einmündenden Lymphgefässen bemerkt man eine Einlagerung von solchen Knötchen, vielfach aber auch verbunden mit einer Verdickung der Wand. Namentlich ist dies der Fall an einigen Lymphgefässen in der Nähe der Drüsen an der Wurzel des Mesenteriums (welche ebenfalls geschwellt und von derselben Beschaffenheit wie die Drüsen an der Aorta sind), die deutlich an ihrer gewundenen Gestalt and an ihrem Zusammenhang mit dem Hauptstamm als Lymphgefässe zu erkennen sind. In diesen Lymphgefässen findet sich theils flüssiger dunkelrother Inhalt theils dunkelrothe Gerinnselmassen mit weissen körnigen Einlagerungen.

Milz gross $(450 \mathrm{Grm}$.) dunkelroth, von unzähligen ganz feinen weissen Knötchen durchsetzt. 
Beide Nieren mit reicher Fettkapsel versehen, gross, die eigentliche Capsel schwer abtrennbar; das Gewebe brüchig, weich, etwas dunkelroth. Zeichnung der Rinde etwas verwischt. Magen, Darmkanal, Beckenorgane ohne Besonderheiten, nur im Anfangstheil des Colon kleine umschriebene Hämorrhagien.

Die Musculatar des oberen Theiles des Dünodarms exquisit gelbbräunlich verfärbt. Die'eigentlichen Mesenterialdrüsen nicht geschwellt, wohl aber die an der Wurzel des Mesenteriums und die um das Pancreas herum gelegenen. Das Pancreas selbst mit kleinen weissen (Felt-) Pünktchen versehen.

Nebenaieren ohne Besonderheiten.

L eber ziemlich gross, mit einigen deutlichen feinen weissen Knötchen.

An der Unterfläche beider Hälften des $Z$ werchfells dichtstehende grave und weisse Knötchen.

Mesenterium sebr fettreich.

Beide 0 ptici erscheinen anfallend schmal, hellgrau verfärbt. Breite der Optici $0,3-0,4 \mathrm{Mm}$., ihre Dicke etwa $1 \mathrm{Mm}$; die graue Verfärbung verliert sich jenseits des Chiasma, doch sind auch beide Tractus opt. sehr schmal.

Av den Vierhügeln und Sebhügeln ist mit Sicherheit vichts Abnormes zu erkennen; die Striae acusticae nur ganz rudimentär angedeutet.

Die Retina beiderseits dünn; in der rechten Chorioidea ein weisses birsekorngrosses Knötehen.

Im äussersten Gliede des linken Linsenkerns ziemlich in der Mitte ein kirschkerngrosser, mit dunkelgraurother gelatinöser Masse erfüllter unregelmässig aber scharf begrenzter Erweichungsheerd.

In Betreff des Mikroskopischen ist nur zu bemerken, dass in dem Aortenthrombus nichts Tuberculöses zu eruiren war.

\section{III. $G \times$ u $p$ p e.}

Grosse Venentuberkel im Pfortadergebiet ohne allgemeine acute Miliartuberculose. Fall XIV.

Franz A., 22 Jahre alt, obducirt am 23. Mai 1881.

Hochgradige Tuberculose der linkseitigen Halslymphdrüsen (Hineinwuchern in die Vena jugularis interna). Tuberculose der retroperitonealen Drüsen, der Portaldrüsen, der Milz (mehrfaches Hineinwachern in die Aeste der Vena lienalis), der Leber, der Nieren, Nierenbecken, Prostata, Haroblase, Haroröhre, des Perim toneum, der lungen, der Dura und Pia mater, der Musculatar an der linken Seite des Halses.

Ueber mittelgrosser, etwas abgemagerter Leichnam. Haut trocken, an einzelnen Stellen mit einem Stich in's Bräunliche, z. B. in der Banchgegend und an beiden Vorderarmen. In der linken Hals- und Unterkiefergegend die Haut durch mehrere baselnussgrosse, confluirende Drüsenpackete, die sich ziemlich resistent anfühlen, hervorgebuchtet. $1 \mathrm{Cm}$. unter dem linken Ohre in der Gegend des linken Unterkieferwinkels ist die Haut durch einen wallnussgrossen, sìch weich anfühlenden Tumor vorgewölbt. Dieselbe ist jedoch an sămmtlichen Stellen auf ibrer Unterlage verschiebbar. Der Musc. sternocleidomastoid. sin. durch diese Drüsenpackete, 
die sich, wie sich nach genauer Besichtigung ergiebt, noch an der ganzen linken Halbseite bis zur Clavicula herunter erstrecken, stark nach aufwärts geschoben, gespannt; seine Farbe blassbraunroth, blasser als der rechte.

Auch das Platysma in seiner Oberhälfte links durch Drüsenpackete stark vorgebuchtet; seine Muskelfasern auseinandergezerrt, von blasser Farbe.

In den Muskeln, die sich über das Drüsenpacket, das sich also vom linken Ohr bis zum Schlüsselbein hinerstreckt, ausbreiten, sieht man deutliche graue und weissliche Knötehen von Stecknadelkopf- bis doppelter Grösse. Dabei sind die Muskeln 2 war blass, abgeplattet, grauroth, aber doch anf der Unterlage leicht verschiebbar. Auch die hinter dem Drüsenpacket nach links gelegenen Muskeln zeigen, soweit sie dem ersteren anliegen, diese Knötcheneruptionen in ihrer Substanz. Das Drüsenpacket selbst hat eine Höhenausdehnung von ca. $16 \frac{1}{2} \mathrm{Cm}$., eine durchschnittliche Breite von $8 \mathrm{Cm}$. und eine durchschnittliche Dicke von $4 \mathrm{Cm}$. Es umschliesst in seinem oberen Theile die Vena jug. interna, während der untere Theil derselben nur oberfächlich an der Innenseite des Drüsenpacketes aufliegt. Der Sympathicus and die Carotis sind nur durch lockeres Zellgewebe mit dem Packete verbunden, ebenso der Vagus. Hingegen gehen von den oberen Halsnerven eine Anzahl eine sehr innige Verbindung mit dem Drüsenpackete ein und verlieren sich zwischen dem hinteren Theile der Drüsen, indem sie theils von denselben umschlossen werden, theils an der Oberfläche derselben durch infiltrirtes Bindegewebe befestigt sind. Schneidet man die Vena jugularis interna auf, so ist dieselbe an einer Stelle, etwa $11 \mathrm{Cm}$. oberhalb der Vereinigung mit der Subclavia an ihrer externen Wand sehr fest mit den anliegenden Drüsen verwachsen, die dieselbe bucklig vorwölben. An einer Stelle bemerkt man 2 linsengrosse derbe Verdickungen der Venenintima, die mit einer etwas höckrigen Oberfläche versehen ein gelblichweisses Aussehen zeigen. An den übrigen Stellen sind die vorgewölbten Buckel mit vollkommen glatter glänzender Venenoberfläche tm Lumen versehen. Die Drüsen selbst sind fast durchweg verkäst; nur hie und da finden sich grane, unter das Niveau der Scbnittläche etwas zurücksinkende Theile, in denen man aber auch noch weisse Pünktchen bemerkt. Die Consistenz der Drüsen ist grösstentheils derb, nur an einzelnen Stellen weicher. In einem von dem linken Kieferwinkel her herunterkommenden Venenaste, der einen Umfang von $6 \mathrm{Mm}$. hat, bemerkt man ebenfalls eine $3 \mathrm{Mm}$. lange, $2 \mathrm{Mm}$. breite derbe Verdickung der Intima, die in ihrem äusseren Theile grau durchscheinend, im Innern aber weisslich trübe erscheint. Diese Vene ist von verkästen Lymphdrüsen umschlossen, aber mit der Wand derselben nur durch Jockeres Bindegewebe verbunden. - Auf der rechten Seite finden sich in der Umgebung der Vena anonyma ebenfalls verkäste Lymphdrüsen in geringerer Masse vor, ebenso sind einige verkäste Lymphdrüsen in der rechten Supraclaviculargegend vorhanden.

In der Trachea, der Zunge, Schilddrüse und in den Mandela nichts Besonderes zu bemerken.

Das Herz (300 Grm.) zeigt vollkommen zarte Klappen. Linker Ventrikel 1,3 Cm. dick, $8 \mathrm{~cm}$. hoch. Aorta 6,75 Cm. Pulm. $7 \mathrm{Cm}$. Con. dexter 0,4 Cm. Nirgends in der Musculatur Knoteneruptionen, hingegen zeigt derselbe ein eigenthümlich glänzendes braunes Aussehen. 
Beide Lungen gut lofthaltig; in ihnen ziemlich spärliche stecknadelkopfbis doppelt so grosse derbe weissliche Koötchen, theilweise mit schwärzlicher Umgebung. Ausserdem vereinzelte Conglomerate solcher Knötchen, die bis Erbsengrösse erreichen, nirgends jedoch grössere Heerderkrankungen. Bronchialdrüsen klein, melanotisch. An der Trachea, etwas nach oben eine verkäste Drüse. Die Pleuren frei, mit sehr spärlichen Verwachsungen. -

Bei Eröffoung des Bauches findet sich das grosse Netz als zartes Gebilde. Es ist durchsetzt von einer ziemlich grossen Zahl discret stehender feiner Knötchen. Das Zwerchfell ist mit Leber, Milz, Magen verklebt, während die Dãrme keine Verklebung unter einander aufweisen und auch nur ganz spärliche Knötcheneruptionen zeigen.

Die Milz (320 Grm.) ist auch an ihrer Rückseite mit dem Peritoneum verklebt. Sie zeigt an ibrer Oberfläche weissliche Fibrinauflagerungen; ausserdem aber schimmern hellröthliche, hier und da auch gelbliche Knoten von Stecknadelkopfbis Kirschkerngrösse durch die Oberfläche hindurch, dieselbe flach kugelig hervorwölbend. Auf einem Durchschnitt sieht man in der ganzen Milz vielfache Knoten eingelagert, die aber bei weitem nicht so dicht stehen wie bei der gewöhnlichen acuten allgemeinen Miliartuberculose. Sie sind von wechseinder Grösse, aber sămmtlicb von einer weissgelben Färbung und etwas über die Scbnittläche hervorragend. Sie schwanken von Stecknadelspitze- bis Kirschkerngrösse, die grösseren sehen theilweise zwar gleichmässig gelblich aus und sind mit einem scharfen Rande versehen, andere aber sind am Rande ganz fein ausgezackt und auch im Innern in kleine Unterabtheilungen eingetheilt, so dass es aussieht, als wären dieselben aus einer grossen Zahl kleiner Knötchen zusammengesetzt. Ein Theil der grösseren Knoten erscheint im Innern bröcklich erweicht. Die Pulpa ist gleichmässig dunkelschwarzroth. Präparirt man die Venen in der Milz, so sieht man an verschiededen Stellen auf der Innenfläche ähnliche Eruptionen. Einzelne derselben stellen feine weisse Pünktchen dar, die in einer etwa $\square$ Millimeter grossen Gruppe zusammenstehen und von einem rötblichen Gewebe, das die Intima etwas überragt, zusammengehalten werden. An anderen Stellen sieht man einzelne stecknadelkopfgrosse und grössere stark vorspringende Knoten in der Intima. An einem grösseren Aste unmittelbar in der Näbe des Hilus ist die Hälfte der Venenperipherie eingenommen von einer gelblichen Auflagerung von $1,5 \mathrm{Cm}$. Länge, $\frac{1}{2} \mathrm{Cm}$. Breite und Dicke. Dieselbe springt ziemlich steil ansteigend mit scharfer Begrenzung in das Innere vor. Ihre Oberfläche erscheint im peripherischen Theile glatt, im Centrum grau, weich, wie ulcerirt. Diese grössere Auflagerung erstreckt sich auch über die Wand der Vene hinaus in die Milzpulpa hinein. Bei näherem Zuseben findet sich noch eine allerdings nur erbsengrosse Auflagerung, die anch mit einem Knoten in der Milzpulpa zusammenbängt, an einem mehr peripherischen Aste der Milzvene. -

Der Peritonealīberzug der linken Seite des $Z$ werchfells, sowie der hintere der Milz, ist, wie sich nach Herausnahme der Milz zeigt, mit einer gelblichhöckrigen, festen Verdickung versehen, auf der noch Fibrinmassen auflagern. Diese höckrigen Verdickungen bestehen theils aus kleinen, weisslichen Knötchen in einem grauen verdickten Gewebe, theils stellen sie unregelmässige grössere derbere Plaques dar, die wie aus kleinen Knötchen zusammengeballt erscheinen. Auf der rechten Seite des Zwerchfells sind diese Verdickungen in geringem Maasse vorhanden, wäh- 
rend allerdings auch hier Fibrinverklebungen da sind. Die eigentlichen Verdickungen sind hier hauptsächlich an dem rechten Flügel des Centrum tendineum zo sehen.

In der linken Niere findet sich im oberen Theile und an der Grenze des unteren Drittels an der Hinterfläche je eine Einlagerung von käsigen Knoten. Die im oberen Theile bat eine keilförmige Gestalt, lässt schon durch die Oberfläcbe weissliche Knoten in einem röthlichen, wie narbigen, Gewebe erkennen. Auf dem Durchschnitt sieht man hier einen grauroth verfärbten Nierenkeil, in dem trüb weissliche, unregelmăssig begrenzte Massen eingesprengt sind. Dieser Keil erstreckt sich bis zu der Spitze einer Nierenpapille. Der sich anschliessende Theil des Nierenkelches ist hämorrhagisch verfärbt. Der untere Heerd zeigt nur einzelne stecknadelkopfgrosse weissliche Knötchen in einer grangefärbten Grundsubstanz, während in der zogehörigen Nierenpapille ein haselnussgrosser gelber, rundlicher, in der Mitte bröcklich zerfallener Heerd sitzt und die Verbindung mit der Oberfläche durch eine grössere Anzahl weisslich knotiger Heerde hergestellt wird. Im Nierenbecken an einer Stelle ein graues, scharf vorspringendes Knötchen, ebenso in einigen Nierenkelchen. Die übrige Nierensubstanz grauroth, Zeichnung deutlich. Glomeruli als feinrothe Punkte sichtbar. Masse: 12. 5. 4,5 cm. Urether frei.

In der rechten Niere spärliche miliare Knötchen, die nar am unteren Ende etwas reichlicher sind. Nierenbecken frei. Arteriae ẹt Venae renales beiderseits frei. Beide Nebennieren derb, etwas wässrig aussehend; Rinde nur schwach verfettet; in der rechten Marksubstanz ein weisses stecknadelkopfgrosses Knötchen.

Gallenwege frei.

Magea, Duodenum, Darmschleimbaut, Mesenterialgefässe obne Besonderheiten.

Mesenterialdrüsen gut entwickelt, aber nicht gerade geschwellt. In der Gallenblase mässig reichliche Galle.

Leber (1500 Grm.). Durch die Oberfläche schimmern schon eine Anzahl weisslicher Knötchen. Auf einem Durchschnitt zeigt sich die Leberzeichnung unregelmässig dunkel und bellgrauroth. Man sieht auf der Schnittfläche eine grosse Anzahl grauer und weisslicber und gelber Knoten und Knötchen. Die Portaldrüsen geschwellt, verkäst, ebenso die Drüsen längs des oberen Randes des Pancreas und die Retroperitonealdrüsen, die eine über faustgrosse Gesammtmasse darstellen und sich noch bis an die Arteria iliaca commnnis sinistra hinstrecken.

Aorta und Vena cara frei.

Ductus thoracicus in Brust- und Halstheil frei.

In der Cysterna chyli ein einzelnes, miliares, scharf vorspringendes, gelbliches Knötchen.

Am Ausgang der Harnblase zeigen sicb gruppenweise stehende weissliche Knötchen in einer graven Grundsubstanz. Dieselben sind am reichlichsten auf dem Caput gallinaginis. Schnejdet man in die Prostata ein, so sieht man auf der rechten Seite einen kirschkerngrossen, links einen erbsengrossen gelben Heerd, der wie aus einzelnen kleinen Knötchen zusammengestellt erscheint. Diese Heerde reichen bis an die Oberfläche der Harnröhre heran. In der Harnröhre selbst sitzen in einem leicht gerötheten Schleimhautgewebe ca, 20 miliare scharf vorspringende theils grave, theils gelbliche distincte Koötchen. Vasa deferentia, Samenblasen, Hoden frei. 
In dem Recessus recto-resicalis peritonei reichliche, miliare bis erbsengrosse, gelbliche Verdickungen.

Dura mater, Schädeldach ohne Besonderheiten. An der Basis des Gebirns ist die Pla mater hinter dem Chiasma nervorum opticorum etwas verdickt und mit reichlichen miliaren Knötchen durchsetzt. Ebenso in der Gegend der Fossae Sylvii. Die Ventrikel sebr weit mit leicht opaleseirender wässriger Flüssigkeit erfültt. An der Basis der Schädelhöhle sitzen auf der Dura kleine Knötchen. Im Rückgratskanal ist die Dura mit der Oberfläche der Pia leicht verklebt, letztere an der Hinterfläche stellenweise getrübt mit Knötchen. Solche finden sich auch auf der Innenfläche der Dura und einzelnen feinen Nervenwurzeln. An elnem Foramen intervert. links eine haselnussgrosse verkäste Lymphdrüse.

Im Knochenmark des 0 berschenkels keine Tuberkel.

\section{Mikroskopische Untersuchng.}

Der grösste Venenknoten. Macht man Schnitte senkrecht zar Venenaxe durch den Kooten und die Venenwand, so ergiebt sich Folgendes: Die Venenwand selbst ist bis dicht an den Knoten heran vollkommen normal. In dessen Nähe aber tritt zunächst eine ganz geringe Rundzellenanbäufung auf und dann fasert sich die Vene förmlich auf und verliert sich in der Rundzellenzone des Knotens. Dieser letztere liegt also theils an Stelle der Venenwand selbst, theils ausserhalb, zum grössten Theile aber im Lumen selbst, wie schon die makroskopische Betrachtung lehrte. Betrachtet man den Durchschnitt des Knotens als einen Kreis, so liegen etwa zwei Drittel seiner Fläche im Innern, ein Drittel nach aussen von der Vene, theils im eigentlichen Milzgewebe, theils in einem Bindegewebszuge, welcher der Vene auf der elnen Seite gerade in der Nähe dieses Knotens anliegt. Die Peripherie des Heerdes bildet einen ziemlich spitzen Winkel mit der benachbarten normalen Intima.

Der Knoten selbst besteht aus einem käsigen Centrum, welches von allen Seiten sowobl ausserhalb der Vene als in dem intravenösen Theile mit zelligen Massen umhüllt ist. Diese sind theils Rundzellen mit undeutlicher Zwischensubstanz, theils solche, zwischen denen sich ein deutliches Reticulum (auch im intravenösen Abschnitte) befindet. In dem Theile ausserbalb der Venenwand verlieren sich die Rundzellen allmählich in dem umgebenden Gewebe. In dem intravenösen Theile finden sich auch hier und da in der äusseren Schicht dünne Lagen rotbgefärbten Gewebes mit flachen Zellen. An manchen Stellen, namentlich auf der Höhe des Knotens, reicht das gleich zu erwähnende kernlose Centrum fast bis an die freie Oberfläche und auch in extravenösen Theile springt es vielfach kolbig in die Zellenmassen vor.

Die kernlosen Massen des Centrums bilden bei weitem die Hauptmasse des Knotens. Sie bestehen aus verschiedenen, nicht ganz regelmàssig angeordneten Bestandtheilen. Mebr im peripherischen Theile, also an der Grenze der kernhaltigen Zellen, liegen kernlose runde Schollen, die eher etwas grösser sind, als die benachbarten Rundzellen; nach innen zu aber, auch schon vielfach in den peripherischen Schichten, sind sie za rosenkranzähnlichen unregelmässigen Zügen zusammengesintert. Diese Dinge nehmen alle eine gelbrothe Tinction an. Dann kommen noch mehr nach innen balkige, gelblich gefärbte Züge, mehr in die Länge gezerrt und im All- 
gemeinen der Oberfläche parallel liegend, endlich als Hauptmasse des Centrums gelblich gefärbtes körniges Material. Alle diese Bestandtheile gehen vielfach in einander über und die oben angegebene Anordaung wird bäufig durchbrochen, indem die körnigen gelblichen Massen bis an die kernhaltigen Zellen vorrücken (namentlich am „Boden“) oder die scholligen von allen Seiten umgeben. Manchmal sehen dann die gelbröthlichen balkigen Massen, wenn die Balken dicht gedrängt und mehr parallel liegen, wie Fetzen von kernlosem Bindegewebe aus, die die Käsemasse einschliesst. Kerne finden sich in all diesen Elementen gar nicht oder nar sehr vereinzelt. Hier und da hingegen die von mir als Kerndetritus gedeuteten Körnchen. Die, am Boden namentlich, vorspringenden kolbigen Forteătze des käsigen Centrums sitzen oft mit einem dünneren Stiel auf, so dass, wenn dieser nicht getroffen wird, der Anschein eines isolirten kleinen Käseheerdes entsteht. -

Wie oben erwähnt, grenzt die Vene und der in ihr sitzende Knoten auf der einen Seite an einen mit Gefässen versehenen Bindegewebsstrang, während der grösste Theil der Peripherie unmittelbar an die Milzpulpa anstösst. In diesem Bindegewebe verlaufen in der Nähe des Käseknotens mehrere kleinere Venenästchen. Sie sind mit kernloser rothgelblicher Substanz und mit kernhaltigen Rundzellen vielfach vollgestopft. Ausserdem verläuft aber in diesem Bindegewebsstrang eine kleine Arterie, die auf der einen Seite von dem Käseheerde und zwar auf einer kleinen Strecke des Längsverlaufes (wie Schnittserien lebren) erreicht wird. Dabei ist an einer Stelle diese Käsemasse in die Wand eingedrungen und hat dieselbe vollkommen bis tief in die Media hinein ersetzt. Der innerste Theil der Media entbehrt ebenfalls seiner normalen Muskelelemente und an deren Stelle ist nor eine Anhäufung von Rundzellen nachzuweisen. Die Intima selbst ist an dieser Stelle und noch eine ganze Strecke weiter stark verdickt zo derbem, mit flachen spärlichen Kernen versehenem Bindegewebe und von Blatgefässen durchzogen. An einer kleinen Stelle ist aber das Gewebe auch dieser Verdickung der Intima kernlos und fahler gefärbt. Durch diese Verdickung, die etwa ein Drittel des Arterienumfangs einnimmt, wird das Lumen der Arterie verengt. Dass sich die Verdickung über die Grenzen der zerstörten Media hinerstreckt, zeigt sich sowohl auf solchen Querschnitten, welche die zerstörte Mediapartie ebenfalls enthalten, als auch an Schnittserien die jenseits dieser letzteren fallen. Dann sitzt auf einer ganz normal aussehenden Media noch eine flache halbmondförmige Verdickung der Intima auf der Seite auf, welche dem Knoten der Vene zugekehrt ist. Weiterbin freilich verschwindet diese Verdickung an Stellen, wo der Käseknoten von der Wand der Arterie entfernter llegt.

Derjenige Theil der Vene, der frei von der Ein- und Auflagerung des grossen Knotens ist, grenzt überall an die Milzpulpa dicht an. In dieser sitzen mehrere fast erbsengrosse Knoten sehr nahe an der Aussenfläche der Vene. Sie bestehen aus einem kernlosen Centrum (körniges Material und schollige Massen) und einem kernreichen Mantel, der das Centrum gleichmässig umgiebt. Zwischen den Rundzellen desselben sieht man stellenweise eine Art Reticulum, stellenweise nicht. Einer der Knoten geht bis unmittelbar an die Vene heran, ohne aber in sie einzudringen, ein anderer dringt durch die Wand bereits hindurch, die hier ihrer bindegewebigen Elemente verlustig gegangen und ron Rundzellen erfültt ist. Die Rundzellen gehen in der 
Umgebung dieser bindegewebsfreien Stelle noch eine Strecke weit in die bindegewebshaltigen Theile der Vene in geringer Menge hinein. Da wo diese Bundzellenmassen die Innenfläche der Vene erreichen, liegt auf der Intima ein aus blättrigen rothgefärbten Massen und blauen Kernen zusammengesetzter flacher Buckel auf, der etwas pilzförmig in seinen ăusseren Theilen überhängt und so die kleine Stelle überschreitet, in welcher die Media durch Rundzellengewebe ersetzt ist.

Die anderen Milzvenentuberkel sind im Ganzen dem eben geschilderten grössten sehr ähnlich gebaut. Das Centrum kernlos, bald mit, bald ohne Kerndetritus, nach aussen davon kernlose Balken und Schollen oder fädiges Fibrin, endlich der Mantel, an Rundzellen reich, mit spärlicher, z. Th. netzförmig angeordneter Interceltularsubstanz. In den untersuchten Knoten (auch in den miliaren) fehlten Riesenzellen gänzlich. In sämmtlichen Fällen lag ein grösserer oder kleinerer Theil des Knotens in dem die Venen umgebenden Milzgewebe, ein anderer im Venenlumen. Beide Theile hingen öfter nur durch eine Art Stiel mit einander zusammen, so dass bel Sebnittserien Stellen vorkommen, in welchen sie anscheinend durch gesundes Gewebe getrennt neben einander lagen. Stets war im centralen Theile die Venenwand selbst in der Verkäsung z. Th. aufgegangen, kernlos, körnig.

Die übrigen Knoten des Milzparenchyms waren mikroskopisch, was ihre Grösse betrifft, in noch mannichfaltigeren Abstufungen zu sehen, als man das makroskopisch vermuthen konnte, da man viele derselben nur mikroskopisch fand. Die Construction war zwar denen der bisher bescbriebenen in vielen Fällen absolut gleich, doch fanden sich in kleinen Knoten oder in solehen, welche milkroskopisch aus mebreren kleineren zusammengesetzt erschienen, manchmal Langhanssche Riesenzellen vor, die in den ganz grossen und in vielen anderen sonst ganz ähnlich aussehenden bleineren fehlten. Die meisten bestanden aus einem, mit den verschiedenen oben erwähnten Theilen versehenen Centrum von rundlicher Gestalt, auch wohl mit deatlichen kolbigen Fortsetzungen, aber auch obne solche, und einem Mantel von Rundzellen obne Riesenzellen. Sehr viele der Knoten reichten mit einem Theile in ein Malpighi'sches Körperchen, welches an seinem Arterienast kenntlich war. Dieser letztere war in seiner Wand oft kernlos, und dann nur an der Elastica kenntlich, das Lumen häufig mit kernhaltigem oder kernlosem Material verstopft.

Die $K n$ ôtchen in der Leber waren dem Bilde des schematischen Tuberkels insofern mehr entsprechend, als sie ausser dem verkästen Centrum etc. auch reichliche Langhans'sche Riesenzellen aufwiesen.

Die Halsiymphdrüsen waren an den meisten Stellen mit nur ganz wenig kernhaltigem Gewebe umgeben, sonst ganı kernlos, körnig. Die an ibnen verlaufenden Nervenstämme in ein schwieliges Bindegewebe eingeschlossen, in dem hier und da Rundzellen sassen. Ueberbaupt war das Gewebe in der Umgebung der käsigen Drüsen meist ein schwieliges.

Die verdickte Stelle in der Y. jugularis sin. hatte ein käsiges Centrum und eine mit spärlichen Rundzellen durchsetzte derbe bindegewebige Ungebung, die den grössten Theil der Verdickung ausmachte und auch die Kăsemasse nach dem Lumen hin fast überall in dicker Schicht bekleidete. Die glatten Stellen zeigten eine intacte Venenwand. - 
Epikritische Bemerkung.

Trotzdem hier über verschiedene Organe die Tuberculose ausgebreitet ist, kann man doch nicht von einer acuten allgemeinen Miliartuberculose sprechen. Die Lungenheerde sind spärlich, und, wie die schiefrige Umgebung lehrt, zum grossen Theil alt, in der Milz und Leber sind zwar auch miliare Knötchen vorhanden, aber daneben viele grössere Heerde. Der Urogenitalapparat befindet sich im Zustande einer chronischen Urogenitaltuberculose. Eine Anzahl Organe, die bei acuter allgemeiner Miliartuberculose so regelmässig befallen sind, sind hier frei (Herz, Schilddrïse etc.). Man kann den Zustand als chronische Allgemeintuberculose auffassen.

Die Venentuberkel stellen in diesem Falle gewissermaassen zwei Generationen dar. Die erste sind die beiden Knoten in der Vena jugularis interna dextra, die durch die schwielige Verdickung grösser erscheinen als die wirkliche tuberculöse Stelle darin; von hier aus ist eine chronische Allgemeintuberculose mit vorwiegender Betheiligung der Milz und des Urogenitalapparats entstanden, von den Knoten der Milz sind dann die Heerde an den Aesten der Vena lienalis hervorgerufen, die ihrerseits die Leber mit sehr reichlichem Tuberkelgift versehen haben.

Liebbaber von Curiositäten mache ich noch auf die schöne Tuberculose in den Halsmuskeln aufmerksam, die von den "scrophulösen" Drüsen ausgeht. Von letzteren ist auch an kleinen Stellen die Venenwand afficirt und so das Gift in den Blutstrom gekommen.

\section{Fall XV.}

Gottlob Friedrich N., 40 Jahre alt, Schachtmeister aus Weissensee, obducirt am 8. October 1881 .

Verkäsung der Bronchialdrüsen. Tuberculöser Knoten in der Vena anonyma sinistra. Grosse käsige Milzheerde mit Cavernenbildung. Ausgedehnte Tuberculoseder Wurzeln der Vena lienalis. Tuberculose der Vena portar. und V. hepat. Sehr reichliche grosse Lebertuberkel. Vereinzelte grosse Nierentuberkel. Sehr wenig Lungentuberkel. Tuberculose des Peritoneums, namentlich am Diaphragma. Tuberculöse Pleuritis links. - Acute Endocarditis mitralis. Hämorrhagis che Nephritis. Blutungen in den Nierenkelchen. Verschluckungspoumonie rechts unten. Kehlkopfgeschwüre.

Mässig gut genäbrter Mann.

Herz $320 \mathrm{Grm}$. Linker Ventrikel 1,1 Cm. dick, $8 \frac{1}{2}$ hoch. Aortenumfang 7 . Pulmonalis 7. Conus dexter 0,4 dick. Klappen zart, aber an der Spitze des hinteren Zipfels der Mitralis, am Schllessungsrande eine erbsengrosse böckrige, weiche 
Wucherung; am vorderẹn Zipfel genau gegenüber von der eben erwähnten Affection eine ganz kleine, stecknadelkopfgrosse, weissliche Wucherung. Musculatur hellbraun. Im Herzen keine Tuberkel.

In der linken Ple urahöhle ca. $\frac{2}{2}$ Liter klarer Flüssigkeit mit wenig Fibringerinnseln. Auf dem Pleuraüberzug des Diaphragma eine reichliche Anzahl miliarer, sehr zarter Knötchen. Auf dem Pleurabezuge des linken Unterlappens spärliche zarte, graue Knötchen.

Die linke Lunge völlig lufthaltig, ödematös, mit ganz vereinzelten, stecknadelkopfgrossen käsigen Kuötchen in Ober- und Unterlappen. Aeltere Affectionen in der Spitze fehlen vollkommen. - Die rechte Lunge äbnlich, aber der Unterlappen schwach luftbaltig, stellenweise luftleer, geröthet; die Schnittfläche theils glatt, dunkelroth, an umschriebenen Stellen gekörnt, graurötblich. Die Bronchialdrüsen gross, melanotisch, mit grauen Körnchen. Die Venen und Arterien frei von Knötchen. Bronchialschleimhaut leicht geröthet.

Am Kehlk opf, im hinteren Theile beider wabren Stimmbänder je ein flaches, etwas zerfressenes Geschwür. Dicht am oberen Rande des Aortenbogens zwischen Subclavia und Carotis sin. sitzt eine wallnussgrosse, derbe, verkäste Drüse, mit einzelnen weichen Stellen daran. An ihrem hinteren Rande noch eine kleine haselnussgrosse Drüse, ehenso verändert; am vorderen Rande dieser Drüse verläuft der Nervus phrenicus, am hinteren Rande der Vagus. Der letztere ist mit ihr sehr eng verbunden und im oberen Theile seiner der Drüse benachbarten Partie zu einem spindelförmigen Gebilde auf das Doppelte verdickt; Aortenintima vollkommen frei, ebenso die übrigen Arterien und der Ductus thoracicus.

Die Vena anonyma sin. ist ebenfalls mit der Drüse sehr eng verbunden und man bemerkt an einer Stelle, wo sie der Drüse anliegt, ein stecknadelkopfgrosses graues Knötchen, auf der Intima frei in das Lumen vorspringend (diese Verhältnisse konnten erst am herausgeschnittenen Präparate constatirt werden).

Schilddrüse ohne Tuberkel.

Hirn ohne Besonderheiten.

Auf dem Peritonealiuberzug des Dịahragma eine reichliche Anzahl miliarer grauer Knötchen links, viel spärlicher nach rechts hin; die Knötchen auf der peritonealen Seite sind reichlicher als die früher erwähnten auf der pleuralen. Auf dem äbrigen Peritoneum sitzen nur ganz zerstreute, miliare Knötchen, am reichlichsten im kleinen Netz und auf dem Mesenterium in der Nähe des Darmes. Sehr reichlich sind dieselben noch im Recessus recto-vesicalis. Art. lienalis etwas geschlängelt, frei; ebenso der Hautstamm der Vena lienalis frei.

Milz mit ihrer Umgebung stellenweise durch Fibrinmassen verklebt, $400 \mathrm{Grm}$. Schon von aussen bemerkt man an der Milz gelbe, durchschimmernde Heerde, namentlich in der Nähe des unteren Endes. Dicht am Hilus sitzt ein haselnussgrosser erweichter; gelber Knoten, der nur durch elne dünne Lamelle vom Peritonealraum abgetrennt ist. Auf dem Durehschnitt finden sich noch 2 andere, ganz besonders grosse Heerde. Der eine, im Allgemeinen unregelmässig begrenzte, in der Nähe des unteren Endes der Milz etwa von Wallnussgrösse, reicht stellenweise bis an die Oberflāche heran und namentlich ist auch die vorhin erwähnte, gelbe Stelle eine Art kurzer Ausläufer dieses grossen Heerdes. Dieser Heerd hat eine exquisit käsige 
Beschaffenheit, ist sehr unregelmässig, aber scharf hegrenzt, stellenweise derb und fest, in der Mitte jedoch in eine Art von Caverne zerfallen, die mit einem schmierigen, gelblichen Brel angefüllt ist und sebr ouregelmässige, fetzige Wände bat. In der Nähe des Hilusendes des Heerdes verläuft eine der Hauptwurzeln der Vena lienalis, an deren Umgrenzung die käsige Masse dicht herantritt. Schneidet man dieselbe auf, so finden sich auf der Intima reichliche, gelbe, stecknadelkopfgrosse, vorspringende Knötchen. Verfolgt man dann die Verästelung der Vena lienalis nach dem käsigen Heerde hin weiter, so zeigen sich die feineren Verästelungen ganz ausgefüllt von käsigen, derben Wucherungen, die an der Mündung in die grösseren Aeste ein wenig in dieselben hineinragen. Andere, namentlich die etwas grösseren Verästelungen sind vollkommen durchgängig, aber an thren Wänden sitzen vielfach ähnliche Knoten wie am Hauptstamm, aber auch noch viel feinere, kaum stecknadelkopfgrosse, graue Knötchen. An den erwähnten grösseren käsigen Knoten schliesst sich dann nach aussen eine wie ein Infarct aussehende unregelmässig keilförmige Stelle an, die eine verwaschen graurothe Farbung zeigt und bis an die Peripherie des lateralen Milzrandes beranreicht. Sie ist gegen ibre Umgebung scharf durch eine etwas hellere, gelbe Linie abgesetzt. Ausser diesem grössten Knoten und dem in der Năhe des Hilus sitzt ein anderer weiter oben, ziemlich in der Mitte, von dem Peritoneum durch eine $1 \mathrm{Cm}$. breite Zone abgetrennt. Er bat $3 \mathrm{Cm}$. im Durchmesser, und besteht aus einer ca. $2 \mathrm{Mm}$. breiten, derben Randzone und einer grossen Höhle, welche mit puriformer Masse erfüllt ist. Die Innenfläche der Höhle ist allerdings ranh, aber doch bet Weitem nicht so fetzig und mehr geglättet als die der anderen Heerde. - Ausser diesen sitzen in der Milz noch eine grössere Anzahl käsiger Heerde von Stecknadelkopf- his Kirschkerngrösse zerstreut, zwischen denen noch reichliches, dem Anscheine nach unverändertes, dunkelgraurothes Pulpagewebe liegt. Präparirt man die Aeste der Milzvene noch weiter, so findet man noch an verschiedenen Stellen ausser der ersterwähnten theils miliare, grane Koötchen, theils grössere (über stecknadelkopfgrosse) gelbe Körnchen, theils diffuse käsige Wucherungen, die kleinere Aeste ganz ausfüllen und in die grösseren noch eine kleine Strecke weit bereingeben.

Gallenwege frei. Die Magenschleimhaut zeigt in der Mitte der Curv. min. eine flache, undeutliche Narbe. Die Musculatur des Pylorus ist auffallend dick (bis $8 \mathrm{Mm}$.), grau, durchscheinend glasig, derb.

Leber sehr gross, $2500 \mathrm{Grm}$., zeigt an ibrer Oberfliche vielfach durchschimmernde, gelbe und weisse käsige Heerde, die auch häufig, namentlich an der Unterfläche über die Serosa hervorragen und dann oft mit einem zarten Fibrinhofe umgeben sind. Auf einem Durchschnitt ist die Läppchenzeichnung der Leber im Allgemeinen undeutlich, das Gewebe erscheint heligrauroth. Es ist durchsetzt von einer Unzahl weisslicher und grauer Heerde, die unregelmässig zerstreut in der Leber sitzen. Ihre Grösse varifirt von der einer Stecknadelspitze bis zu Kirschkerngrösse. Die grösseren sind in der Mitte erweicht und enthalten gelbe oder grünliche, bröcklige Masse. Die Gallenwege sind, soweit sie sich mit der Scheere verfolgen lassen, frei von Knötcheneruptionen. Hingegen sitzen in vielen Verästelungen der Vena portae, dle vollkommen durchgängig sind, an der Wand graue und gelbe in das Lumen vorspringende Knötchen, die regelmässig mit einem käsigen Heerde 
in der Umgebung zusammenhăngen. An ganz vereinzelten Stellen findet man auch in der Vena hepatica stecknadelkopfgrosse, graue, ähnliche Knötchen.

Die portalen Lymphdrü sen stark geschwellt, grauroth, mit miliaren gelben Knötchen versehen.

Darmschleimhaut, Blase, Prostata etc. frei.

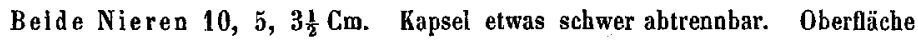
grauroth, mit deutlichen Venenverästelungen und mässig reichlichen, scharf umschriebenen, dunkelrothen Punkten. Schon durch die Oberfiäche schimmern vereinzelte, weissliche, anscheinend erbsengrosse Knoten durch, und an der einen Stelle ist ein noch grösserer gelber Heerd vorhanden, der die Oberfläche erreicht und sich in einen keilförmigen Heerd in der Niere selbst fortsetzt, dessen Basis etwa $1 \mathrm{Cm}$. beträgt. Die erwähnten Stellen sind verkäste Massen, von denen der grösste im Innern erweicht ist. An einzelnen Stellen finden sich Blutungen in den Nierentelchen. Die Rindenzeichnung ist undeutlich, fleckig, grau und gelbroth, mit vereinzelten, dunkelrothen, scharf umschriebenen Pankten. Rindenbreite 0,8. Marksubstanz blass, grauroth.

Weder im Nierenbecken, noch im Nebenhoden oder im Vas deferens käsige Wucherangen. Im rechten Oberschenkelbein keine Koötchen.

Chorioidea nicht nachgesehen.

Mikroskopische Untersuchang.

Die Knoten und Knötchen in den Milzvenen stimmten in ihrer mikroskopischen Structur ganz mit denen des vorigen Falles überein. Ebenso im Ganzen auch die Milzknoten selbst. Die mittleren erschienen häufiger aus mehreren kleineren, noch deutlich abgegrenzten Heerden zusammengesetzt, bei den grösseren war so etwas nicht nachzuweisen, anch der Rand zwar oft sehr unregelmässig gestaltet, aber nicht deutlich in Knötchen gegliedert. Die kleineren zeigten oft Riesenzellen, die grösseren bestanden nur aus einem käsigen Centrum mit kernreichem Mantel. In den beiden ganz grossen war der letztere vielfach verhälnissmăssig kernarm. Auch über die mit käsiger Masse erfüllten Venenäste ist nichts Besonderes zu bemerken, ihre Wand war schwer zu erkennen. - Bemerkenswerth war nur das Verhalten der nicht tuberculösen Theile der Milz. Hier waren die kleinen Venenästchen, die also nicht mit Knötchen in Verbindung standen, sehr reich an grossen epithelioiden Zellen, welche theils der Wand ansassen, theils das Lumen erfüllten. Manchmal sahen sie dann wie Epithelschläuche aus.

Die Knoten in den Pfortaderverästelungen der Leber waren den Milzvenenheerden durchaus analog gebaut, auch was ihren Zusammenhang mit den im Leberparenchym sitzenden Knoten and die Beschaffenheit der Venenwand anbelangt. Mikroskopisch fanden sich auch in der Leber mit kăsigen Massen erfüllte, von undeutlicher kernloser oder umgekehrt an $\mathrm{R}$ und zellen reicher Wand begrenzte Pfortaderästchen vor, die den makroskopisch erkennbaren mit Käsemassen thrombosirten Milzvenenästen entsprachen. Manchmal waren solche kleine Aestchen noch mit kernhaltigen Bundzellen erfüllt, oder es ragten von der Wand her kleine, an Kernen reiche Knöspchen in's Lumen binein. Stets lagen so veränderte Gefässe im Bereiche von Parencbymknoten.

Diese letzteren selbst waren denen der Milz ähnlich gebaut, nur fanden sich 
hier auch an der Peripherie der grösseren ab und zu Riesenzellen und die kleineren waren viel reicher an solchen, wäbrend sie an den Venenknoten nicht deutlich waren. Die Käsemasse der grōsseren enthielt stets Gallenpigment im Innern.

In der Umgebung der Heerde sah man öfter noch erhaltene kleine Gallengänge. Die Arterien ebenfalis wohl erhalten oder mit undeutlichen resp. ganz verschwondenen Kernen der Wand, wenn die Gefässe im Bereiche der Knoten lagen. Das Lumen dann erfüllt mit Leucocythen oder kernlosem Material.

Die Lebercapillaren an den freien Stellen enthielten in grosser Anzabl dieselben epithelioiden Zellen, whe die kleinen Milzgefăsse.

Das Knötchen in der Vena anonyma war genau so construirt wie die kleinen Milzvenenknötchen im vorigen und in diesem Falle. Auch hier die grössere Ausdehnung der Wucherung jenseits der Intima im Lumen, gegenüber der Grösse des kernlosen Heerdes in der Media; auch hier eine dünnere Verbindung der erkrankten Stelle der Venenwand mit dem ausserhalb der Vene gelegenen Käseheerde, so dass an manchen Schnitten der Serie der Venenknoten von letzterem unabhängig schien. Die Venenwand sehr reich an Rundzellen weit über das Knötchen binaus. Nach aussen von ihr die Käsemasse der Drüse fast unmittelbar angrenzend. Dieser ausserbalb der Vene gelegene kleine Käseheerd mit Rundzellenumgebung war nur einer der vielen, die in dem schwieligen Gewebe lagen, welches die verkästen Drüsen umgab. Manche derselben, mit schönen Riesenzellen versehen, reichten bis dicht an die Vagusbündel, die im Uebrigen an der spindlig aufgetriebenen Stelle durch ein sehr reichliches Bindegewebe auseinander gedrängt waren.

Die kleinen verkästen Stellen verschmolzen z. Th. mit den grösseren verkästen Partien der Drüsen, in deren Umgebung sich Rund- und Riesenzellen fanden.

Aehnlich waren die Portaldrüsen.

Der keilförmige Heerd in der Milz war ein Infarct, wohl bedingt durch Thrombose einer kleinen Arterie.

\section{Epikritische Bemerkung.}

Auch hier baben wir keine Ueberschuttung der Organe mit Miliarknötchen, wie bei der acuten allgemeinen Miliartuberculose, wenn auch eine geringe acute Knötcheneruption in den Lungen nacbweisbar ist. Sonst haben wir es mit einer chronischen Allgemeintuberculose zu thun, die ihren Ursprung von dem Hineinwuchern der Tuberculose in die Blutbahn in der Gegend der Vena anonyma sinistra hat. ob gerade das kleine Knötchen der einzige Eintrittsort war, wage ich nicht zu sagen, die Untersuchung wurde erst an den ausgeschnittenen Organen gemacht.

Die Peritoneal- und Pleuratuberculose in den beiden Jetzten Fällen hat mit der Blutinfection selbst nichts zu thun, sondern ist durch ein directes Uebergreifen von den Milz- und Leberheerden auf das Bauchell und Fortschreiten auf die Pleura hervorgerufen. Auch die Menin- 
gealtuberculose des vorigen Falles rechne ich nicht zur Blutinfection, wie spätere Theile dieser Beiträge ausführlicher besprechen sollen.

Die Venentuberkel zerfallen hier in drei Generationen 1) ein solches, das von den käsigen Bronchialdrüsen direct abhängt. Von hier oder einem anderen früher bestandenen ging das Gift ins Blut. 2) Die indirect nach Absetzung des Giftes aus dem Blute in die Milz und nach Wucherung von Tuberkelknoten in letzterer entstandenen Tuberkel der Milzvenenäste, die einem directen Uebergreifen der Milzknoten ihren Ursprung verdanken, 3) die Knötchen der Pfortader- und Lebervenenäste, welche von den Leberknoten direct ausgehen. Diese letzteren sind durch Tuberkelgift (zum grössten Theil wenigstens) hervorgerufen, welches von den Milzvenentuberkeln in die Pfortader und Leber gelangte.

Fassen wir die bisher beschriebenen Fälle von Venentuberculose zusammen, so finden sich dieselben auf folgende Venen vertheilt:

V. pulmonalis a) Miliarknoten: z. B. Fall 3, 6, 12, 13 etc. und die Fälle von Mügge.

b) Grosse Heerde: Fall 1, 2, 3, 6, 7, 8, 10.

v. lienalis: $5,14,15$.

v. portarum: 12,15 .

V. hepatica: 15 .

V. azygos: 12.

V. anonymae: $4,15$.

V. jugularis interna sin.: 14 .

V. suprarenalis 9 .

V. thyreoidea 11.

\section{Abschnitt.}

Verwerthung des casuistiseben Materials für die Lehre von der tuberculösen Blutinfection.

Wenn wir nunmehr in eine nähere epikritische Besprechung der geschilderten Venenveränderungen eingehen, so ist die erste Frage die:

Sind die geschilderten Producte wirklich tubercnlöser Natur? 
Für die miliaren Knötchen erledigt sich diese Frage nach den obigen Schilderungen von selbst. Auch die grösseren Lungenheerde mit ihren zahlreichen Langhans'schen Riesenzellen und typischen kleinsten Tuberkel in den peripherischen Theilen dürften keinem Zweifel in der Deutung als tuberculöser Producte begegnen. Der grosse Heerd in der V. suprarenalis ferner enthält zwar nur wenig Langhans'sche Riesenzellen und typische miliare Knötchen mit solchen and epithelioiden Zellen, doch genügen diese immerhin für die einfache Diagnose der Tuberculose im anatomischen Sinne. Im Uebrigen werden gerade diese polypösen Formen weiter unten noch eingehender in Bezug auf ihre Eigenart besprochen werden. Nur far einige der grossen Knoten in den Milzvenenästen könnten einige schematische Histologen vielleicht Anstand nehmen, sie als echte Tuberkelproducte anzuerkennen. Sie bestehen zwar aus einem käsigen Centrum mit Umgebung von Rundzellen, sind aber zu gross um als Miliarknötchen zu gelten and enthalten auch in ihrer Peripherie keine dentlichen miliaren Tuberkel oder auch nur Langhans'sche hiesenzellen. Aber gerade sie zeigen, wie wenig für die tuberculöse Natur eines Krankheitsproductes eine einfache Schematisirung genügt ${ }^{1}$ ). Sie zeigen einmal in den Venen selbst die mannichfaltigsten makroskopischen Uebergänge za miliaren Knötchen, die ebenfalls keine Riesenzellen enthalten, andererseits sind sie durchaus gleich construirt mit grösseren Heerden der Milzpulpa, welche ihrerseits wieder viele Uebergänge zu kleineren Knoten mit oder ohne

1) Martin (Arch. de phys. 1880 und 1881) ist durchaus im Irrthum, wenn er meint, dass er zuerst die Unzulänglichkeit der einfachen mikroskopischen Untersuchung für die Beurtheilung des wahren Taberkels statuirt habe, wenn auch vielleicht der Name "Psendotuberkel “ vorher nicht gebraucht seỉn dürfte. Sein Irrthum, der in dem Satze gipfelt "L'étude des tubercules locales est baśé toute entière (von Marti n selbst hervorgehoben) jusqu"à présent sur l'emploi da microscope", ist einfach daraus zu erklären, dass er von den deutschen Arbeiten nur ungemein mangelhafte Referate vor sich gehabt haben muss. Das gilt selbst für die von ihm erwähnten Autoren. In meiner ersten Mittheilang z. B., die Martin sogar citirt, sind die Grundsätze für die Beartheilung dessen, was man tuberculös im ătiologischen Sinne zu nennen hat, schon angefübrt, ja wie ich glaube noch präciser, als bei Martin. Noch schärfer hat dieselben Cohnheiu nachber in seinem Aufsatz: "Die Tuberculose vom Standpunkt der Infectionstheorie" entwickelt. Auch andere deutsche Autoren haben Aehnliches wohl schom bemerkt. 
Riesenzellen, sowie zu grösseren aus kleineren zusammengesetzten mit Riesenzellen in dem kernhaltigen peripherischen Theil zeigen. Diese Uebergänge sind sehr grober Art und durchaus nicht mit den „Zellübergängen " zu verwechseln, die vielfach missbraucht und mit Recht etwas in Misscredit gerathen sind. Die käsigen Heerde in der Milz muss man daher entweder sämmtlich oder garnicht als Tuberkel bezeichnen, und da das letztere bei der exquisit tuberculösen Natur eines Theils derselben, bei der exquisit tuberculösen Beschaffenheit der Leber-, Peritoneal- etc. Knötchen gewiss Niemanden einfallen wird, so müssen auch die grösseren Venenheerde für Tuberkel angesprochen werden. Aebnliches gilt für die Heerde in der Leber des Falles 15 und die Pfortaderknoten, die freilich fast sämmtlich noch in das Bereich der miliaren gehören. Die Käseheerde der Nebennieren selbst zeigen ebenfalls analoge Verhältnisse, wenn auch der Heerd in der Vene deutliche Riesenzellen etc. aufweist. Mebr wird an dieser Stelle über die grossen Käseknoten bei Tuberculose nicht zu bemerken sein, es genügt für das Verständniss der Venenveränderungen.

Sind aber alle die geschilderten Venenveränderungen tuberculöse, so müssen sie von irgend woher mit Tuberkelgift versorgt worden sein. Die nächste Frage ist daher:

\section{Wie tritt das Tuberkelgift an die Venen heran?}

A) Für die miliaren Knötchen in den Lungenveneri z. B. in unsern Fällen 6, 12, in den Mügge'schen Fällen, für die der V. portarum im Falle 12, der V. azygos, Fall 12, ist die Sache ziemlich klar. Sie sehen genau so aus, wie alle andern Miliarknötchen, die über verschiedene Organe zerstreut sind, und es liegt kein Grund vor einen andern Entstehungsmodus anzunehmen. Da diese andern aber ihr Gift auf dem Blutwege bekommen haben müssen, so kann man das Gleiche immerhin auch von diesen feinen Venenknötchen annebmen. Eine nehensächliche Frage wäre daun die, ob das Gift aus dem Hauptgefäss oder aus den Vasa vasorum abgesetzt wäre. Mügge scheint sich für das erstere zu entscheiden. Man könnte es nach seinen Auseinandersetzungen in der That für nicht gut denkbar balten, dass das Gift von den Vasa vasorum her die gefässlose Intima durchsetzt, auf welcher nach ihm erst die Knötchen aufsässen, während die Venenwand selbst frei sei. Dies wäre schon nicht so undenkbar, aber in meinen Fällen war sogar 
stets bei Serienschnitten in der Mitte eine Stelle bemerkbar, welche die Intima durchsetzte und in die Media hineinragte. Auch bei ganz grossen Knoten haben wir übrigens oben Aehnliches geschildert.

Als begünstigendes Moment für die Absetzung des Giftes aus dem Hauptlumen führt Mügge noch das an, dass der Strom nur in den Venen langsam genug wäre, um eine solche zu gestatten. Daher kämen solche Miliarknötchen niemals in den Arterien vor. Diese Annahme ist aber irrthümlich. Schon Marchand (damals in Breslau) zeigte mir einen Tuberkel der Aorta und Dr. Huber hat hier ebenfalls solche gefunden, die die exquisiteste Tuberkelstructur, Riesenzelle, verkästes Centrum etc. aufwiesen.

Aus meinen Mittheilungen wird man übrigens entnehmen, dass diese Miliarknötchen nicht blos, wie man nach den Mügge'schen und meinen früheren Mittheilungen glauben könnte, in den Lungenvenen, sondern auch in Körpervenen vorkommen.

B) Ebenfalls einfach, ja noch viel klarer liegen die Verbältnisse in den Fällen 14 und 15, in welchen es sich um Knoten in der Milzvene handelt. Die Milzvenenäste, die förmlich eingemauert in die Milzpulpa sind, sind gewissermaassen disponirt dazu, an Erkrankungen der letzteren Theil zu nehmen, wenn diese nur die Fähigkeit haben sich auf die Umgebung auszubreiten, und ich bin überzeugt, dass man bei fleissigem Nachsuchen noch viel öfter Milzvenentuberkel finden muss. In unsern Fällen kann man nun dieses Uebergreifen der tuberculösen Veränderungen des Milzgewebes auf die Venen Schritt fïr Schritt verfolgen. Man sieht einzelne Knoten in der Nähe der Vene bis an die Aussenfläche der Wand reichen; andere haben dieselbe durchsetzt und es findet sich auf der Intima bereits eine zarte Zellanhäufung, noch andere wölben sich mehr und mehr in's Innere vor. Sind die Venen sehr klein, so wird die ganze Peripherie in die tuberculöse Veränderung aufgenommen, die Vene obliterirt. Bei grösseren Veneu betrifft der Durchbruch der Wand nur einen Theil der Peripherie, der übrige bleibt zunächst frei und der Blutstrom wird nicht unterbrochen.

Ganz genau so liegen die Vertältnisse bei den Pfortadertuberkeln des Falles 14.

Dem Princip nach nit dem Verhalten der Milzvene übereinstimmend ist dann das der V. anomyma im Falle 4 und 15 und der V.jugularis im Falle 14. Auch hier kommt das Gift deutlich 
aus den benachbarten verkästen Drü sen nur mit dem Unterschiede, dass die Venenwand erst fest mit diesen Drüsen verwachsen war, ehe dies Uebergreifen statthatte. Dass in der That diese exquisit "skrophulösen" Drüsen die Fähigkeit besassen Tuberkelgift von sich ausgehen zu lassen, beweist die schöne Miliartuberculose in den angrenzenden Halsmuskeln bei Fall 15, sowie die Entstehung echter Miliarknötchen in der Umgebung im Falle 14, in welchem sie sogar auf den Nervus vagus übergriffen und eine Art umschriebner Perineuritis tuberculosa erzeugten. Aehnlich liegen endlich auch die Beziehungen der Nebennierentuberkel zu denen der Venen. Die des Nebennierenparenchyms gehen auf kleinere über und ein vielleicht isolirt liegender in dem Gewebe um die grosse Vene auf die letatere. -

Sehr bemerkenswerth seheint im Vergleich zu dem der Venen das Verhalten der Arterien. Diese gehen in unsern Fällen, wenn sie klein sind in der Verkäsung ganz unter, thrombosiren und verlieren ihren Charakter als offne Gefässe. Interessant ist aber namentlich die Beschaffenheit der Wand einer Arterie im Falle 15. Auch hier ist die Adventitia und Media von dem tuberculösen Prozess zerstört, aber die Intima ist nicht von demselben durchwachsen, sondern sie ist vielmehr einfach regenerativ verdickt, wie bei einer atheromatösen oder syphilitischen Zerstörung der anliegenden Gewebsschichten und sogar, wie bei einer solchen, an einer kleinen Stelle kernlos (obne Rundzellenwucherung ete. in der Umgebung). Auf eine Erklärung dieses Unterschiedes kann ich mich hier nicht einlassen.

C) Schwieriger waren die Verhältnisse bei den polypösen Lungentuberkeln zu constatiren, ja es ist mir einigermaassen zweifelhaft, ob ich im Falle $7 \mathrm{zu}$ einem Resultate gelangt bin. In meiner vorigen Mittheilung hatte ich die Frage nach den Uebertritt des Giftes offen gelassen und nur darauf hingewiesen, dass man in künftigen Fällen besonders die Umschlagsstelle der Pleura in ihren Beziehungen zu den Venen beachten solle. Da in diesen Fällen kein Grund dafür vorlag, so fällt diese Möglichkeit des Giftübertrittes von selbst fort.

Dass von einem der Miliartuberkel der Lunge etwa die Ursache für die Venentuberculose ausgehen sollte, ist selbstverständlich von vornherein undenkbar, denn die frischen Knötchen können diese 
mächtigen alten Wucherungen nicht ihrerseits erzeugt haben. Das Gift muss vielmehr von einer Stelle aus übergreifen, die ebenfalls älteren Datums ist, und die ausserhalb der eigentlichen Wand liegt, wenn man nicht etwa die sehr unwahrscheinliche Annahme substituiren wollte, dass die Venenwand von dem eingeathmeten Gifte direct afficirt werden könnte. Es ist freilich in den Fällen, in welchen nicht Reste der (verdiekten) Elastica interna über die Lage der Intima orientiren, ungemein schwierig zu sagen, ob die tuberculöse Wucherung sich noch in den Grenzen der Venenwand hält oder im umgebenden Gewebe liegt!

Nichtsdestoweniger bin ich in den Fällen 6 und $8 \mathrm{zu}$ einem Resultate gekommen. Im Fall 6 (es handelt sich nur um den Knoten in einer Vene der rechten Lunge, der der linken blieb zur makroskopischen Demonstration reservirt) schien die Sache auf den ersten Blick ungemein einfach zu sein. Bei der makroskopischen Untersuchung lagen der Vene grössere verkäste Drüsen anscheinend dicht an, und es schien als ob von diesen unmittelbar die Tuberculose des Gefässes inducirt sei. Das erwies sich aber als irrthümlich. So weit diese grossen Drüsen reichten, war immer zwischen ihnen und der Venenwand eine Schicht gesunden Gewebes. Nun sehen wir ja oft genug von einem käsigen Heerde Túberkelwucherungen auch mit freien $Z$ wischenräumen ausgehen, aber in unserm Falle liess sich doch noch ein sichererer Nachweis des Zusammenhangs finden, indem man einen etwa erbsengrossen käsigen Heerd mit Miliartuberkeln, Rundzellenwucherung, Netzwerk etc. fand, der ausserhalb der Vene lag, aher mit dem käsigen Centrum des Venentuberkels in cinem ganz unmittelbaren Zusammenhange stand. Dieses Gebilde konnte man ganz gut für eine grösstentheils verkäste tuberculöse kleine Lymphdrüse ansehen, von deren normalen Theilen allerdings nichts mehr übrig war. Es würde sich also hier um das Uebergreifen einer kleinen lymphatischen Anbäufung mit tuberculöser Entartung direct auf die Venenwand handeln.

Beim ralle 8 spielte sich die Ueberwuchung auf einem sebr kleinen Raume $a b$ und das Auffinden derselben gelang erst nach einer recht mühsamen Durchsuchung hintereinander folgender Schnitte.

Der Uebertritt liess sich hier nicht wie im Falle 6 am centralen Ende, sondern erst an der äussersten Spitze des peripherischen Endes 
auffinden und zwar in der kleinen Vene, welche an der Stelle ausmündete, wo in der grösseren eine mit kleiner Basis aufsitzende polypöse Wucherung sich vorfand. Am peripherischen Ende dieser kleinen Vene nun sass seitlich, da wo eime noch kleinere Vene in die erstere mündete, ein Knötchen, so gross wie ein Stecknadelkopf auf, das in das umgebende Bindegewebe hineinragte und aus lymphoiden und Riesenzellen bestand, an die sich nach der Venenseite hin die Käsemasse anschloss, die die ganze Wand des Gefässes durehsetzte und mit der Käsemasse im Innern desselben direct zusammenhing. Nach dem Bindegewebe zu klangen die Rundzellen gewissermaassen allmählich $a b$. Dies war die einzige Stelle auf der ganzen langen Strecke, wo die Käsemasse das Gewebe der Adrentitia ja der Media überschritt. Aber was war das für eïn Knötchen? Ich glaube es ebenfalls als ein Jymphatisches Knötchen deuten zu müssen, denn es enthielt exquisites Lungenpigment, mit dem selbst die Riesenzellen, und gerade nur bier in der ganzen Venenstrecke, versehen waren. Dieses Kohlenpigment deutet darauf hin, dass das Knötchen mit dem Innern der Alveolen in Lymphgefässverbindung stand. Einige kleine Lymphfollikel lagen übrigens auch in der Nachbarschaft innerhalb des hier ziemlich reichlich vorhandenen Bindegewebes. Sie waren ebenfalls zum Theil verkäst. Es kann demnach augenscheinlich von diesen ganz kleinen Lymphapparaten her, auf welche Arnold in neuerer Zeit die Aufmerksamkeit gelenkt hat, das Tuberkelgift auf eine benachbarte Vene übergreifen.

Im Falle 7 endlich war auf der ganzen, so ausgedehnten tuberculösen Strecke, nur am centralen Ende eine Partie aufzufinden, welche als die Uebertrittsstelle angesehen werden konnte. Hier fehlte auf einer grösseren Strecke die Elastica ganz, während sie sonst uberall nur in geringer Ausdehnung defect war und die Tuberkelwueberung nirgends deutlich die Venenwand überschritt. Doch war hier soviel von der Käsemasse erweicht, dass bur ein schmaler Streifen in den Schnitten erhalten blieb, von dern es freilich nicht zu beweisen ist, ob er etwa den Rest einer mit der Venenwucherung zusammengeschmolzenen und durch Erweichung gleichlalls zerstörten Lymphdrüse darstellt. Die Möglichkeit ist gewiss nicht abzuleugnen.

In jedem Falle sehen wir, dass von einer der Vene 
anliegenden und nit ihr verschmelzenden kleinen Lymphdrüse auch in den Lungen das Gift in jene übertreten kann und zwar bald am centralen bald am peripherischen Ende der Wucherung. Dass aber in eine Lymphdrüse das Gift von aussen her leicht gelangen kann, ist selbstverständlich, und so wäre für diese Fälle der Weg des Tuberkelgiftes in das Blut hinein klar genug.

Es muss nun weiter untersucht werden, wie eigentlich die Pathogenie dieser Venentuberkel ist, soweit man das bei dem jetzigen Stande der Tuberkellehre überhaupt kann.

Für die miliaren Knötchen wird eine Bemerkung weiter nicht zu machen sein, für sie gilt eben Alles, was wir überhaupt von der Pathogenie miljarer Knötchen wissen. Wohl aber müssen wir einige Worte über die grösseren Knoten bemerken.

In meiner ersten Mittheilung hatte ich mich auch über diese Frage nicht weiter ausgelassen. Ich hatte nur bemerkt, man könnte vielleicht dieselbe so entscheiden, dass man an "tuberculös organisirte" Thromben dächte. Thrombenbildungen spielen in der That eine gewisse Rolle bei diesen Bildungen, aber doch, wie ich jetzt glaube, wohl nur eine secundäre. Keinesfalls ist der Vorgang so aufzufassen, als ob sich zuerst ein grösserer Thrombus bildete und in diesen erst die tuberculösen Producte hineinwücbsen. Und doch sprach gerade der Anblick der grossen Lungenvenenheerde zunächst sehr für eine solehe Auffassung. Sie imponiren auf den ersten Blick entschieden als „Thromben“ durch ihre polypöse Gestalt, die an die der klappenständigen marantischen Thromben erinnert, und aus Analogie mit diesen augenscheinlich ähnlich entstandenen Gebilden konnte man selbst für die nicht polypösen an eimen enlsprechenden Vorgang denken. Ich bin aber nachträglich nocb auf eine Angabe Virchow's ${ }^{1}$ ) gestossen, die beweist, dass es noch eine Stelle giebt, in welcher tuberculöse Producte ebenfalls eine polypöse Gestalt annehmen, ohne dass hier an Thrombenbildung zu denken wäre, nehmlich den 4. Hirnventrikel. Für diese Stelle erwähnt Virchow ausdrücklich, die merkwürdige Form, welche sich fast ganz in die vierte Hirnkammer hervorwölbt - beinahe der einzige Fall, wo grössere Tuberkel in einer gleichsam polypösen Form vorkommen". In den Venen hätten wir also dann doch noch einen zweiten Ort für diese sonst so seltene Tuberkelform.

1) Die krankhaften Geschwïlste. Bd. 2. S. 664 . 
Wenn demnach die makroskopische Gestalt nicht für die Annahme eines grösseren, tuberculös erst nachträglich durchwachsenen Thrombus spricht, so sind noch eine Anzahl unterscheidender Momente vorhanden, welche diese Gebilde, ganz abgesehen von den im anatomischen Sinne echten tuberculösen $\mathrm{Zu}$ thaten, als Dinge sui generis gegenüber den gewöhnlichen marantischen Thromben kennzeichnen:

Bei den nunmehr doch schon recht zahlreichen Einzeltuberkelheerden in den Venen, ist niemals ein Zustand gefunden worden, der einem „unorganisirten" d. b. in diesem Falle noch nicht tuberculös entarteteu grösseren, Thrombus entspräche. Ein solcher müsste nach Analogie der andern Venenthromben, die nicht etwa pyämischer Natur sind, eine rauhe, graue Oberfläche zeigen und von der eigenthümlichen Consistenz der gewöhnlichen prämortalen Venengerinnseln sein. Hier finden wir aber sämmtliche derartige Vegetationen, soweit dieselben nicht erweicht sind, für das blosse Auge ganz spiegelnd glatt, ja gerade die jüngsten, d. h. am wenigsten vorgewölbten runden Heerde sind so beschaffen und von diesen sieht man alle möglichen Uebergänge zu kugligen und połypösen.

Ebenso ist das gelbe käsige Ausseben, ferner das polypöse Aufsteigen mitten aus der Continuität der Vene durchaus abweichend auch von älteren gewöhnlichen Thromben.

Auch das mikroskopische Verhalten ist von dein der letzteren verschieden.

Die jüngeren Stadien bestehen nie aus jener unregelmässigen Mischung kernhaltiger Leucocythen und ibres Derivates, des Fibrins, eventuell mit eingeschlossenen Heerden rother Blutkörperchen, wie die gewöhnlichen marantischen Thromben, sondern haben stets schon an der 0 berfläche Gewebsbildung und erst im Innern amorphe kernlose Massen. Aber auch diese letzteren zeigen durch ihren Zusammenhang mit solchen ausserhalb des Venenlumens oft genug an, dass sie nicht aus Leucocythen des Blutstroms abstammen, wie die Fibrinmassen der Thromben es thun. Die älteren Heerde wieder bestehen nicht wie ein gewöhnlicher organisirter Thrombus aus scholligen, oft hyalin glänzenden ${ }^{1}$ ) Fibrinmassen mit einer

1) Ueber die Umstände, unter welchen sich aus gewöhnlichem Fibrin byaline Massen bilden, habe ich dieses Archiv Bd. 79 S. 121 gesprochen. 
diffusen Gewebsbildung, die in der Nähe der Venenwand am stärksten ist, sondern auch sie zeigen eine Schale organisirten Gewebes, welche körnige Massen einschliesst und welche gerade oft an der Venenwand selbst ganz frei von bindegewebigen Elementen ist. Dieses Verhalten giebt sich an den alten bandförmigen Auflagerungen in den Lungenvenen schon makroskopisch zu erkennen, indem auf Durchschnitten der gelbe käsige Kern von grauem Gewebe ganz umschlossen erscheint.

Ich glaube man wird am besten thun, zunächst diese Bildungen einfach als ein Uebergreifen des tuberculösen Prozesses auf die Venenwand anzusprechen und statt von tuberculös organisirten Thromben von "grösseren Venentuberkeln " oder "tuberculöser Phlebitis"zu reden. Das Wesen des Vorgangs bleibt ganz dasselbe, wie das in den benachbarten Lymphdrüsenknoten, Milztuberkeln etc. Das Zellmaterial, welches dabei neu entstebt, entstammt in dem einen Fall den Organen resp. ihren Gefässen, im andern der Venenwand resp. den Vasa vasorum. Rückt der Prozess schneller vor, so wird die Decke nur aus dem gewöhnlichen rundzellenreichen Gewebe besteben, welches in der Umgebung von Tuberkeln sich vorfindet. Geht der mit dem Tuberkelprozess verbundene Zerstörungsvorgang aber nur langsam weiter, so gewinnt das neugebildete Gewebe Zeit sich weiter zu organisiren und bildet jene dicken Schalen von Bindegewebe, welche den Käseheerd nach dem Lumen zu abschliessen, während nach der Venenwand hin die feste verdickte Elastica die Grenze bildet. Es verhält sich bier ganz so wie bei den tuberculösen Knoten in dem Lungengewebe selbst, die sich bei langsam vorrückendem Tuberkelprozess mit schwieligem, schiefrigem Gewebe umgeben. Nichtsdestoweniger ist aber ein wirkliches Sistiren der tuberculösen Gewebsschädigung nicht anzunehmen. Das Fortglimmen der Giftwirkung giebt sich im Gegentheil in' jenen kleinen Rundzellenwucherungen und Miliartuberkeln zu erkennen, wie wir sie namentlich in den Seitentheilen finden. Gelegentlich kann der Prozess auch stärker angefacht werden und die Decke, die vielleicht gar Jahre lang schon den Blutstrom von dem centralen Giftheerd abschloss, wird dann durchbrochen und das Virus communicirt mit dem kreisenden Blute.

Thrombenbildungen können sich gelegentlich hinzugesellen und zwar einmal wenn der Prozess von Anfang an auf 
die Innenfläche so schnell vorrückt, dass das Endothel an umschriebenen Stellen zerstört und nicht gleich wieder ersetzt wird ${ }^{1}$ ). Dann können sich Fibrinniedersehläge bilden. Als solche sind die öfters zu findenden (auch von Mügge erwähnten) flachen Auflagerungeu (in Carmin) rothgefärbter Substanz anzusehn, die sich an den Kuppen der Tuberkel mikroskopisch nachweisen liessen, die aber immer sehon mit kernhaltigen Zellen durchsetzt waren. Es scheint also auch hier sehr bald eine Gewebsneubildung zu erfolgen, welebe das Endothel wohl auch ersetzen und weitere Ablagerung von Fibrin hindern kanu.

Sodann kommt es bei der Erwejchung der grossen Heerde, wenn die Decke ausgiebig zerstört ist, zu grösseren Fibrinablagerungen.

Die sonderbare Gestalt der polypösen Langenvenenheerde und des gleichaussehendeo der Nebennierenvene erklärt sich einfach daraus, dass die frei in den Blutstrom hineinwachsenden Tuberkelmassen, wenn sie gross genug sind, von dem Blutstrom in der ihm entsprechenden Richtung abgebogen werden. Diese Form der Tuberkel findet ein Analogon in den Wucherungen von bösartigen Gesehwülsten in die Venen hinein, die man häufig finden kann, wenn man auch bei ihnen die Gefässe genügend präparirt. (Stets wird man venöse Krebsknoten z. B. finden, wenn secundäre Lungencarcinome vorhanden sind.)

Jetzt kommen wir weiter zu der Frage: Kann von diesen Heerden eine tuberenlöse Blutiufection ansgehen, und unter welchen Umständeu geschieht dies?

Für die grossen Tuberkel der Lungenvenen habe ich das schon in meinen vorigen Beiträgen entwickelt und ich könnte daranf verweisen, wenn nicht einem Forscher wie Arnold ${ }^{2}$ ) die Beweiskraft meiner damaligen Auseinandersetzungen nicht genügt $\mathrm{zu}$ haben schiene, und wenn nicht noch einige neue Momente zu entwickeln wären.

Wenn noch durch gar keine anderweitigen Ermittlungen die infectiöse Kraft des Tuberkelagens nachgewiesen wäre, selbst dann könnte man, glaube ich aus diesen Befunden den Schluss auf eine

1) Ueber das Verhalten des Endothels konnte ich (wie gewőhnlich bei Venen aus Leichen) nichts entscheiden, es ist daher von ihm nie die Rede gewesen,

2) Dieses Archiv Bd. 87 S. 145. 
solche mit einer gewissen Wabrscheinlichkeit machen. Wenn wir hierbei zunächst an die Fälle von acuter allgemeiner Miliartuberculose mit grossen Venentuberkeln denken, so können wir einmal statuiren, dass die Grösse dieser Gebilde, das organisirte Ausseken der Oberfläche, die starke Verkäsung im Innern dafür bürgt, dass die in Rede stehenden Affectionen nicht gleichzejtig mit den disseminirten miliaren Knötchen der Organe entstanden sind; sondern dass sie viel âlteren Datums sein müssen.

Andererseits ist das bäufige Vorkommen bei allgemeiner acuter Miliartuberculose im Gegensatz zu dem sonstigen zum mindesten sehr seltenen Vorkommen derselben ein Zeichen dafür, dass beide in einem causalen Zusammenhange stehen. Ich habe wenigstens noch nie Gelegentieit gehabt, solche Dinge ohne Beziehung zu einer Ueberschwemmung des Blutes mit Tuberkelagens zn sehen (wegen der Solitärtuberkel der Milzverie s. u.) und auch das bisherige absolute Schweigen der bewährtesten Autoren über sie spricht vielleicht für ihre Seltenheit im Allgemeinen.

Giebt man aber einmal zu, dass ein Causalzusammenhang zwischen ihnen und der acuten allgemeinen Miliartuberculose bestebt, so kann derselbe in Anbetracht des grösseren Alters der grossen Venentuberkel nur darin bestehen, dass die Gebilde die Ursache der Miliartuberculose seien.

Man müsste das, glaube ich, zugeben, auch wenn noch kein Mensch einen Beweis für die Verschleppbarkeit des Tuberkelagens oder gar für die Infectiosität der Tuberculose im Sinne eines Virus beigebracht hätte. Aber da wohl Niemand an einer einfachen Verschleppbarkeit des Tuberkelagens zweifeln kann, der auch nur an das Fortschreiten der Tuberculose in den Lymphbabnen z. B. am . Darm denkt, so ist für Jeden der Zusammenhang zwischen diesen grossen ulcerirten Gebilden und einer tuberculösen Blutüberschwemmung ein so klarer, diese Fälle der sonst so unklaren allgemeinen acuten Miliartuberculose werden so verständlich, dass ein Bedenken absolut nicht mehr aufkommen kann. - -

Nun giebt es aber Fälle von grossen, selbst zahlreichen Tuberkeln in offenen Venen, welche nicht zu einer echten acuten allgemeinen Miliartuberculose Veranlassung geben und gerade diese scheimbaren Ausnabmen sind sebr interessant und stützen die Lehre von der tuberculösen Blutinfection durch solche Gebilde. 
Es sind oben zwei Fälle ausführlich geschildert, in denen grosse Knoten in der Milzvene sassen und wo doch keine acute allgemeine Miliartuberculose (im obigen Sinne!) vorlag, trotzdem die Venen nicht obliterirt waren. Hingegen zeigt die Schilderung der Leberveränderungen in den Fällen, dass hier doch eine bedeutende Verschleppung von Tuberkelagens in die Pfortader binein statthatte, denn die Lebern sind so mit Tuberkeln und zwar auch mit grossen durchspickt, wie man das nie bei der gewöhnlichen Lebertuberculose, ja auch kaum bei acuter allgemeiner sieht. Verschleppt ist also das Gift, aber in den übrigen Theilen des Körpers sind nur sebr spärliche Massen von Miliarknötchen von demselben und auch nur im Falle 15 erzeugt worden. Die dieselben veranlassenden geringen Giftmassen finden vielleicht gar die Erklärung ihres Ursprungs in den Tuberkeln der Lebervenen etc., nicht in denen der Pfortader und ihrer Wurzeln. Jedenfalls besteht keine acute allgemeine Miliartuberculose, keine plötzliche Ueberschwemmung des Gesammtkreislaufes mit Tuberkelgift - und doch ist es in die Blutbahn und sogar von grossen Heerden her (s. unten) eingetreten. Wie soll man sich das erklären?

Man kann sozusagen alle Tage constatiren, dass selbst recht reichliche Tuberkel in der Leber vorkommen, obne dass sonst im Körper andere vorhanden wären, deren Ursprung man auf Giftpartikel im Blute zurückführen müsste. Wie kommen die Giftmassen aber in die Leber? Meiner Erfahrung nach findet man in den bei weitem meisten Fällen dieser Art tuberculöse Prozesse im Darm (Geschwüre oder verkäste kleine Follikel). Es liegt nun sehr nahe anzunehmen, dass demnach von hier aus $d$. h. durch die Pfortaderwurzeln das Gift aufgenommen wurde. Ja es giebt sogar, wie wir gelegentlich zeigen werden, Befunde, welche darauf hinweisen, dass auch ohne Darmläsion die Pfortader Gift aus dem Chymus aufnimmt. Wie es scheint, besitzen die Darmwurzeln der Pfortader viel mehr wie andere Gefässe die Fähigkeit, Tuberkelgift zu resorbiren, was vielleicht mit ihrer besonderen Beziehung zur Darmresorption überhaupt im Zusammenhange steht $^{1}$ ).

1) Dass die Leber auch aus dem Gesammtkreislauf Gift anfnehmen kann, lehrt jeder Fall von acuter allgemeiner Miliartuberculose. Ob aber gerade die Leber isolirt hăufig solches aus demselben entnimmt, scheint mir noch fraglich, wenn auch hier die Analogie mit bösartigen Geschwülsten eher dafür spricht. 
Jedenfalls sehen wir also auch unter andern Umständen die Leber is olirt mit Tuberkelgift vom Blute ber inficirt und das würde also heissen: Die Leber besitzt die Fähigkeit nicht nur Seminien bösartiger Geschwülste, sondern auch das Tuberkelgift, welches ihr dureh das (Pfortader-) Blut zugeführt wird in ähnlicher Weise zurückzuhalten, wie dies die Lymphdrüsen mit dem Gifte vermögen, welches ihnen die Lymphgefässe zuführen. Die obigen beiden Fälle fügen dem nur noch hinzu, dass sogar grosse Mengen von Tuberkelgift, welche durch die Pfortader in sie gelangen, durch die Leber sequestrirt werden können.

Wir würden also von denjenigen Venentuberkeln, welche acute allgemeine Miliartuberculose durch Uebersch wemmung des allgemeinen Kreislaufes mit dem Gifte erzeugen können, die der Milzvene und überhaupt wohl die der Pfortaderwurzel ausnebmen müssen. -

Aber auch sonst bracht durchaus nicht jeder Venentuberkel zur Entstehung einer acuten allgemeinen Miliartuberculose Veranlassung zu geben (ebenso wenig, wie jeder Tuberkel des Ductus thoracicus), So sehen wir im Falle 14 und 15 Tuberkelbildung in Körpervenen und doch fehlt hier eine Erkrankung in jener Form. Allerdings ist das Gift in die Blutbahn getreten, aber es hat sich nur in einem Theile der bei typischer acuter Miliartuberculose befallenen Organe deponirt und der Organismus ist nicht so rasch zu Grunde gegangen wie bei letzterer Erkrankung. Es sind dafür die Local wirkungen in der Milz etc. stärker gewesen, wie wir das späterhin einmal ausführlicher erörtern wollen. Es ist also eine chroniscbe generalisirte Tuberculose entstanden mit verhältnissmässig spärlichen acuten Beigaben in den Organen. Wie kommt das? Nach den obigen Auseinandersetzungen ist das sehr wobl zu verstehen. Eine acute allgemeine Miliartuberculose setzt eine Ueberschwemmung des Blutes mit Tuberkelgift voraus. Würde sich nun freilich das letztere im Blute sebr schnell vermehren können, wie etwa das Milzbrandgift, so würde schon eine sehr kleine Giftmenge, die in's Blut trit,, genügen, um sehr bald eine schwere Allgemeinvergiftung des Körpers zu Stande zu bringen.

Ich habe den Eindruck, dass Milz und Nieren mehr dazu disponiren, als die Leber, Tuberkelgift vorzugsweise in sich zurüekzuhalten. 
Im Allgemeinen (mit Ausnahmen, die uns bier nicht interessiren) ist aber das Tuberkelgift, wie die klinischen Beobachtungen und die Cohnheim'schen Experimente an der vordern Augenkammer lehren, ein sehr langsam wachsendes Gift, von dem es auch noch nicht nachgewiesen ist, dass es sich im Blute vermehrt. Tritt nun von diesem eine sehr geringe Menge auf einmal in's Blut und werden diese geringen Mengen durch Festhalten in den Organen immer wieder aus dem Kreislaufe ausgeschaltet, so kann eine reichliche Bildung vieler gleichzeitigoder kurz nacheinander entstehender Knötchen nicht erfolgen. Das wird nur möglich sein, wenn der Heerd, aus welchem das Blut das Gift entnimmt, von vornherein an das vorüberfliessende Blut immer wieder grosse Massen von Tuberkelgift abgiebt, so dass dasselbe binnen kurzer Zeit reichliche Mengen davon erhält, die dann in die Organe deponirt gleichzeitig oder schnell nach einander eine grosse Anzahl Knötchen entstehen lassen, an denen der Organismus bald zu Grunde geht. Der Heerd, der viel Gift an's Blut abgiebt, muss aber viel davon enthalten d. h. muss ein grosses Depot von solchen repräsentiren. Dies wird dann der Fall sein, wenn die ältere Tuberkelwucherung, von welcher die Blutinfection ausgeht, von bedeutender Grösse ist, wenn sie also entweder einen einzelnen verkästen grossen Knoten, oder eine grosse Masse kleinerer repräsentirt. Das erstere traf bisher für die Venen, das letztere für dén Ductus thoracicus in meinen Fällen zu. Namentlich stellten jene polypösen Knoten ganz besonders grosse mit dem Lumen der offenen Gefïsse in Communication stehende Heerde infectiösen Käses dar. In jenen oben erwähnten beiden abweichenden Fällen aber fanden sich nur ganz vereinzelte kleine Wucherungen, von denen die im Falle 14 in der Vena jugularis nur deshalb noch etwas grösser erschienen, weil die zwei kleinen Käseheerde von einer grossen Masse schwieligen Gewebes umschlossen waren, die sie vielleicht schliesslich wieder ganz vom Blute separirten ${ }^{\mathbf{1}}$ ).

1) Ob übrigens das aufgefundene kleine Knötchen der Vena anonyma sin. im Falle 15 wirklich den Ausgangspunkt für die chronische Allgemeininfection darstellt, will ich durchaus nicht behaupten. Seine Anwesenheit ist nur ein Zeichen dafür, dass die verkästen Drüsen überhaupt auf die Venen übergriffen, der schuldige Tuberkel kann in einer längst obliterirten kleinen Vene gesessen haben. Grössere Knoten aber fehlten ganz sicher an dieser Stelle. 
Je grösser der Knoten ist, je plötzlicber er seinen giftigen Inhalt in's Blut entleert, desto stürmischer müssen die Erscheinungen der acuten allgemeinen Miliartaberculose sein und umgekehrt.

Da fernerhin der Tuberkelheerd, welcher die acute Miliartuberculose wirklich erzeugen soll, älter sein muss, als die durch sein, dem Blute mitgetheiltes Gift hervorgerufenen Knötchen der Organe, so ist es klar, dass die Tuberkel des Endocards ebensowenig als die feinen frischen Venenknötchen irgend etwas mit der Genese der in Rede stehenden Krankheit zu thun haben können. Vou diesen Knötchen (ebenso wie von den Endocardknötchen, auf deren fast regelmässiges Vorkommen ich schon mehrfach hingewiesen habe) kann ja freilich auch wieder etwas Gift in's Blut ubergehen, aber damit diese zerstreuten Tuberkel überhaupt entsteben konnten, muss das Blut schon vorher reich an Tuberkelgift sein, was Mügge übrigens auch hervorhebt. So finden sich denn solche Knötchen in Fällen (z. B. 12), wo man die Entstehung der acuten Miliartuberculose auf ganz sichere Weise anderweitig erklären kann. Die miliaren, zerstreuten frischen Tuberkel der Venenintima in den Mügge'schen Fällen, sowie in Fall 3, 6, 12 etc., haben demnach für die Pathogenie der acuten allgemeinen Miliartuberculose gar keine Bedeutung. Ihr Interesse liegt im Gegensatz zu den alten, grossen Heerden nur darin, dass durch sie das Dogma von der Immunität der Venenintima gegen Tuberculose ebenfalls zerstört wird. Dje kleineren älteren Heerde können hingegen sehr wohl eine Uebergangsform oder chronische allgemeine Tuberculose erzeugen.

Kann man nun wohl annehmen, dass in allen Fällen der acuten allgemeinen Miliartnberculose solche Veränderungen der Blut- oder Lymphwege gefunden werden müssen, welche den jetzt erörterten Bedingungen entsprechen?

A priori möchte ich das (für Erwacbsene wenigstens) jedenfalls bejahen und es frägt sich nur, wie weit die bisherige Erfahrung eine solche aprioristische Annahme unterstützt. Wenn erstere die letztere fest begründen soll, so müsste eigentlich in allen Fällen von acuter allgemeiner Miliartuberculose eine entsprechende Veränderung jener Wege aufzufinden sein, welche den besprochenen Anforderungen entspricht. Sollte dies aber vorläufig nicht zu erreichen sein, so müsste doch wenigstens in der Mehrzahl der Fälle 
die Quelle der Blutinfection aufzufinden sein und der Umstand, dass man diese nicht immer findet, müsste sich aus bestimmten Fehlerquellen erklären lassen.

Nachdem ich in drei Fällen hintereinander die grossen tuberculösen Affectionen in den (offenen) Lungenvenen gefunden hatte, hatte ich die Hoffnung immer die Quelle des massenhaften Eintritts von Tuberkelgift in's Blut zu finden. Diese Dinge waren bisher unbeachtet geblieben und wenn man die Po afick'sche Tuberculose des Ductus thoracicus berücksichtigte, so konnte man denken, die Frage der acuten allgemeinen Miliartuberculose so weit wenigstens gelöst zu haben. Aber so glatt ging die Sache nicht. Bis zum 10. Januar 1881 hatten wir unter 14 Fällen nur 4 Mal das Glück die Quelle des Gifteintrittes genügend zu eruiren. Seitdem habe ich selbst (bis zum 3. Februar 1882) fünf neue Fälle secirt '), in denen sämmtlich die Aufgabe gelöst wurde, Dr. Huber, mein College, einen gleichen, zwei wurden seit jenem Zeitpunkt in meiner Abwesenheit in einem Feriencurse secirt und dabei die Quelle der Blutinfection nicht gefunden, aber auch nicht das Venengebiet etc. genau untersucht.

Das Gesammtresultat ist also folgendes:

Vor dem Auffinden der Venentuberculose secirt 2 Fälle.

Die Quelle der Blutinfection nicht gefunden in 13 Fällen

$$
\text { gefunden }-13 \text { - (wenn }
$$

Fall 11 als positiver gilt).

Diese letzteren vertheilen sich folgendermaassen:

Ductus thoracicus 3 Fälle (darunter Fall 12 und Fall 13, der dritte ist in diesem Aufsatz nicht erwähnt, weil Venentuberkel dabei nicht gefunden wurden).

Vena pulmonalis: 8 Fälle (Fall 1, 2, 3, 6, 7, 8, 10 dieser Veröffentlicbungen und der Fall von Dr. Huber).

Vena thyreoidea 1 Fall? (11).

Vena suprarenalis 1 Fall (9).

Es ist demnach bei Einrechnung von Fall 11 genau in der Hälfte der. Fälle der Quelle der Infection nicht gefunden, in der Hälfte gefunden. Das wäre gegenüber der früheren völligen Unkenntniss über diese Dinge immerhin schon ein Resultat, aber doch kein ge-

1) Die Fälle 7, 8, 9, 13, und einen Fall vom 17. Februar 1881, bei welchem eine Tuberculose des Ductus thoracicus ohne Venentuberculose sich fand. 
nügendes, wenn wir uns nicht zweier Fehler schuldig gemacht bätten. Einmal baben wir in der Zeit der geringen Ausbeute den Ductus thoracicus oft erst nach Entfernung der Hals- und Baucheingeweide (incl. des Mesenteriums) untersucht, also nur den Brusttheil, dann aber haben wir die Körpervenen nicht genügend berücksichtigt, namentlich eine derselben nicht, an welche ich am wenigsten gedacht hätte: die Vena suprarenalis. Wie wir oben gesehen haben, kann von dieser sehr wohl die Blutinfection ausgehen und es ist bemerkenswerth, dass unter den negativen Fällen nicht weniger als viermal grössere Käseknoten in der Nebenniere notirt sind. Auch die Nieren, die Prostatavenen und die Spermaticae müssen in Zukunft genau untersucht werden, denn unter jenen Fällen sind wiederum vier mit Urogenitaltuberculose. Wenn man bedenkt, wie oft ein Anfänger bei einer Lungenarterienembolie den zugehörigen Thrombus nicht findet, während der geïbtere sehr selten in dieser Lage ist, so wird man uns, die wir diesen Dingen gegenüber gewisse "Anfänger" waren, die grosse Zahl von Fehlsectionen schon verzeihen. Es ist immerhin bemerkenswerth, dass wir jetzt, wenn die zwei Fälle des Feriencurses abgerechnet werden, in 6 Fällen hintereinander die $Q$ uelle der Blutvergiftung gefunden haben.

Seitdem ich erkannt habe, dass eine Vene wie die Vena suprarenalis die Quelle für eine acute allgemeine Miliartuberculose werden kann, sind meine Hoffnungen, diese Quelle immer aufufinden etwas herabgesetzt, denn wer kann alle Venen (incl. der des Rückgrats z. B.) präpariren? Aber für das Princip wird es schon genügen, wenn die Stelle des Gifteintritts in der grossen Mehrzabl der Fälle eruirt wird, die Fehlsectionen werden dann durch die grosse Menge der Venen erklärlich, unter denen sich die schuldige immerhin der Nachforschung einmal entzieben kann.

Jedenfalls ist in Zukunft keine Section von acuter allgemeiner Miliartuberculose fur vollstïnàig anzusehen, in welcher nicht die Verhältnisse des Ductus thoracicus und der Venen auf's genaueste berücksichtigt sind. Als practische Regel möge man sich dabei merken, dass man in erster Linie stets die Lungenvenen und den Ductus thoracicus berücksichtige, in zweiter diejenigen Venen, welche in der Nähe eines älteren Käseheerdes verlaufen. - 
Wenn wir nun endlich noch eine Antwort auf die Frage versuchen, warum bei Phthise so selten acute allgemeine Miliartuberculose vorkommt, so kann diese vorläufig nur vermuthungsweise gegeben werden. Ich denke mir, dass bei der Lungenschwindsucht neben dem einfach tuberculösen Prozesse, durch die zerstörten Lungenmassen bedingte noch andere "Entzündungsreize“ thätig sind, die die Venen leichter zur Obliteration führen, als weun das Lungengewebe in der Nähe der Venen nicht zerstört ist. Wenn natürlich, was vielleicht seltener ist, eine andere Vene des Körpers oder der Ductus thoracicus bei gleicbzeitiger Phthise erkrankt, so kann von hier das Blut mit Tuberkelgift überschüttet werden. Vielleicht gehört, wenigstens bei Erwachsenen, aber auch eine sehr lange Zeit zur Entwicklung jener Venenveränderungen, welche bei schneller zum Tode führender Phthise nicht vorhanden ist. Aber das ist alles nur Vermuthung.

Nun endlich noch ein Paar Worte über die anderen Formen der tuberculösen Blutvergiftung, die chronische allgemeine Tuberculose und die Uebergangsformen.

Bei der cbronischen allgemeinen Tuberculose ist eine acute Ueberschwemmung des Körpers mit Tuberkelgift nicht vorauszusetzen. Schon die ungleichmässige Entwicklung der einzelnen Heerde spricht dagegen, dass dieselben ihren Ursprung einem einzigen oder mehreren zeitlich nur wenig auseinanderliegenden Giftschüben verdanken sollten. Auch der klinische Verlauf lässt dies meist erkennen. Für diese chronische Form der generalisirten Tuberculose dürfte also wobl die Häufigkeit des Gifteintritts das ersetzen, was bei den acuten die Reichlichkeit der schädlichen Materie in den spärlicheren Schüben bewirkt.

Die Tuberkelheerde, die hier das Gift in's Blut bringen, müssen demnach kleinere sein, die man wohl nur ausnahmsweise finden wird. Es wird dies um so schwerer sein, als die befallenen Gefässe bei dem chronischen Verlauf längst obliterirt sein können, nachdem sie vorher noch Gift an's Blut abgaben. Man kann es aber den vielen obliterirten Gefässen bei Phthise etc. natürlicb nicht ansehn, ob sie eine Zeitlang noch mit den Blutstrom communicirt haben und doch schon von der Erkrankung ergriffen waren. Nichtsdestoweniger kann es bisweilen gelingen solche Stellen aufzufinden 
z. B. kleine Tuberkel in grossen Venen, vereinzelte im Ductus thoracicus etc. So sahen wir ja oben in den Fällen 14 und 15, dass kleine Tuberkeleinbrutche in den Venen um die Drüsen statthatten, von denen aus sich ganz gut eine allmähliche Abschwemmung von Gift in kleinen Quantitäten annehmen lässt. Diese deponirten sich nicht in allen den Organen, in welchen sie bei der grossen Giftmenge der eigentlichen acuten miliaren Tuberculose auftreten, sondern nur in solchen, welche das Gift aus dem Blute am leichtesten festhalten. Warum das bestímmte Organe thun, können wir in diesem Aufsatze nicht weiter erörtern.

Was die Uebergangsformen betrifft, $d$. h. diejenigen Formen der Tuberculose, in denen vereinzelte Tuberkel in Milz, Niere, Herz etc. neben Lungenschwindsucht vorkommen, so schliessen sie bei der geringen Menge derselben ebenfalls die Möglichkeit einer Ueberschwemmung des Blutes mit Tuberkelgift aus. Sie sind jedenfalls die häufigste Form der generalisirten Tuberculose und vom Standpunkt der Infectionstheorie hat man sie so aufzufassen, dass bei ihr geringe Mengen von Tuberkelgift in spärlichen Schüben in's Blut treten. Dieser Uebertritt findet sich num auch bei der gewöhnlichen Lungenschwindsucht oft genug, auch bei Erwachsenen. Das Zustandekommen solch geringfügiger tuberculöser Blutvergiftung ist wohl auch hier so zu erklären, dass beim Vordringen des tuberculösen Prozesses auf die Venen zwar wie gewöhnlich eine Obliteration erfolgt, dass aber, noch ehe dieselbe vollendet ist, eine gewisse kleine Menge von Gift sich dem Blute beizumischen vermag, worauf dann diese Giftquelle durch vollständigen Verschluss des Gefässes bald versiegt. Wir werden ähnliche Verhältnisse bei Besprechung der Peritonealtuberculose auch für das Bauchfell kennen lernen, wo es sich aber nicht um ein Fortschreiten der Tuberculose in Blutgefässen handelt.

Dass man demnach auch hier nur selten Gelegenheit haben wird die Giftquelle zu finden, ergiebt sich von selbst. -

Für alle diese Formen der Tuberculose besteht aber eine bemerkenswerthe Differenz zwischen den verschiedenen Geschöpfen. Kleine Thiere bekommen diese Arten der generalisirten Tuberculose, namentlich auch die chronische allgemeine bei Tuberkel-Impfung in irgend eine beliebige Körperstelle, wenn auch vielleicht nicht immer, so doch auffallend häufig, wie dies längst bekannt ist. Aehnlich verhalten 
sich die Affen bei ihrer spontanen Tuberculose, aber einigermaassen analoge Verhältnisse finden wir auch bei kleinen Kindern. Wenn auch freilich nicht von jeder scrophulösen Lymphdrüse eine generalisirte Tuberculose eingeleitet wird, so neigt die Tuberculose anderer Organe bei Kindern sehr zur Verallgemeinerung mit Entwicklung grösserer und kleinerer Knoten selbst in chronischerer Form.

Man könnte also sagen bei diesen Geschöpfen treten leicht kleinere Mengen Tuberkelgift in's Blut, die dann schliesslich, wenn diềs an vielen Stellen immer wieder geschieht, zu einer allgemeinen Durchseuchung des Körpers führen. Wie das zu erklären ist, muss der Zukunft überlassen bleiben. Vielleicht ist es aber erlaubt die Vermuthung auszusprechen, dass die grössere Zartbeit der Gefässe derselben eine so schnelle Durchdringung mit Tuberkelgift gestattet, dass das Gefäss nicht Zeit hatte zu obliteriren, bevor das Gift in ihr Lumen gedrungen ist, während bei erwachsenen Menschen das Umgekehrte bäufiger ist.

Es dürfte wohl angezeigt sein, zum Schluss ein Resumé derjenigen Punkte zu geben, auf welche es bei der Beurtbeilung der Pathogenese eines concreten Falles von acuter allgemeiner Miliartuberculose ankommt. Wenn ein in einer Vene etc. vorkommender Tuberkel sich als die Quelle der acuten Blutüberschwemmung mit Tuberkelgift erweisen soll, so muss er folgende Bedingungen erfüllen:

1) Die vorgefundenen Tuberkel müssen ibrem Bau nach (Verkäsung, Grösse etc.) sich als älter erweisen, wie die acut entstandenen Miliarknötchen der Organe. Nur so können sie als Primäraffectionen angesehn werden. Sehr wünschenswerth ist es, wenn man die Quelle für die Tuberkelentwicklung in der Vene in einem (noch älteren) Heerde des anliegenden Gewebes findet.

2) Die Tuberkelentwicklung muss (wenn sie nicht im Herzen sitzt) in einer Vene oder grossem Lymphgang stattfinden resp. in eine solche bineinreichen, welche offen, nicht obliterirt ist. Diese Forderung dürfte selbstverständlich sein. Nur wenn sie erfüllt ist, kann sich ja das Gift dem Blute beimengen.

3) Die Tuberkeleruption muss eine solche sein, welche einen rejchlichen Eintritt von Gift in's Blut erklärlich 
macht, da nur so eine Ueberschwemmung mit demselben in kurzer Zeit erfolgen kann. Diese Forderung könnte etwas problematisch erscheinen, wenn man die mathematisch genaue Bestimmung über den Umfang einer solchen Tuberkelwucberung verlangte. Man kann ja den Begriff von "viel" und "wenig" nicht definiren, wie man ja auch nicht sagen kann, wo ein "Haufen" anfängt. Aber es handelt sich hier meist um Extreme, wo dann ein Streit nicht möglich ist. Selten wird wie im Falle 11 dem subjectiven Ermessen des Secirenden das Urtheil überlassen werden müssen, ob der gefundene Heerd für die Blutüberschwemmung ausreichend ist oder ob man noch weiter suchen muss. Aehnlichen Zweifeln begegnen wir aber oft genug beim Seciren z. B. bei der Frage, ob ein Herz schon als hypertrophisch bezeichnet werden soll, oder noch nicht. Vor allem gilt hier für die Venen, für das Herz und den Ductus thoracicus der Satz, dass für eine acute allgemeine Miliartuberculose einzelne kleine Knötchen nicht als pathogenetische Heerde anzusehn sind, während dieselben immerhin Uebergangsformen und chronischen generalisirten Tuberculosen sehr wohl zum Ursprung dienen können.

4) Das Gift muss in der That die Oberfläche des Heerdes erreichen d. h. mit dem Lumen des Gefässes communiciren. Beim Ductus thoracicus, wo die Knötchen auf der freien Fläche sitzen, dürfte das wohl stets der Fall sein. Bei den compacteren Venenheerden z. B. der Lunge muss eine stellenweise Erweichung oder dergleichen vorhanden sein.

5) Die Venentuberculose darf nicht in einer Pforta derwurzel sitzen, weil sonst die Hauptmasse des Giftes in der Leber zurückgehalten wird.

Ob diese Sätze zu modificiren sind, müssen weitere Beobachtungen lehren, vorläufig dürften sie als Anhaltspunkte immerhin sehon von Nutzen sein. Jedenfalls bitte ich die Fachgenossen sehr, den Venentuberkeln ihre Aufmerksamkeit zuzuwenden. Freilich ist die Durchsuchung der Blutgefässe oft recht zeitraubend, aber es bandelt sich ja hier nicht um die sehr untergeordnete Frage, ob die Venen überhaupt für Tuberkelentwicklung immun sind, oder nicht, sondern um Fragen, die für die ganze Auffassung der acuten allgemeinen Miliartuberculose wichtig genug sind, um eine kleine Mühe zu belohnen. 
$\mathrm{N}$ a c h t r a g.

Inzwischen habe ich bei dem einzigen neuen Falle von acuter allgemeiner Miliartuberculose (22. April 1882) wieder die Quelle der Blutinfection in Form einer ulcerirten ausgedehnten Phlebitis tuberculosa pulmonalis gefunden, so dass jetzt in $\mathbf{7}$ Fällen hintereinander die Pathogenese insoweit klar gelegt ist.

\title{
XXII. \\ Kleinere Mittheilungen.
}

\author{
1. \\ Weitere Mittheilungen zur Lehre von der Menstruation. \\ Von Dr. Wilhelm Stricker, \\ pract. Arzte in Frankfurt a. M.
}

(Vergl. dies. Archiv Bd. 68, S. 295; Bd. 72, S. 281; Bd. 76, S. 212; Bd. 78, S. 194.)

In den nachfolgenden Mittheilungen will ich den Versuch machen, eine Tabelle der bis jetzt wissenschaftlich beobachteten Fälle von frühzeitiger Entwickelung beim Weibe zusammenzustellen. Ich schicke einige Notizen über die neuere Literatur dieses Themas voraus.

Welches Unbeil eine falsche Notiz in einem verbreiteten Werk auf lange Zeit binaus anrichten kann, beweist der Mandelslo'sche (Mandelshof'sche) Fall (vergl. dieses Archiv Bd. 78. S. 195). Soweit ich den Stammbaum übersehen kann, ging aus dem 1658 erschienenen Werke des 0learius der Fall über in Mart. Schurig's 1729 ersehienenes Werk: parthenologia historico-medica, S. 135. Dann finden wir diesen Fall, als auf "Mandels hof's “ Autopsie beruhend, in dem 1820 erschienenen 46. Bande des Dictionnaire des sciences médicales, in den 1826 erschienenen Forschungen des 19. Jahrhunderts im Gebiet der Geburtshülte, der Franen- und Kinderkrankheiten, herausgegeben von F. L. Meissner.

Gottl. Chr. Fr. Ha aff (Medicinische Abhandlungen, Stuttgart 1839) citirt den Fall sogar zweimal: S. 15 aus Schurig: "Albrecht von Mandelslow spricht von einem Mädchen ", S. 16: Mandelshof will in Indien ein Mädchen gesehen haben, hält also diesen Fall für zwei.

Ferner finden wir Mandelsh of nach Dict. de med. in der vortrefflichen Abhandlung von A. Kussmaul über geschlechtliche Frühreife in der Würzburger medicinischen Zeitschrift, 1862, III, 346, und endlich im Bulletin de l'Acad. R. de médecine de Belgique, 1878, XII. 